\title{
Science and Engineering Research Semester Internship Spring 1997 Abstracts and Research Papers
}

\author{
Beverly Williams \\ SERS Program Coordinator
}

October 1997

This is an informal report intended primarily for internal or limited external distribution. The opinione and conchusione stated are thowe of the author and may or may not be those of the Laboratory.

Work performed under the auspices of the U.S. Department of Energy by the Lawrence Livermore National Laboratory under Contract W-7405-Eng-48. 


\section{DISCLAMMER}

This document was prepared as an account of work sponsored by an agency of the United States Government. Neither the United States Government nor the University of California nor any of their employees, makes any warranty, express or implied, or assumes any legal liability or responsibility for the accuracy, completeness, or usefulness of any information, apparatus, product, or process disclosed, or represents that its use would not infringe privately owned rights. Reference herein to any specific commercial product, procese, or service by trade name, trademark, manufacturer, or otherwise, does not necesearily constitute or imply its endorsement, recommendation, or favoring by the United States Government or the University of California. The views and opinions of authors expressed herein do not necessarily state or reflect those of the United States Government or the University of California, and shall not be used for advertising or product endorsement purposes.

This report has been reproduced directly from the best available copy.

Available to DOE and DOE contractors from the Office of Scientific and Technical Information P.O. Box 62, Oak Ridge, IN 37831

Prices available from (615) 576-8401, FTS 626-8401

Available to the public from the National Technical Information Service

U.S. Department of Commerce 5285 Port Royal Rd. Springfield, VA 22161 
SCIENCE \& ENGINEERING

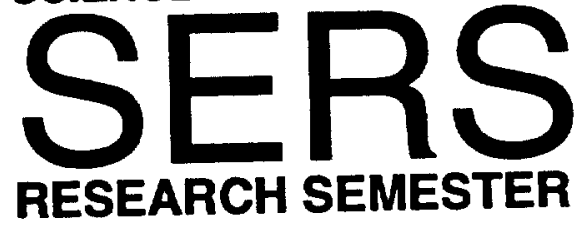

Lawrence Livermore National Laboratory

Spring 1997

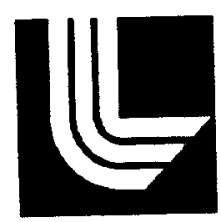

\section{ABSTRACTS \\ FOR}

\section{STUDENT SYMPOSIUM}

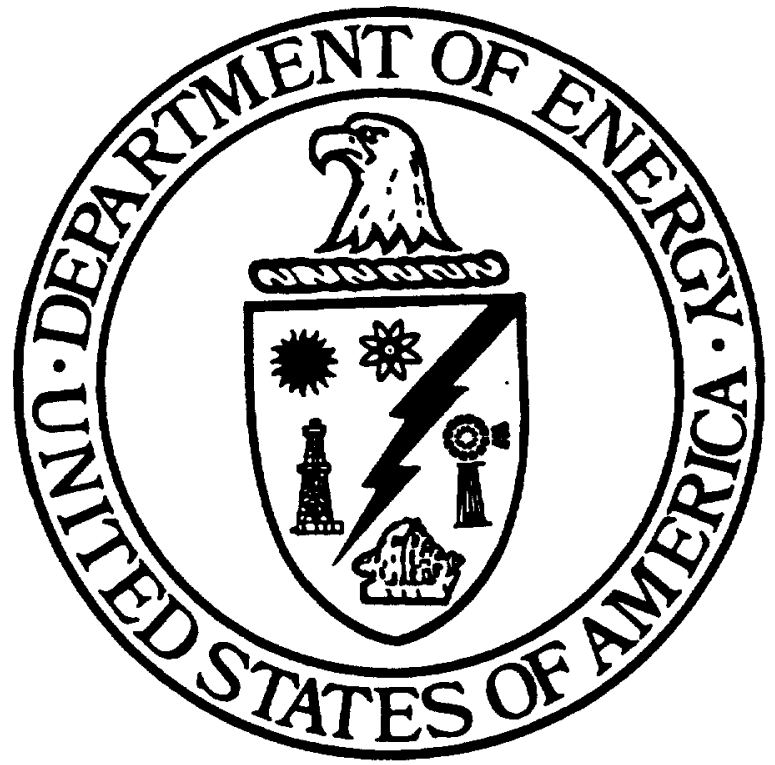

Sponsored by:

The U.S. Department of Energy Office of Defense Programs 


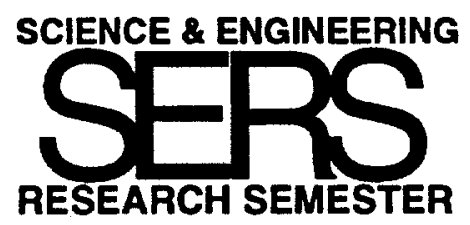

Table of Contents

Abstracts

i -viii

Bridget Bergquist Detection ${ }^{99} T c$ in Natural Arid Soil by Accelerator

Mass Spectrometry

Narada Bradman Optimized Power Systems for Remote Communities

Surina Briscoe Finite Element Analysis of Ground Movement and Its Surface

During an Earthquake

Michael Cariaso IMAGEne - Database of the Relationships Between Genes and Clones

Brett Hall Developing a Prototype for the National Ignition Facility Optical Installation System

Charity Hayden

Analysis of Acid-Volatile Sulfide (AVS) and Simultaneously Extracted Metals (SEM) For the Characterization of Toxic Sediments in the San Francisco Bay

Anabel Miranda

Changes in Pore Water Chemistry as a Function of Microbial Growth in Yucca Mountain Tuff 


\title{
Science and Engineering Research Semester \\ Spring 1997 Internship Program \\ at \\ Lawrence Livermore National Laboratory
}

\author{
Authors \\ Bridget Bergquist \\ Narada Bradman \\ Surina Briscoe \\ Michael Cariaso \\ Brett Hall \\ Charity Hayden \\ Anabel Miranda \\ Shane Oram
}

Affiliations: Bridget Bergquist, University of Wisconsin, Madison; Narada M. Bradman, Florida International University; Surina Briscoe, University of Maryland, Eastern Shore; Michael Cariaso, University of Florida, Gainesville; Brett Hall, North Carolina State University; Charity Hayden, Norwich University; Anabel Miranda, Turabo University; Shane Oram, Ithaca College; 


\title{
Detection ${ }^{99} \mathrm{Tc}$ in Natural Arid Soils by Accelerator Mass Spectrometry
}

\author{
Bridget Bergquist, B.S. Chemistry and B.S. Geology \\ University of Wisconsin, Madison \\ Center for Accelerator Mass Spectrometry
}

\begin{abstract}
To allow for rapid and sensitive detection of technetium-99 in the environment, our group is developing a ${ }^{99} T c$ AMS technique for the measurement of ${ }^{99} T c$ in natural arid soils. Chemical methods required to complete this technique include:

(1) an oxidation/distillation technique to produce a sample matrix (rhodium carrier) clean of ruthenium (an isobaric interference of ${ }^{99} \mathrm{TC}$

(2) the use of a TEVA-spec column to recover and concentrate ${ }^{99} T c$ from soil samples
\end{abstract}

From the oxidation/distillation technique, we have lowered the $\mathrm{Ru} / \mathrm{Rh}$ ratio in the Rh carrier from $\sim 70 \mathrm{ppm}$ to $\sim 80 \mathrm{ppb}$ bringing us near the level needed ( $\sim 10 \mathrm{ppb})$ for the desired ${ }^{99}$ Tc AMS sensitivity of $10 \mathrm{fg}$. Using the TEVA-spec column and liquid scintillation counting, we have demonstrated $90-95 \%$ recovery and concentration of ${ }^{99} \mathrm{TC}$ from spiked soil samples. Preliminary tests of blanks and standards has also shown good linearity and reproducibility. We expect further improvements in the oxidation/distillation method lowering Ru to levels required for the ${ }^{99} T_{c}$ AMS sensitivity. This along with good recovery from e TEVA-spec method should allow for ${ }^{99} \mathrm{Tc}$ measurement in natural soil samples in the future. 


\title{
Optimized Power Systems for Remote Communities
}

\author{
Narada Bradman \\ Florida International University \\ Energy Manufacturing and Transportation Technologies
}

\begin{abstract}
As a result of their remote location, many small communities in Alaska are forced to pay exorbitant prices for the diesel fuel used to produce their electricity and heat their homes. We have developed a code that models various combinations of locally available renewable resources and storage systems to reduce the cost of electricity and/or the diesel consumption. We have modeled a number of scenarios with the wind as the primary source, hydrogen storage, and diesel as a backup. We have also begun runs incorporating solar resources. So far we have found that it is economically feasible to displace most of the diesel using wind power and hydrogen storage.
\end{abstract}




\title{
Finite Element Analysis of Ground Movement and Its Surface Effects During an Earthquake
}

\author{
Surina Briscoe \\ B.S. Mathematics \\ University of Maryland, Eastern Shore \\ EPD-Geophysics \& Global Security
}

\begin{abstract}
Ground motion recordings during recent earthquakes reveal that little is understood about how earthquakes rupture and why unusual ground motion is recorded. Computer modeling of earthquakes will provide a further understanding of the dynamics of earthquake fault rupture and the observed ground motion. We developed a model of a fault and its surroundings using Maze, and a nine node, kinematic earthquake rupture simulation using two dimensional Dyna codes. The simulations represent a combination of rupture velocities, rupture histories, and load curves. Seismograms were made for two points on the surface, and were analyzed for significance. The model will soon be implemented to a dynamic three dimensional rupture, and will be referenced in the future construction of bridges and buildings.
\end{abstract}




\title{
DATABASE of the Relationships Between Genes and Clones
}

\author{
Michael Cariaso \\ University of Florida, Gainesville \\ Biology and Biotechnology Research Program
}

\begin{abstract}
This paper discusses the development of IMAGEne, a publicly accessible genetics database. ESTs are clustered and aligned with known genes to create maps of clone coverage. Initial testing has provided new information on clone distribution and additional sequences for several partially known genes. IMAGEne serves as a useful tool for genetics researchers.
\end{abstract}




\title{
Developing a Prototype for the National Ignition Facility Optical Installation System
}

\author{
Brett Hall \\ B.S. Electrical Engineering \\ North Carolina State University \\ Electrical Engineering
}

\begin{abstract}
This paper describes the design and assembly of a 1/3 scale model of an automated laser optic installation system for the National Ignition Facility. The model will serve as a proof of concept, an electronics test bed, and demonstration tool. This model was constructed by reducing and redesigning the full scale components. It is anticipated that the fully developed scale model will be capable of performing the same functions as the full scale prototype. Results from the assembly and automation of the model will aid evaluation of key mechanical and electrical components.
\end{abstract}




\title{
DATABASE of the Relationships Between Genes and Clones
}

\author{
Michael Cariaso \\ University of Florida, Gainesville \\ Biology and Biotechnology Research Program
}

\begin{abstract}
This paper discusses the development of IMAGEne, a publicly accessible genetics database. ESTs are clustered and aligned with known genes to create maps of clone coverage. Initial testing has provided new information on clone distribution and additional sequences for several partially known genes. IMAGEne serves as a useful tool for genetics researchers.
\end{abstract}




\title{
Optimized Power Systems for Remote Communities
}

\author{
Narada Bradman \\ Florida International University \\ Energy Manufacturing and Transportation Technologies
}

\begin{abstract}
As a result of their remote location, many small communities in Alaska are forced to pay exorbitant prices for the diesel fuel used to produce their electricity and heat their homes. We have developed a code that models various combinations of locally available renewable resources and storage systems to reduce the cost of electricity and/or the diesel consumption. We have modeled a number of scenarios with the wind as the primary source, hydrogen storage, and diesel as a backup. We have also begun runs incorporating solar resources. So far we have found that it is economically feasible to displace most of the diesel using wind power and hydrogen storage.
\end{abstract}




\title{
No significant Evidence Found For A DNA Fingerprint from Densely lonizing Radiation Based on F Ratios Calculated From Stable Chromosome Aberrations
}

\author{
Shane Oram \\ B.A. Biology \\ Ithaca College \\ Biology Biotechnology Research Program
}

\begin{abstract}
The purpose of this study is to measure the ratio of translocations to pericentric inversions for low-LET radiation and high-LET radiation using fluorescence in situ hybridization (FISH). A composite chromosome lp telomeric region specific probe, a chromosome 1 heterochromatin probe and a pan-centromere probe were developed to identify pericentric inversions. A chromosome 1 paint probe was employed to measure translocations on chromosome 1 as described by Lucas et al. $(1989,1992)$. Translocation frequencies and pericentric inversion frequencies were calculated as described by Lucas $e t$ al. $(1989,1996)$.

Translocations are interchromosomal aberrations (breaks in different chromosomes), while pericentric inversions are intrachromosomal aberrations (breaks in the same chromosome). High-LET radiation produces energy depositions that are much closer together (dense) than those produced by low-LET radiation (sparse). Hence, it may be more likely for high-LET radiation to cause multiple breaks in the same chromosome than it is for low-LET radiation. If this is true, then it is expected that the ratio of translocations to pericentric inversions(F-Ratio) for high-LET radiation will be less than the F-Ratio for low-LET radiation. Therefore facilitating a "fingerprint" for high-LET radiation (Brenner, 1996).
\end{abstract}

Contrary to prediction, there does not appear to be a "fingerprint" for high-LET radiation. The F-Ratios found for high- and low-LET radiation were similar, with the high-LET radiation being slightly lower. 


\title{
Detection of ${ }^{99} \mathrm{Te}$ in Natural Arid Soils by Accelerator Mass Spectrometry*
}

\author{
Bridget A. Bergquist \\ University of Wisconsin-Madison \\ Lawrence Livermore National Laboratory \\ Livermore, CA 94550
}

May 9, 1997

Prepared in partial fulfillment of the requirements of the Science and Engineering Research Semester under the direction of Jeffery McAninch, Research Mentor, in the Lawrence Livermore National Laboratory.

*This research was supported in part by an appointment to the U.S. Department of Energy Science and Engineering Research Semester (herinafter called SERS) program administered by LLNL under Contract W-7405-Eng-48 with Lawrence Livermore National Laboratory. Funding for the SERS program provided by the Office of Defense Programs. 


\section{Abstract:}

To allow for rapid and sensitive detection of technetium-99 in the environment, our group is developing accelerator mass spectrometry for the measurement of ${ }^{99} \mathrm{Tc}$ in natural arid soils. Chemical methods required to complete this technique include:

(1) an oxidation/distillation technique to produce a sample matrix (rhodium carrier) clean of ruthenium $\left({ }^{99} \mathrm{Ru}\right.$, an isobaric interference of ${ }^{99} \mathrm{Tc}$ )

(2) the use of a TEVA-spec column to recover and concentrate ${ }^{99} \mathrm{Tc}$ from soil samples

From the oxidation/distillation technique, we have lowered the $\mathrm{Ru} / \mathrm{Rh}$ ratio in the $\mathrm{Rh}$ carrier from $\sim 70 \mathrm{ppm}$ to $\sim 80 \mathrm{ppb}$ bringing us near the level needed ( $\sim 10 \mathrm{ppb})$ for the desired ${ }^{99} \mathrm{Tc}$ AMS sensitivity of $10 \mathrm{fg}$. Using the TEVA-spec column and liquid scintillation counting, we have demonstrated $90-95 \%$ recovery and concentration of ${ }^{99} \mathrm{Tc}$ from spiked soil samples. Preliminary tests of blanks and standards has also shown linearity and reproducibility. We expect further improvements in the oxidation/distillation method lowering Ru to levels required for the ${ }^{99} \mathrm{Tc}$ AMS sensitivity. This along with good recovery of ${ }^{99} \mathrm{Tc}$ from the soil samples have demonstrated that it should be possible to measure ${ }^{99} \mathrm{Tc}$ at environmental levels in natural arid soils.

\section{Introduction:}

With the interest in long term storage of radioactive waste and the movement of environmental waters, various studies of radionuclide transport through soils are being done today. One radionuclide of interest is ${ }^{99} \mathrm{Tc}$. Technetium was the first element to be made artificially, has no stable isotopes, and is not naturally occurring. It is one of the 
most abundant fission products by mass and has been widely distributed in the environment through the nuclear fuel cycle, weapons testing, and use in nuclear medicine (Yoshihara, 1996). As of 1993, an estimated 78 metric tons of ${ }^{99} \mathrm{Tc}$ had been created. Its high abundance, long half life (200,000 years), and high mobility make the study of ${ }^{99} \mathrm{Tc}$ important for decisions concerning the disposal radioactive waste. By studying ${ }^{99} \mathrm{Tc}$ in natural systems, a clearer understanding of the potential for radionuclide transport in the environment is possible. Also, studies of ${ }^{99} \mathrm{Tc}$ in soils may help our understanding of environmental water movement.

To enable these studies, we are developing techniques to analyze ${ }^{99} \mathrm{Tc}$ at environmental levels (lower fg region). Present ${ }^{99} \mathrm{Tc}$ analytical techniques are cumbersome and/or require relatively large samples $(>250 \mathrm{~g}$ ). Part of this project is developing accelerator mass spectrometry (AMS) for ${ }^{99} \mathrm{Tc}$ which would be competitive with other techniques in sensitivity, sample throughput, ease of sample preparation, and analysis cost. Fig. 2 shows other techniques available for the detection of ${ }^{99} \mathrm{Tc}$ and their detection limits. Based on positive results from preliminary tests to examine the technical feasibility of AMS for the detection of ${ }^{99} \mathrm{Tc}$, we have begun to develop the chemical methods required to complete the AMS technique for measurement of ${ }^{99} \mathrm{Tc}$ in natural soils. These methods include extraction and concentration of the ${ }^{99} \mathrm{Tc}$ from soil samples and purification of the sample matrix.

This project is part of "Hydrologic and Geochemical Controls on the Transport of Radionuclides in Natural Undisturbed Arid Environments as Determined by Accelerator Mass Spectrometry Measurements." (Gregory J. Nimz, Marc W. Caffee, Robert C. Finkel, Jeffrey E. McAninch) 


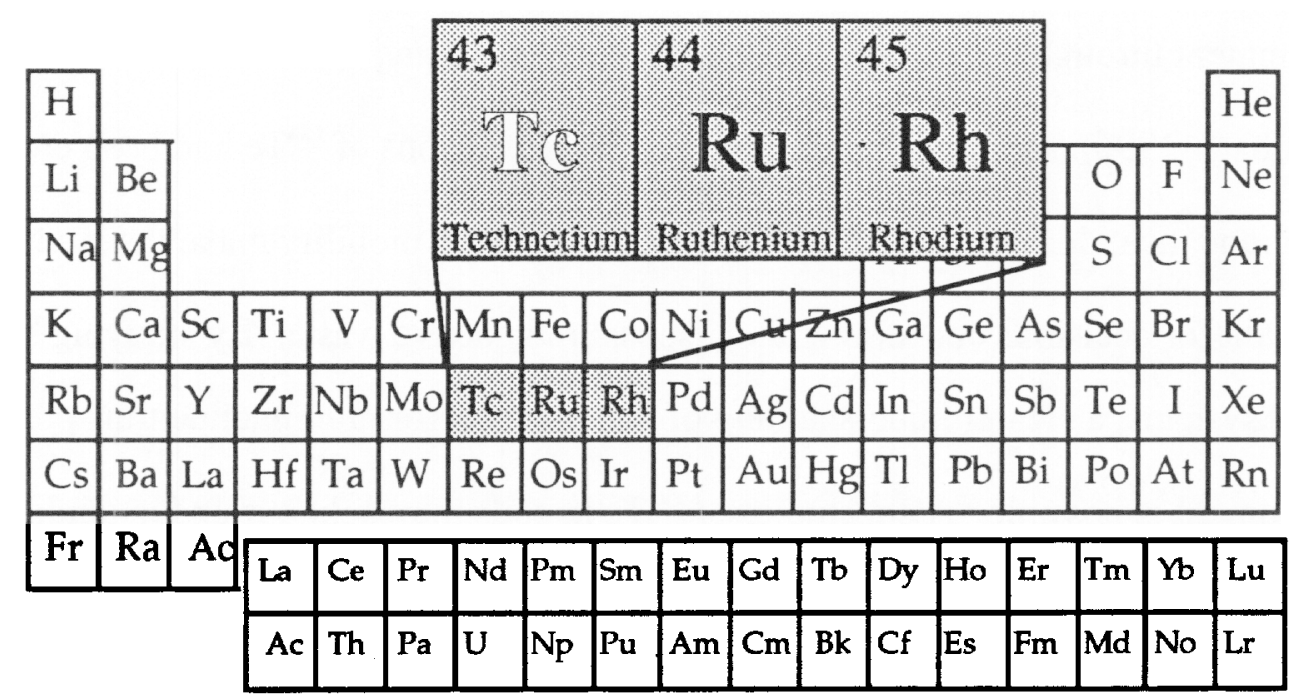

Fig. 1: Periodic table highlighting the elements of interest in this paper. ${ }^{99} \mathrm{Tc}$ is the element we wish to measure. $\mathrm{Rh}$ is the sample matrix and $\mathrm{Ru}$ has a natural isotope $\left({ }^{99} \mathrm{Ru}\right)$ which is an interference of ${ }^{99} \mathrm{Tc}$ which can not be separated by the accelerator mass spectrometer.

\begin{tabular}{|c|c|c|c|}
\hline analytical method & $\mathbf{m B q}$ & mass & atoms \\
\hline liquid scintillation (LSC) & 30 & $50 \mathrm{pg}$ & $3 \times 10^{11}$ \\
\hline low background LSC & $1-5$ & 2-8 pg & $1-5 \times 10^{10}$ \\
\hline gas flow counting & $1-5$ & 2-8 pg & $1-5 \times 10^{10}$ \\
\hline activation analysis $(\mathbf{n}, \mathbf{g})$ & 2.5 & $4 \mathrm{pg}$ & $3 \times 10^{10}$ \\
\hline ICP-MS & $2-4$ & 3-6 pg & $2-4 \times 10^{10}$ \\
\hline$\overline{\text { HR-ICP-MS }}$ & 0.002 & $3 \mathrm{fg}$ & $2 \times 10^{7}$ \\
\hline RIMS & 0.0005 & $1 \mathrm{fg}$ & $5 \times 10^{6}$ \\
\hline
\end{tabular}

† values from Yoshlhara, Topics in Current Chemistry 176, 18 (1996)

$$
\text { We are aiming for an AMS detection limit of }-10 \mathrm{fg}
$$

Fig. 2: Detection limits for ${ }^{99} \mathrm{Tc}$ using various analytical methods. The purpose of the present work is to be competitive with these other techniques in sensitivity, sample throughput, ease of sample preparation, and analyst cost. ICP-MS stands for inductively coupled plasma mass spectrometry, HR-ICP-MS for high resolution ICP-MS, and RIMS for resonance ionization mass spectrometry. 


\section{Background:}

Accelerator Mass Spectrometry (Vogel, 1995):

AMS is an established technique for the detection of long-lived radionuclides at environmental levels. One such example is ${ }^{14} \mathrm{C}$ which is used in ${ }^{14} \mathrm{C}$ dating, determination of the carbon cycle, medicine, and much more. A schematic of the AMS is shown in Fig. 3. The high energy Cs sputter source produces negative ions from the solid samples that are then passed through a low energy mass spectrometer which selects for mass 99. The negative ions then accelerate towards the positive terminal ( $+9 \mathrm{MV})$ where they pass through a thin carbon foil that removes electrons making positive ions $\left({ }^{99} \mathrm{Tc}^{+9}\right.$ through $\left.{ }^{99} \mathrm{Tc}^{+14}\right)$. The positive ions then accelerate back to ground potential obtaining energies of $>\mathrm{MeV}$. The ions then pass through a high energy mass spectrometer which includes a rigidity filter and velocity filter which selects ions based on charge, mass and velocity. The only ions that should make it to the detector are ${ }^{99} \mathrm{Tc}^{+12}$ and ${ }^{99} \mathrm{Ru}^{+12} \cdot{ }^{99} \mathrm{Ru}$ is the main interference of ${ }^{99} \mathrm{Tc}$ and it can not be separated by the spectrometer. Measurements were performed using the $10 \mathrm{MV}$ FN tandem accelerator at the Center for Accelerator Mass Spectrometry at Lawrence Livermore National Laboratory (Southon, 1990).

AMS offers several advantages. It has high sample throughput (minutes per sample) and is mostly insensitive to matrix effects. The accelerator also destroys molecular species. Many other interferences are avoided because of the negative ion formation, high energy to which ions are accelerated, selection of charge state for detection, and filters. The high energy to which ions are accelerated also allows for postspectrometer nuclear physics like particle identification and quantification.

Post spectrometer ion detection and identification allows for additional rejection of the ${ }^{99} \mathrm{Ru}$ interference. Following the spectrometer, a characteristic projectile $\mathrm{x}$-ray detector is used in which ions are incident on a thin foil (McAninch, 1995). As the ions lose energy in the foil, there is some probability for electrons vacancies to be produced in 
the ions, inducing $\mathrm{x}$-rays. The energy levels, and hence the $\mathrm{x}$-ray energies, are atomic number dependent providing an identification of the ion by element. The peaks of the ${ }^{99} \mathrm{Tc}$ and ${ }^{99} \mathrm{Ru} \mathrm{L} \mathrm{x}$-rays (Fig. 4) are not fully resolved, however the line shapes are very stable and can be well-determined from measurements of blanks and standards allowing the two peaks to be unfolded. With proper background subtraction and sufficient statistics, the detection limit for ${ }^{99} \mathrm{Tc}$ can be on the order of $\sim 1 \%$ of the ${ }^{99} \mathrm{Ru}$ level. This will allow us to detect $\sim 10 \mathrm{fg}$ of ${ }^{99} \mathrm{Tc}$ in the presence of $\sim 5-10 \mathrm{pg}$ of $\mathrm{Ru}$. The natural occurrence of Ru is low, so this should be attainable. However, this requires chemically lowering the $\mathrm{Ru}$ level in the $\mathrm{Rh}$ carrier to $\sim 10 \mathrm{ppb} \mathrm{Ru} / \mathrm{Rh}$.

\section{Sample Matrix:}

In order for ${ }^{99} \mathrm{Tc}$ to be measured by AMS, some stable element must serve as a yield monitor, chemical carrier, and sample matrix. In the AMS detection of other isotopes, such as ${ }^{14} \mathrm{C}$, the stable isotopes of the element of interest fills theses roles. The radioactive-to-stable isotope ratios $\left(\right.$ e.g. ${ }^{14} \mathrm{C} /{ }^{13} \mathrm{C}$ ) are then measured. However, ${ }^{99} \mathrm{Tc}$ lacks a stable isotope for AMS measurement. Therefore, some other element must fulfill the requirements normally filled by the stable isotope. In this case, the element chosen was rhodium, which has only one stable isotope, ${ }^{103} \mathrm{Rh}$. However, the rhodium stock solution contains $\sim 70 \mathrm{ppm} \mathrm{Ru/Rh}$ which presents a problem because of ${ }^{99} \mathrm{Ru}$, a stable isotope of $\mathrm{Ru}$ with a natural abundance of $12.7 \%$. The ${ }^{99} \mathrm{Ru}$ interference can not be removed using the spectrometer, and must be removed chemically from the sample matrix. The Ru in the Rh carrier must be lowered from $70 \mathrm{ppm}$ to $\sim 10 \mathrm{ppb}$ in order to achieve a detection limit of $10 \mathrm{fg}$ for ${ }^{99} \mathrm{Tc}$. 


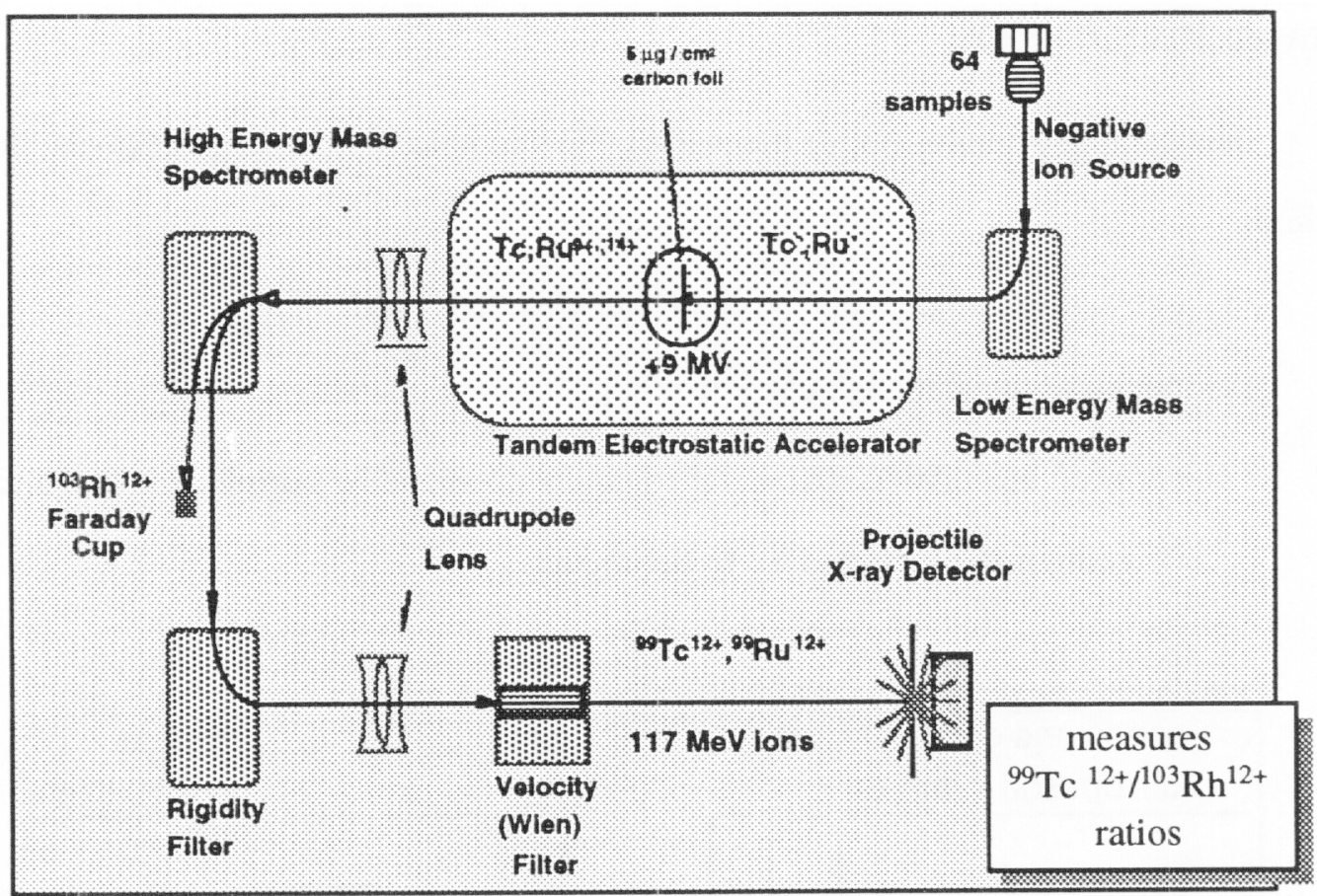

Fig. 3: A schematic of the accelerator mass spectrometer showing the detection of ${ }^{99} \mathrm{Tc}$.

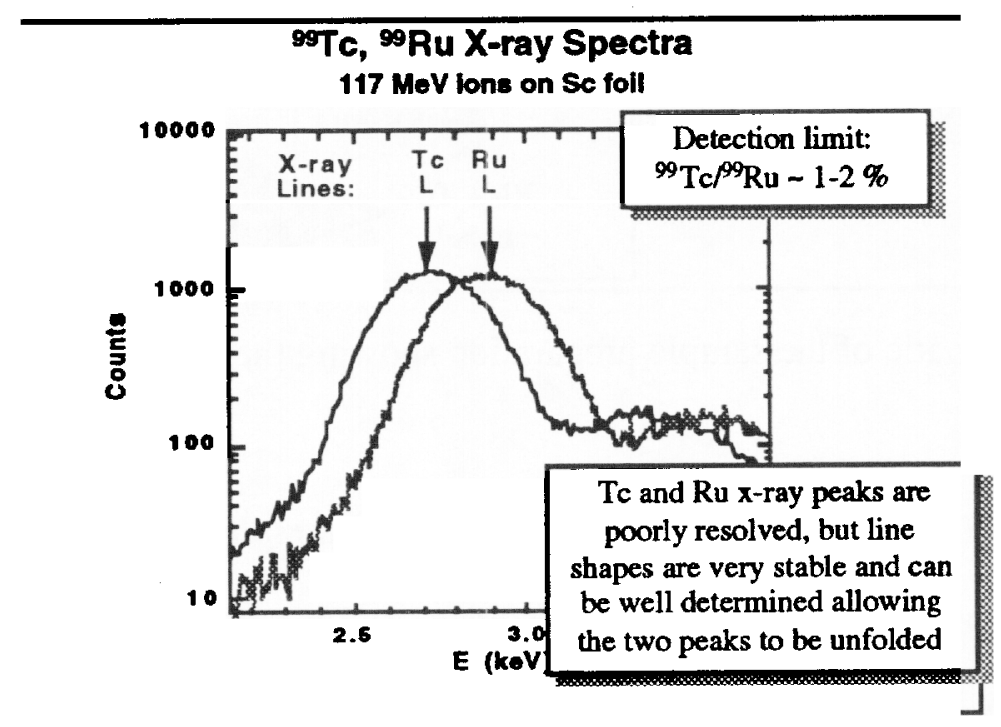

Fig. 4: Characteristic projectile $x$-ray spectrum for ${ }^{99} \mathrm{Tc}$ and ${ }^{99} \mathrm{Ru}$. By summing the counts in the separate Tc and Ru windows, the contribution of Ru counts in the Tc window can be subtracted. 


\section{Sample Preparation:}

The sample preparation for measuring ${ }^{99} \mathrm{Tc}$ in natural arid soils involves three methods:

(1) extraction and concentration of the $99 \mathrm{Tc}$ from soil samples

(2) purification of the Rh carrier

(3) addition of purified Rh carrier to concentrated ${ }^{99} \mathrm{Tc}$ sample solution and reduction of $R h$ and $T c$ to the metal

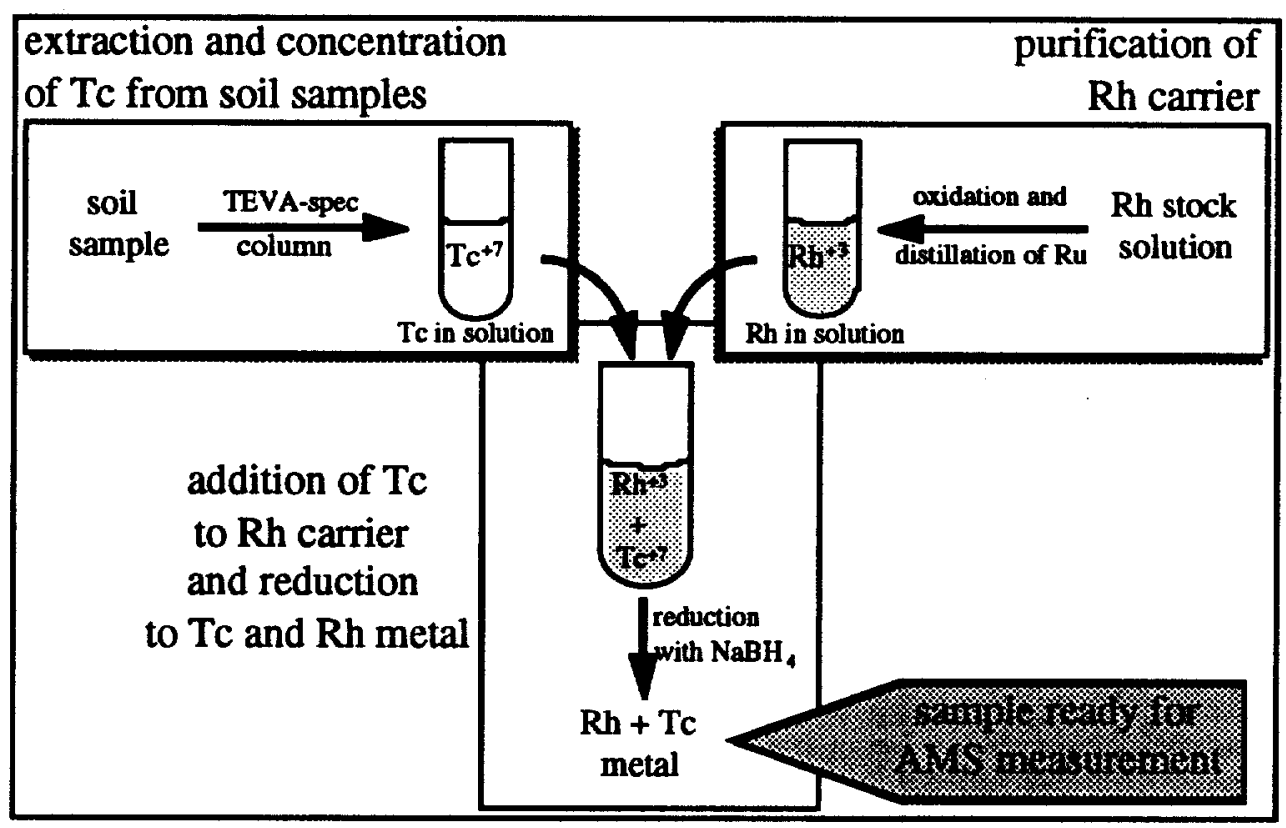

Fig. 5: A schematic of the sample preparation showing the three separate methods.

\section{Extraction and concentration of the ${ }^{99} \mathrm{Tc}$ from soil samples:}

Measurement of ${ }^{99} \mathrm{Tc}$ requires separation and concentration of ${ }^{99} \mathrm{Tc}$ from the soil samples before the Rh carrier can be added to the sample. Soil samples are leached overnight with deionized water. To the filtered leachates, concentrated $\mathrm{H}_{2} \mathrm{O}_{2}$ is added to the filtrates to fully oxidize the ${ }^{99} \mathrm{Tc}$ to $\mathrm{TcO}_{4}^{-}$and destroy organic material. The filtrates are boiled for two hours to remove the remaining $\mathrm{H}_{2} \mathrm{O}_{2}$. Filtrates are then passed through 
a TEVA-spec column (Eichrom Industries) to extract the $\mathrm{TcO}_{4}^{-}$. Column is rinsed with dilute $\mathrm{HNO}_{3}(0.1-1 \mathrm{M})$ to remove unwanted species. The $\mathrm{TcO}_{4}^{-}$is eluted from the column using $10 \mathrm{ml}$ of $6.0 \mathrm{M} \mathrm{HNO}_{3}$.

Preliminary tests of this procedure were performed to evaluate the chemical recovery of this procedure. Soils were spiked with relatively high quantities of ${ }^{99} \mathrm{TcO}_{4}^{-}$ $(\sim 10,000 \mathrm{dpm})$. Soils were allowed to dry completely and then treated as described. Recovered ${ }^{99} \mathrm{Tc}$ was measured by liquid scintillation counting (LSC). Typical recoveries in these tests were 90-95\%.

\section{Purification of the Rh carrier:}

For $\mathrm{Rh}$ to serve as a sample matrix and normalization isotope, $\mathrm{Ru}$ must be removed to ultratrace levels. Solutions of $\mathrm{Ru}$ can form a volatile oxide $\left(\mathrm{RuO}_{4}\right)$ when treated with strong oxidizing agents like potassium persulfate $\left(\mathrm{K}_{2} \mathrm{~S}_{2} \mathrm{O}_{8}\right)$ (Cotton \& Wilkinson, 1980). Solutions of $\mathrm{RhCl}_{3}$ are taken to dryness with $1 \mathrm{M} \mathrm{H}_{2} \mathrm{SO}_{4}$ to remove the chloride and convert $\mathrm{RhCl}_{3}$ to $\mathrm{Rh}_{2}\left(\mathrm{SO}_{4}\right)_{2}$. Samples are brought back into aqueous solution with deionized water and heat. Solutions are then treated with $\mathrm{K}_{2} \mathrm{~S}_{2} \mathrm{O}_{8}$ and solutions distilled under vacuum. Various conditions were testing along with other oxidizing agents $\left(\mathrm{NaBrO}_{3}, \mathrm{HIO}_{4}, \mathrm{O}_{3}\right)$. Ru/Rh ratios were measured by AMS.

\section{Addition of $R h$ carrier to $T c$ sample and reduction of $R h$ and $T c$ to the metal:}

To obtain reliable ${ }^{99} \mathrm{Tc} / 103 \mathrm{Rh}$ ratios, the ${ }^{99} \mathrm{Tc}$ must be homogeneously distributed through out the $\mathrm{Rh}$. This was done by reducing the $\mathrm{Tc}$ and $\mathrm{Rh}$ to the metal using a reducing agent, $\mathrm{NaBH}_{4}$. First known amounts of the purified $\mathrm{Rh}$ solutions are combined with the ${ }^{99} \mathrm{Tc}$ sample solutions. Solutions are then evaporated to dryness to remove $\mathrm{HNO}_{3}$. After bring the samples back into aqueous solution with deionized water, $\sim 2 \%$ solution of $\mathrm{NaBH}_{4}$ is added dropwise to the sample solutions resulting in a fine black 
precipitate. Precipitates are kept in suspension with shaking until the samples are centrifuged. Precipitates are then rinsed with deionized water, dried, and packed into AMS holders. Samples are then ready for AMS measurement.

\section{Results:}

We have demonstrated a significant reduction in the Ru from the $\mathrm{Rh}$ carrier using the oxidation/distillation method. Initially the $\mathrm{Rh}$ stock solution contained $70 \mathrm{ppm}$ $\mathrm{Ru} / \mathrm{Rh}$. We have lowered the $\mathrm{Ru} / \mathrm{Rh}$ ratio to $80 \mathrm{ppb}$ so far. It appears that the desired $\mathrm{Ru} / \mathrm{Rh}$ ratio of $10 \mathrm{ppb}$ can be obtainable with improvements in the method.

With these reductions in Ru, preliminary AMS measurements of $99 \mathrm{Tc}$ standards and blanks have been made. These test have shown linearity and reproducibility with a rms relative deviation of $+/-15 \%$ (Fig. 6). The observed variations are thought to be caused by fractionation between $\mathrm{Tc}$ and $\mathrm{Rh}$ in the sputtering process as the samples reach depletion. This effect may be minimized by changes in sample matrix and size. In our first attempt, we were able to obtain a detection limit of 5-7 pg in the presence of $1.5-2 \mathrm{ng}$ of $\mathrm{Ru}(\sim 1 \mathrm{ppm} \mathrm{Ru} / \mathrm{Rh}$ ) (Fig. 7). A second run with lower $\mathrm{Ru} / \mathrm{Rh}$ ratios and technical improvements in the AMS had a detection limit for ${ }^{99} \mathrm{Tc}$ of $0.5-0.6 \mathrm{pg}(500-600 \mathrm{fg})$. This brings us close to out goal of $10 \mathrm{fg}$.

The results from the extraction of Tc from the soils have been good also. From LSC, $>90 \%$ of the ${ }^{99} \mathrm{Tc}$ can be recovered from the TEVA-spec column and method for leaching the $\mathrm{Tc}$ from the soils. Various conditions were tested including letting a spiked soil go completely to dryness before leaching. No difficulties in leaching the ${ }^{99} \mathrm{Tc}$ out of the soils have been encountered.

With good results from our extraction and concentration method, we made a first attempt to measure a spiked soil sample and three unspiked soil samples by AMS. It was found that out sensitivity was impaired due to an interfering $x$-ray from sulfur. This can 


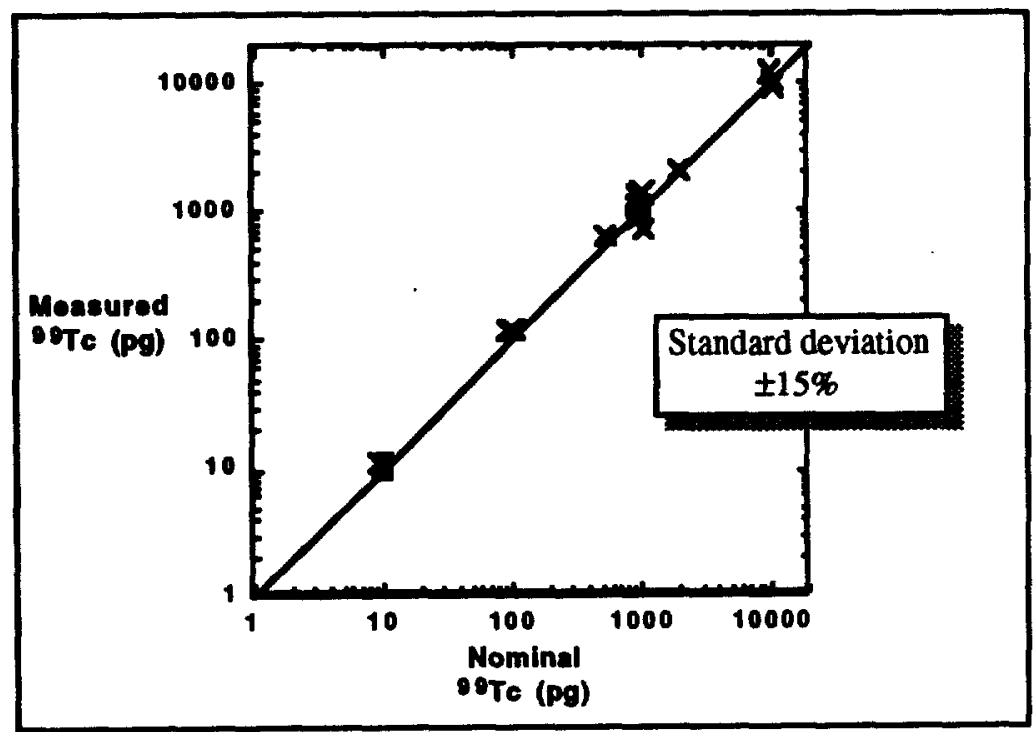

Fig. 6: Measurement of Tc standards by AMS, first attempt. The rms relative deviation of the measured values from the nominal was $+/-15 \%$. The observed variations are though to be caused largely by fractionation between $T c$ and $R h$ in the sputtering process as the samples reach depletion.

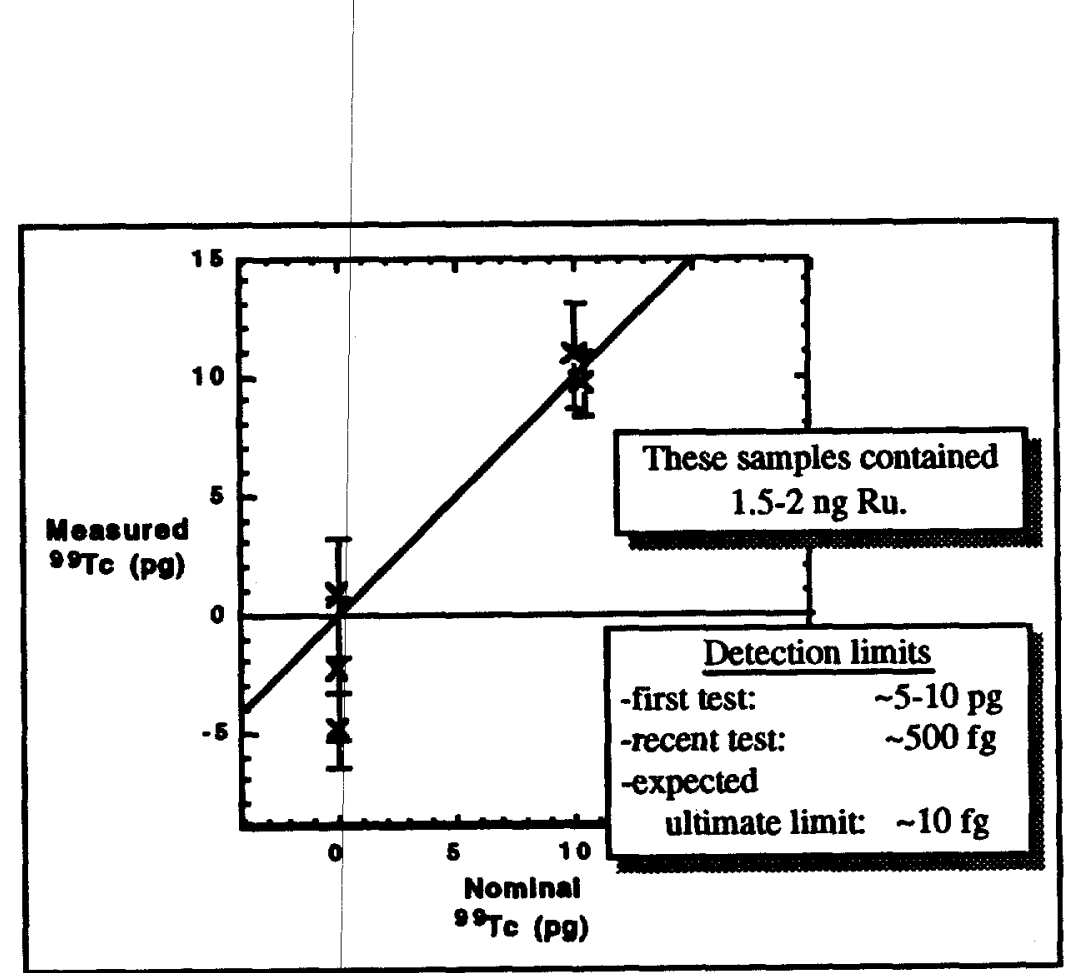

Fig. 7: Measurement of ${ }^{99} \mathrm{Tc}$ in blanks and standards by AMS, first attempt. The minimum detection limit was approximately $5-7 \mathrm{pg}$. Ru levels in these samples were $1.5-2 \mathrm{ng}$. The detection limit in a subsequent run was $0.5-0.6$ $(500-600 \mathrm{fg})$. The goal is a detection limit of $10 \mathrm{fg}$. 
be explained by the formation of a stable molecular ion of mass 99 between ${ }^{36} \mathrm{~S}$ and ${ }^{63} \mathrm{Cu}$ that makes it into the accelerator. This should be avoidable in the future by switching from a +12 charge state to a +10 charge state in the AMS determination. Even with the interference, the spiked soil sample showed a recovery of $60 \%$. This is lower than expected since LSC indicated $>90 \%$ should be recoverable. The low recovery may be explainable by known experimental losses with this particular sample. The results of the unspiked soils samples were inconclusive because of the sulfur interference.

\section{Conclusions:}

Preliminary work has demonstrated that it should be possible to measure ${ }^{99} \mathrm{Tc}$ in soil samples by AMS. A detection limit of $500 \mathrm{fg}$ has been reached. The goal detection limit of $10 \mathrm{fg}$ should be obtainable with further reductions of $\mathrm{Ru}$ in the $\mathrm{Rh}$ carrier and technical improvements in the AMS and detector. There have been positive results from the recovery of ${ }^{99} \mathrm{Tc}$ from the soils. With some improvements in the method, future AMS measurements of spiked soils should show better recovery. A lower detection limit and good recovery of the ${ }^{99} \mathrm{Tc}$ from soil samples will hopefully lead to measurement of natural ${ }^{99} \mathrm{Tc}$ in a soil sample. 
13

References:

Cotton, F.A.; Wilkinson, G. Advanced Inorganic Chemistry. Wiley-Interscience Publishing, New York, 1980.

McAninch, J.E.; Bench, G.S.; Freeman, S.P.H.T.; Roberts, M.L.; Southon, J.R.; Vogel, J.S.; Proctor, I.D. Nucl. Instr. and Meth. B99, 541-545, 1995.

Southon, J.R.; Caffee, M.W.; Davis, J.C.; Moore, T.L.; Proctor, I.D.; Schumacher, B.; Vogel, J.S. Nucl. Instr. and Meth. B52, 301, 1990.

Vogel, J.S.; Turteltaub, K.W.; Finkel, R.; Nelson, D.E. Analytical Chemistry 67, 353 A, 1995.

Yoshihara, K. in Topics in Current Chemistry V. 176, pg. 2, eds. K. Yoshihara and T. Omori, Springer-Verlag, 1996. 


\section{Optimized Power Systems For}

Remote Communities
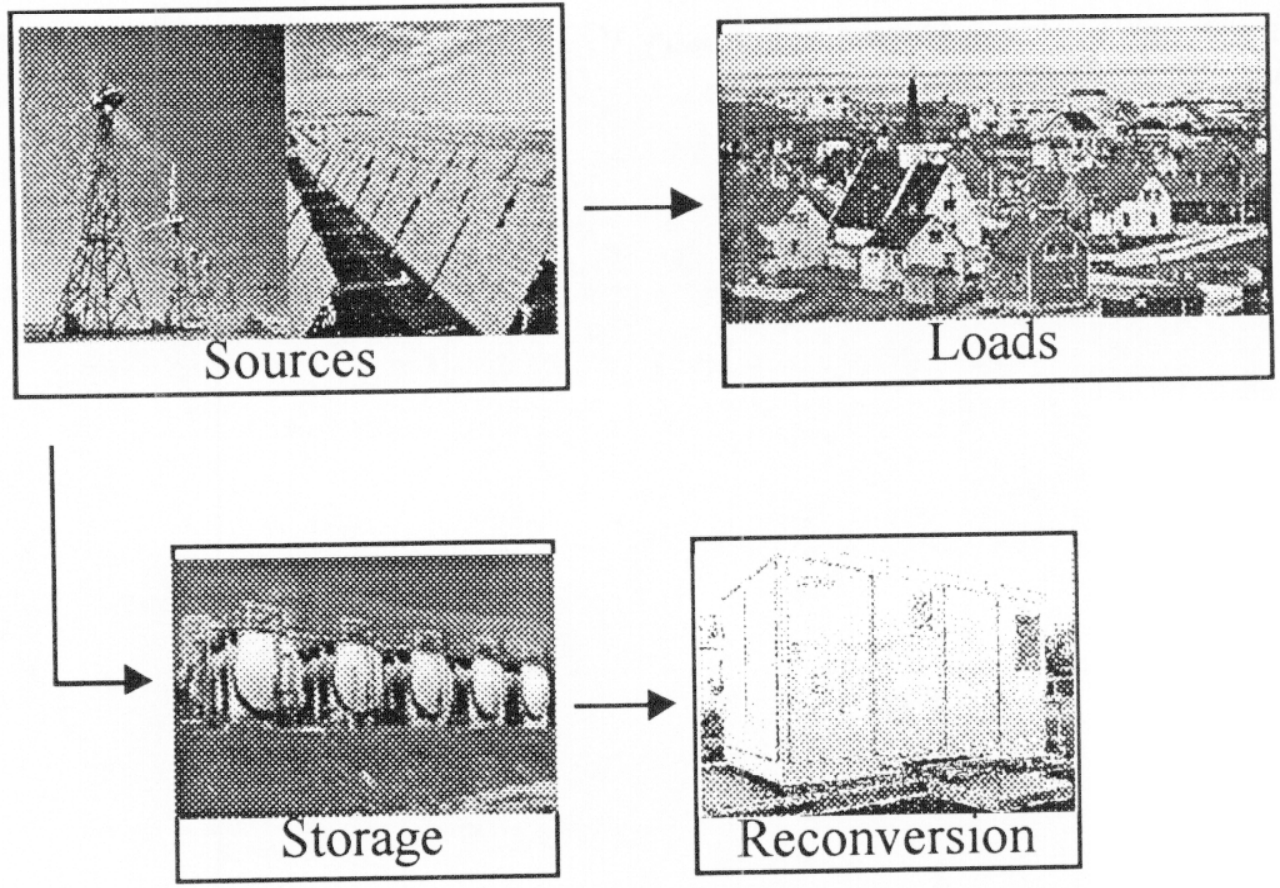

Narada Muni Bradman Florida International University

Under the direction of Ray Smith \& Salvador Aceves

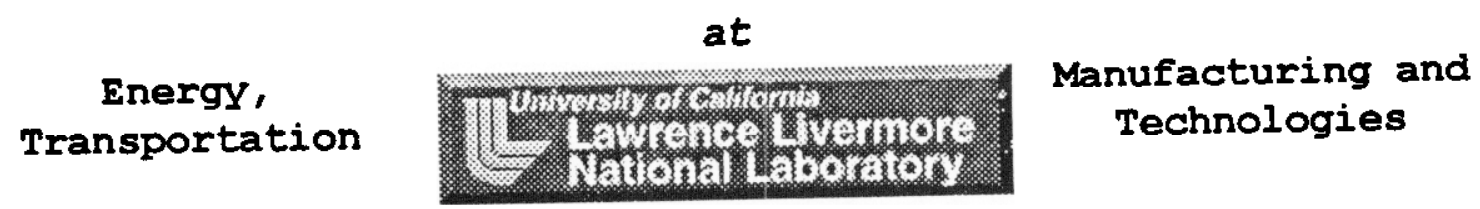




\section{Abstract}

As a result of their remote location, many small communities in Alaska have to pay high prices for the diesel fuel used to produce their electricity and heat their homes. We have performed a system design and analysis to characterize the system that delivers the lowest cost of energy. 
Background:

A significant portion of the population in the state of Alaska resides in small communities located in rural areas. These communities are sufficiently isolated that they are considered by the local utilities to be ineligible for service, i.e. not part of the existing grid and too small to justify the cost of expanding the grid. Therefore the communities in these areas are forced to meet their electrical and heating demands by importing diesel to run local diesel generator sets and heaters. Because of their remote and isolated locations(access is often limited to small air strips and snow mobiles), the cost of importing diesel is often high. It has been proposed that the electrical and heating demands of such remote communities could be met with a lower overall cost by utilizing a combination of locally available renewable resources, such as wind, solar or micro-hydroelectric power, and a storage system, such as compressed hydrogen storage. In order to evaluate the feasibility of using such a system(a system consisting of locally available renewable resources coupled with a storage system)to supplement or even supplant the usage of diesel, we have compiled a computer code to model such remote communities. 
Methodology:

The methodology consisted of the following.

Perpetually modifying the code.

Obtaining and formatting the data.

Setting parameters.

Running the code.

Analyzing the results.

Changing parameters if necessary or desired.

Optimizing the resulting system.

The code consist of a program that takes the electrical demand and subtracts it from the total energy available from the sources, on an hourly basis. If there is excess energy, it goes, depending of the energy management strategy, either to alleviate some of the heating demand or into storage. If there is a need for more energy it is taken from storage or if the storage is empty, the diesel back-up system is used. The code was initially designed to model a system consisting of wind turbines and the diesel back-up system. It was gradually modified to model a system consisting of the combination of solar arrays and any one of a variety of 
storage systems, in addition to wind turbines and the diesel back-up system.

In order to model a system, certain data was necessary which consisted of the following:

Availability of resources(on an hourly basis)

-wind speed

-insolation

Loads (on an hourly basis)

-electrical demand profiles

-heating demand profiles

Efficiency of system components

-wind turbine efficiency

-solar array efficiency

-storage system efficiency

-diesel generator set efficiency

The cost of the system components

-wind turbine cost $(\$ / k W)$

- solar array cost $\left(\$ / \mathrm{m}^{2}\right)$

-storage system cost

Compressed hydrogen storage system

-Electrolyzer cost ( $\$ / \mathrm{kW}$ peak)

-pressurized storage tank cost ( $\$ / k W h)$

-hydrogen ICE* $\operatorname{cost}(\$ / k W)$

or

$-\mathrm{PEM}^{* *}$ fuel cell cost $(\$ / \mathrm{kW})$

Zinc-air storage system

-zinc-air fuel cell ( $\$ / k W)$

-storage $\operatorname{tank}(\$ / k W h)$

-diesel gen set cost $(\$ / k W)$. 
-diesel fuel cost(\$/gal)

* ICE-Internal Combustion Engine

* PEM-Proton Exchange Membrane

Since the loads (electrical and heating demands) as well as the availability of resources were very location dependent, we had to select a particular location and obtain the necessary data for that location. The location selected was a small village named Deering, located on the north-west coast of Alaska(see Figure 1, Appendices). The hourly wind speed variation and insolation for Deering were obtained from various NREL databases. A sample of the solar insolation files(for Kotzubue, Alaska, on April $1 \& 2$, 1978) obtained from the NREL database is included in the Appendices. Although the file included hourly values for extraterrestrial horizontal radiation, extraterrestrial direct normal radiation, global horizontal radiation $\left(\mathrm{Wh} / \mathrm{m}^{2}\right)$, direct normal radiation, and diffuse horizontal radiation, the only value the code needed was the global horizontal radiation $\left(\mathrm{kw} / \mathrm{m}^{2}\right)$. Therefore it was necessary to reformat the file to remove the excess data and place the necessary data in the correct format $\left(\mathrm{kw} / \mathrm{m}^{2}\right.$ rather than $\left.\mathrm{wh} / \mathrm{m}^{2}\right)$. The electrical demand profile was obtained from a previously conducted NREL study and we determined a heating demand profile based on the 
local temperature variation. The efficiencies of most of the system components were obtained from the specifications of commercially available equipment. The efficiencies of the wind turbines and the diesel gen sets were a function of wind speed and fraction of instantaneous power output to maximum power output, respectively. The efficiency of the solar array was a constant value, since the variations resulting from temperature fluctuations were considered to be negligible. The efficiencies of the various storage systems were not only functions of the efficiencies of the components of the storage system and the conditions that they were subjected to, but also of the energy management strategy used. For example, the efficiency of the compressed hydrogen storage system was a function of the efficiencies of the electrolyzer and the PEM fuel cell(or hydrogen ICE), both of which were functions of the fraction of instantaneous power output to maximum power output. Additionally, the overall efficiency of the storage system was also a function of the energy management strategies used, which was one of the parameters set before running the code, as will be discussed below. It should be noted that although literature on the zinc-air fuel describes its efficiency as being essentially constant, this technology is only in the prototype stage and has not yet 
been subjected to the same degree of testing as the commercially available PEM fuel cells.

The code parameters, are used to define a particular system to be modeled. The relevant parameters included the energy management strategies used, the system efficiencies effected by the energy management system used, and the number(or size) of system components.

An example of an energy management strategy is as follows below. Each hour, the demand for electrical energy is subtracted from energy received from the wind turbines and the solar array. If there is an energy deficiency, that is the wind turbines and solar array do not provide the amount of energy necessary to meet the demand, energy is drawn from the storage or if the storage is empty, the diesel back-up system is used. If there is an energy surplus, that is energy derived from the wind turbines and solar array more than meets the demand, the energy is sent to storage. An alternative energy management strategy is one in which instead of sending the surplus energy to storage, the energy is used to satisfy some portion of the heating demand, which was previously being met by diesel heaters. These two energy management strategies result in approximately the same amount of diesel consumption, since using the surplus energy to 
alleviate the heating demand, instead of putting it into storage, results in the energy in the storage running dry sooner, which requires the use of the diesel back-up system, which raises the overall diesel consumption. Other energy management strategies involved the consideration of cogeneration systems in which the waste heat from some particular system component is used to meet a portion of the heating demand. These strategies are particularly advantageous when the system is using either of the fuel cells, PEM or zinc-air, both of which operate at elevated temperatures and therefore have a significant amount of waste heat. Since the efficiency of each of the system components is defined as the ratio of the usable output energy to input energy, by using the waste heat of PEM or zinc-air fuel cells, the useable output energy is increased, therefore increasing the efficiency of the component. The theoretical physical configuration of systems utilizing co-generation was of two basic types. In one of the configurations the fuel cell was a centralized unit, and the waste heat could only be used to satisfy the portion of the heating demands represented by the localized commercial sector of the community(e.g. a downtown area of schools, businesses etc.) which on average was determined to be $50 \%$ of the total 
heating demand. In the other configuration the fuel cells were small distributed units, as opposed to a singular centralized unit, essentially a fuel cell per household, which allowed virtually all of the waste heat to be used to alleviate the heating demand.

The number systems components, such as wind turbines, or the size of system components, such as the area of the solar array or the power capacity of the electrolyzers, were also set before running the code.

Running the code modeled the system functioning, hour by hour, continuously for three years. The system parameters used as well as the annual operating cost and diesel consumption were outputs sent to data files.

The output data was then analyzed to determine if the results were reasonable for the system defined. If inconsistencies were found the parameters responsible for the inconsistency were reset and the code run again.

Once a system was determined to be error free, it was run through the optimizer. The optimizer(SuperCode) would run the code and change select parameters, such as the number of wind turbines, and size of the solar area, to determine their effect on the annual operation cost. The optimizer would run the code until it found the lowest possible annual cost it 
could by changing the parameters that it was allowed to change. The process of optimizing a particular system is repeated for various systems of interest.

Data/Results:

As mentioned above the results that the code output were sent to data files. Each system model yielded a different set of results. A sample of the results after optimizing the code is as follows.

\section{Set System Parameters}

Diesel Gen Set $\$ 200 / \mathrm{kw}$

Diesel Fuel

Fuel Cell $\$ 2.50 / \mathrm{gal}$

Compress Hydrogen Storage $\$ 1500 / \mathrm{kw}$ Electrolyzer $\$ 15 / \mathrm{kwh}$ Wind Turbine $\$ 1000 / \mathrm{kw}$ $\$ 2400 / \mathrm{kw}$

\begin{tabular}{|l|l|}
\hline Number wind turbines & 13.95 \\
\hline Size of storage & $5 \times 10^{3} \mathrm{kWh}$ \\
\hline Capacity of the Electrolyzer & $50 \mathrm{~kW}$ \\
\hline Diesel used for electricity & $26,760 \mathrm{gal}$ \\
\hline Diesel used for heating & $24,100 \mathrm{gal}$ \\
\hline Total Diesel used & $50,860 \mathrm{gal}$ \\
\hline Capital Cost of system & $\$ 1,022,000$ \\
\hline Period RoI & 7.89 years \\
\hline Yearly Cost & $\$ 229,000$ \\
\hline Yearly Cost (diesel base case) & $\$ 255,763$ \\
\hline
\end{tabular}

The period till Return of Investment is based on the assumption of a zero interest loan from the state and a constant cost for the diesel fuel. It should be noted that the minimum storage size was set at $5 \times 10^{3} \mathrm{kWh}$, the minimum 
capacity of the Electrolyzer is $50 \mathrm{~kW}$. The remainder of the data for the various systems modeled are in the appendices.

Conclusions:

A number of the systems modeled were able to compete with a diesel system on a purely economic basis, particularly systems using the zinc-air storage systems. However, since most of the systems modeled just barely broke even or did not provide significant economic benefits over the existing diesel systems, impetus for the conversion to such systems will have to come from advancements in renewable resource conversion devices(e.g. higher efficiency, lower cost solar cells) or other non-economic factors. Consideration of other factors not strictly economic in nature, would make these systems more desirable. Such factors include independence from the need for external energy sources(oil), the decrease in $\mathrm{CO}_{2}$ and $\mathrm{NO}_{\mathrm{x}}$ emissions and a decrease in the overall detrimental environmental impact.

Since the availability of resources is very location dependent, it is important to select a suitable location. For example, selecting a location in the Aleutian Islands would be particularly advantageous because, by virtue of their off- 
shore location, they have what is arguably the best wind resource available in Alaska(see Figure 2, Appendices). Other suitable locations include a number of communities that are located on the banks or in close proximity to a major river, making them suitable for mirco-hyrdoelectric power. The additional availability of a resource, such as the increased wind resource in the Aleutian Islands, or the availability of an additional resource, as in the addition of microhydroelectric, would greatly increase the feasibility of these systems.

It is economically feasible to implement a number of the systems modeled. However, because no significant economic advantage is imparted by implementing any of the current systems, impetus for the implementation of such a system will have to come from factors that allow these systems to convey a greater economic advantage, such as advancements in the technology used in the system componentsle.g. zinc-air storage systems or higher efficiency, lower cost solar cells) or selection of an advantageous location, or other noneconomic factors such as a less detrimental environmental impact. 
Appendices 
Sample of data file from a NREL database.

\begin{tabular}{|c|c|c|c|c|c|c|c|c|c|c|c|}
\hline 6 & & & & & & & AK & -9 & & 52 & \\
\hline 78 & 4 & 1 & 1 & 0 & 0 & 0 & $? 0$ & 0 & $? 0$ & 0 & $? 0$ \\
\hline 78 & 4 & 1 & 2 & 0 & 0 & 0 & $? 0$ & 0 & $? 0$ & 0 & $? 0$ \\
\hline 78 & 4 & 1 & 3 & 0 & 0 & 0 & $? 0$ & 0 & $? 0$ & 0 & \\
\hline 78 & 4 & 1. & 4 & 0 & 0 & 0 & $? 0$ & 0 & $? 0$ & 0 & ?0 \\
\hline 78 & 4 & 1 & 5 & 0 & 0 & 0 & $? 0$ & 0 & $? 0$ & 0 & ?0 \\
\hline 78 & 4 & 1 & 6 & 0 & 0 & 0 & $? 0$ & 0 & $? 0$ & 0 & \\
\hline 78 & 4 & 1 & 7 & 0 & 0 & 0 & $? 0$ & 0 & $? 0$ & 0 & \\
\hline 78 & 4 & 1 & 8 & 58 & 1027 & 18 & H5 & 113 & H4 & 11 & H5 \\
\hline 78 & 4 & 1 & 9 & 178 & 1369 & 89 & G5 & 406 & G4 & 36 & G5 \\
\hline 78 & 4 & 1 & 10 & 311 & 1369 & 190 & H5 & 604 & $\mathrm{H} 4$ & 52 & 5 \\
\hline 78 & 4 & 1 & 11 & 430 & 1369 & 292 & $\mathrm{H} 4$ & 718 & H4 & 66 & 5 \\
\hline 78 & 4 & 1 & 12 & 527 & 1369 & 379 & G4 & 784 & G4 & 77 & \\
\hline 78 & 4 & 1 & 13 & 594 & 1369 & 441 & H4 & 821 & H4 & 85 & \\
\hline 78 & 4 & 1 & 14 & 627 & 1369 & 473 & H4 & 838 & H4 & 89 & 45 \\
\hline 78 & 4 & 1 & 15 & 624 & 1369 & 470 & G4 & 836 & G4 & 89 & G5 \\
\hline 78 & 4 & 1 & 16 & 585 & 1369 & 434 & H4 & 818 & H4 & 84 & H5 \\
\hline 78 & 4 & 1 & 17 & 512 & 1369 & 366 & H4 & 776 & H4 & 76 & HS \\
\hline 78 & 4 & 1 & 18 & 411 & 1369 & 275 & G4 & 703 & G4 & 64 & G5 \\
\hline 78 & 4 & 1 & 19 & 289 & 1369 & 172 & H5 & 578 & H4 & 50 & H5 \\
\hline 78 & 4 & 1 & 20 & 154 & 1369 & 73 & H5 & 361 & H4 & 32 & H5 \\
\hline 78 & 4 & 1 & 21 & 49 & 799 & 13 & G5 & 76 & G4 & 9 & G5 \\
\hline 78 & 4 & 1 & 22 & 0 & 0 & 0 & $? 0$ & 0 & $? 0$ & 0 & ? \\
\hline 78 & 4 & 1 & 23 & 0 & 0 & 0 & $? 0$ & 0 & $? 0$ & 0 & $? 0$ \\
\hline 78 & 4 & 1 & 24 & 0 & 0 & 0 & $? 0$ & 0 & $? 0$ & 0 & $? 0$ \\
\hline 78 & 4 & 2 & 1 & 0 & 0 & 0 & $? 0$ & 0 & $? 0$ & 0 & $? 0$ \\
\hline 78 & 4 & 2 & 2 & 0 & 0 & 0 & $? 0$ & 0 & $? 0$ & 0 & $? 0$ \\
\hline 78 & 4 & 2 & 3 & 0 & 0 & 0 & $? 0$ & 0 & $? 0$ & 0 & $? 0$ \\
\hline 78 & 4 & 2 & 4 & 0 & 0 & 0 & $? 0$ & 0 & $? 0$ & 0 & $? 0$ \\
\hline 78 & 4 & 2 & 5 & 0 & 0 & 0 & $? 0$ & 0 & $? 0$ & 0 & $? 0$ \\
\hline 78 & 4 & 2 & 6 & 0 & 0 & 0 & $? 0$ & 0 & $? 0$ & 0 & $? 0$ \\
\hline 78 & 4 & 2 & 7 & 0 & 0 & 0 & $? 0$ & 0 & $? 0$ & 0 & $? 0$ \\
\hline 78 & 4 & 2 & 8 & 62 & 1117 & 22 & H5 & 148 & H5 & 14 & H6 \\
\hline 78 & 4 & 2 & 9 & 187 & 1368 & 100 & G5 & 403 & G5 & 45 & G5 \\
\hline 78 & 4 & 2 & 10 & 320 & 1368 & 204 & H5 & 617 & H5 & 59 & H6 \\
\hline 78 & 4 & 2 & 11 & 439 & 1368 & 308 & H4 & 737 & H5 & 71 & H5 \\
\hline 78 & 4 & 2 & 12 & 535 & 1368 & 392 & G4 & 821 & G4 & 71 & G5 \\
\hline 78 & 4 & 2 & 13 & 602 & 1368 & 453 & H4 & 854 & H4 & 78 & H5 \\
\hline 78 & 4 & 2 & 14 & 635 & 1368 & 485 & H4 & 870 & H4 & 81 & H5 \\
\hline 78 & 4 & 2 & 15 & 631 & 1368 & 481 & G4 & 868 & G4 & 81 & G5 \\
\hline 78 & 4 & 2 & 16 & 592 & 1368 & 445 & $\mathrm{H} 4$ & 851 & H4 & 77 & H5 \\
\hline 78 & 4 & 2 & 17 & 520 & 1368 & 378 & H4 & 812 & H4 & 69 & H5 \\
\hline 78 & 4 & 2 & 18 & 419 & 1368 & 286 & G4 & 745 & G4 & 58 & G5 \\
\hline 78 & 4 & 2 & 19 & 296 & 1368 & 182 & H5 & 629 & H4 & 46 & H5 \\
\hline 78 & 4 & 2 & 20 & 162 & 1368 & 81 & H5 & 424 & H4 & 31 & H5 \\
\hline 78 & 4 & 2 & 21 & 52 & 866 & 16 & G5 & 116 & G4 & 9 & G5 \\
\hline 78 & 4 & 2 & 22 & 0 & 0 & 0 & $? 0$ & 0 & $? 0$ & 0 & $? 0$ \\
\hline 78 & 4 & 2 & 23 & 0 & 0 & 0 & $? 0$ & 0 & $? 0$ & 0 & $? 0$ \\
\hline 78 & 4 & 2 & 24 & 0 & 0 & 0 & $? 0$ & 0 & $? 0$ & 0 & $? 0$ \\
\hline
\end{tabular}


Figure 1:Location of Deering.

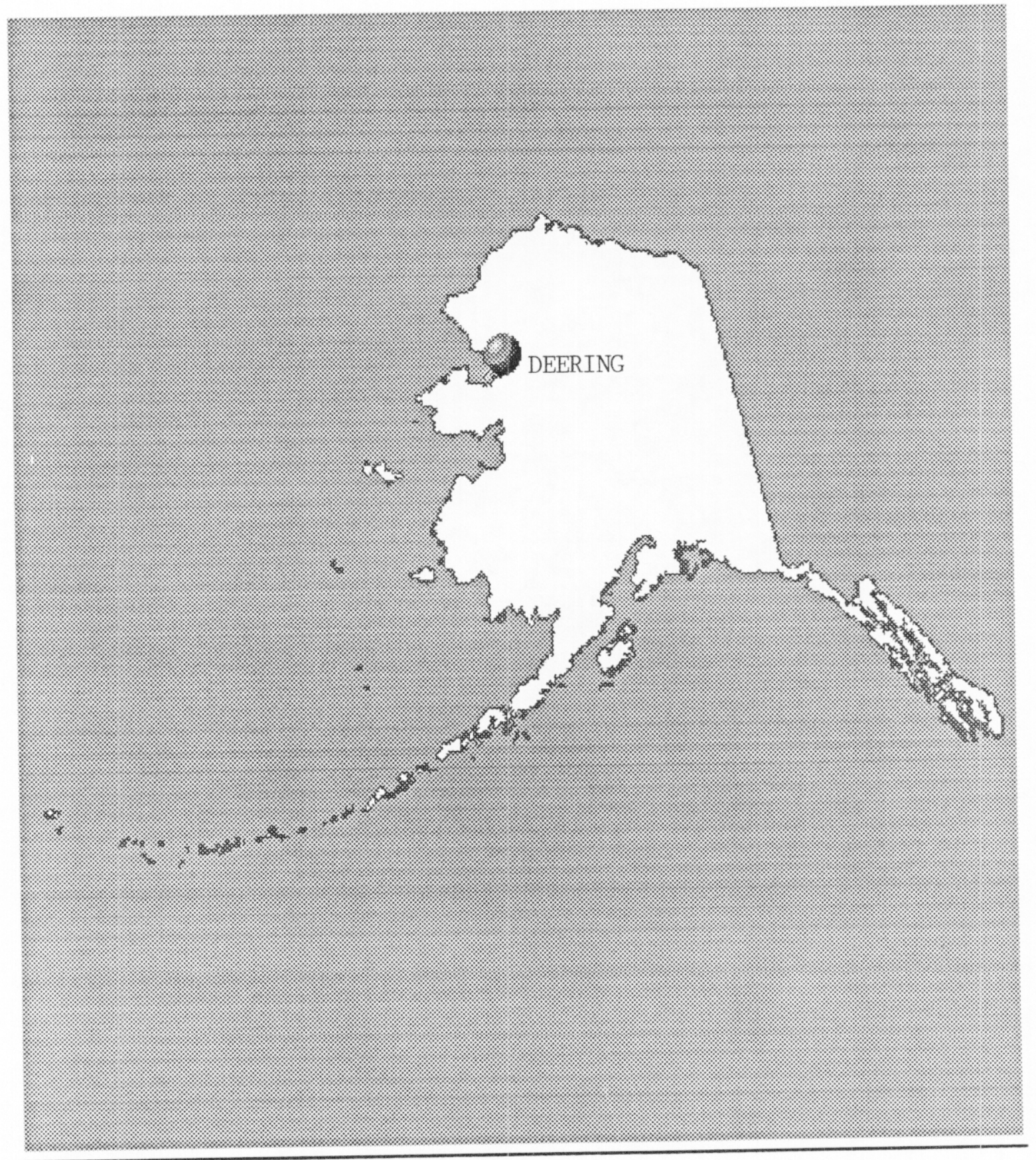


Figure 2: Wind Resource Availability

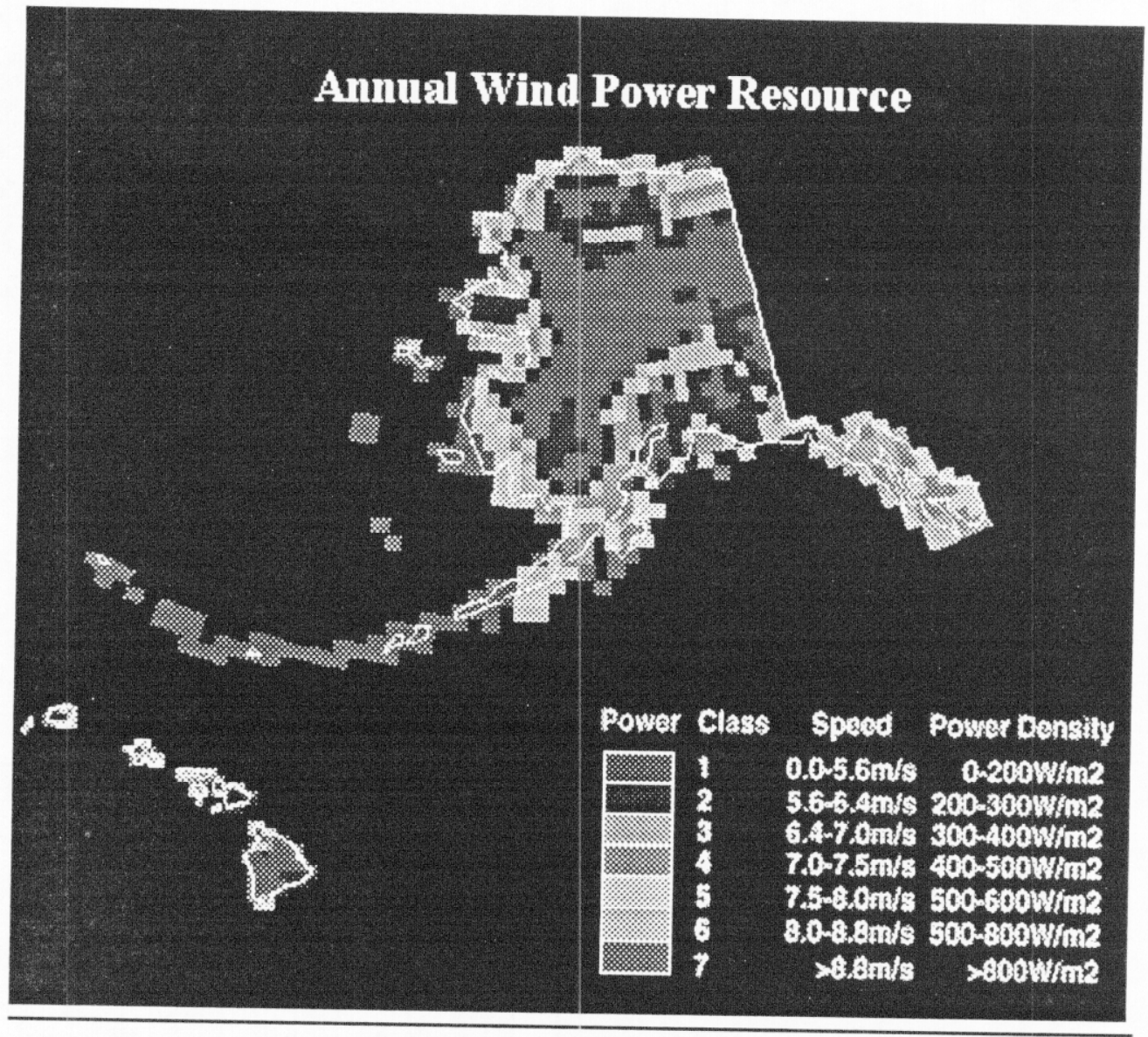


Tabulated Data/Results

ICE system.

Set system Parameters

\section{Cost}

Diesel Gen Set

$\$ 200 / \mathrm{kw}$

Diesel Fuel

ICE

Compressed Hydrogen Storage

$\$ 2.50 / \mathrm{gal}$

$\$ 200 / \mathrm{kw}$

Electrolyzer

wind Turbine

\$15/kwh

$\$ 1000 / \mathrm{kW}$

$\$ 2400 / \mathrm{kW}$

\section{Energy Management strategies}

Surplus energy to alleviate heating demand first.

Co-generation

( $30 \%$ of heating demand can be met using waste heat)

\begin{tabular}{|l|l|}
\hline Number wind turbines & 13.95 \\
\hline Size of storage & $5 \times 10^{3} \mathrm{kWh}$ \\
\hline Capacity of the Electrolyzer & $50 \mathrm{~kW}$ \\
\hline Diesel used for electricity & $26,760 \mathrm{gal}$ \\
\hline Diesel used for heating & $24,100 \mathrm{gal}$ \\
\hline Total Diesel used & $50,860 \mathrm{gal}$ \\
\hline Capital Cost of system & $\$ 1,022,000$ \\
\hline Period RoI & 7.89 years \\
\hline Yearly Cost & $\$ 229,000$ \\
\hline Yearly Cost (diesel base case) & $\$ 255,763$ \\
\hline
\end{tabular}


PEM system

\section{Set System Parameters}

\section{Cost}

Diesel Gen Set

$\$ 200 / \mathrm{kw}$

Diesel Fuel

$\$ 2.50 / \mathrm{gal}$

Fuel Cell

Compressed Hydrogen Storage $\$ 1500 / \mathrm{kw}$

Electrolyzer

wind Turbine

$\$ 15 / \mathrm{kwh}$

$\$ 1000 / \mathrm{kW}$

$\$ 2400 / \mathrm{kw}$

\section{Energy Management Strategies}

Surplus energy to alleviate heating demand first.

Minimal co-generation

( $50 \%$ of heating demand can be met using waste heat)

\begin{tabular}{|l|l|}
\hline Number wind turbines & 14.56 \\
\hline Size of storage & $5 \times 10^{3} \mathrm{kWh}$ \\
\hline Capacity of the Electrolyzer & $50 \mathrm{~kW}$ \\
\hline Diesel used for power & $26,940 \mathrm{gal}$ \\
\hline Diesel used for heating & $26,880 \mathrm{gal}$ \\
\hline Total Diesel used & $53,820 \mathrm{gal}$ \\
\hline Capital Cost of system & $\$ 882,000$ \\
\hline Period RoI & 7.2 years \\
\hline Yearly Cost & $\$ 223,000$ \\
\hline Yearly Cost (diesel base case) & $\$ 255,763$ \\
\hline
\end{tabular}


Zinc-air system

Set System Parameters

Cost

Diesel Gen Set

$\$ 200 / \mathrm{kw}$

Diesel Fuel

Zinc-air fuel Cell

$\$ 2.50 / \mathrm{gal}$

Zinc-air Storage

$\$ 200 / \mathrm{kw}$

wind Turbine

$\$ 4 / \mathrm{kwh}$

$\$ 2400 / \mathrm{kw}$

\section{Energy Management strategies}

Surplus energy to alleviate heating demand first.

Co-generation

(50\% of heating demand can be met using waste heat)

\begin{tabular}{|l|l|}
\hline Number wind turbines & 16.92 \\
\hline Size of storage & $12.4 \times 10^{3} \mathrm{kWh}$ \\
\hline Capacity of Electrolyzer & $113.1 \mathrm{~kW}$ \\
\hline Diesel used for power & $11,390 \mathrm{gal}$ \\
\hline Diesel used for heating & $29,870 \mathrm{gal}$ \\
\hline Total Diesel used & $41,260 \mathrm{gal}$ \\
\hline Capital Cost of system & $\$ 918,000$ \\
\hline Period RoI & 5.93 years \\
\hline Yearly Cost & $\$ 194,000$ \\
\hline Yearly Cost (diesel base case) & $\$ 255,763$ \\
\hline
\end{tabular}


Finite Element Analysis of Ground Movement and Its
Surface Effects During an Earthquake

\author{
Surina L. Briscoe \\ University of Maryland Eastern Shore \\ Lawrence Livermore National Laboratory \\ Livermore, California 94550
}

May 8, 1997

Prepared in partial fulfillment of the requirements of the Science and Engineering Research Semester under the direction of Lawrence Hutchings, Research Mentor, in the Lawrence Livermore National Laboratory.

*This research was supported in part by an appointment to the U.S. Department of Energy Science and Engineering Research Semester (hereinafter called SERS) program administered by LLNL under Contract W-7405-Eng-48 with Lawrence Livermore National Laboratory. Funding for the SERS program provided by the Office of Defense Programs. 
Finite Element Analysis of Ground Movement and Its Surface Effects During an Earthquake

\section{Abstract}

Ground motion recordings during recent earthquakes reveal that little is understood about how earthquakes rupture and why unusual ground motion is recorded. The primary goals of this study are to: 1) develop kinematic simulations for a dip slip earthquake using DYNA codes, 2) use the simulations and seismograms to study the dynamics of earthquake rupture, and 3) study the seismograms to make an interpretation of the earthquake rupture process in the 1971 San Fernando earthquake.

The model of the fault and its surrounding is created using MAZE input commands. The MAZE output is used to run DYNA2D, and the DYNA output is used to create the simulations and seismograms. The examination of the simulations and seismograms show that there are slight differences between the haskell and gaussian load curves.

Each rupture velocity and rupture history show these same differences. The haskell, 1.5 velocity, down dip rupture best describes the rupture process in the 1971 San Fernando earthquake. 


\section{Introduction}

Although earthquake fault rupture is a natural phenomena, practical steps can be taken to ensure that damage and fatalities are minimal. A step towards this process would be the comprehension of the earthquake rupture process. This process requires the study of:

- fault mechanics

- wave propagation

- plate tectonics

- ground motion prediction

- structural response

Our project emphasizes the study of ground motion prediction and the resulting surface effects. We use the DYNA2D finite element code for its proficiency in modeling problems where high rate dynamics or stress wave propagation effects are important (Whirley, Engelmann, Hallquist, 1992). It also provides the flexibility we need to model complicated fault geometries.

Creating synthesized seismograms provides a way for us to interpret past earthquake rupture processes. This allows us to predict future rupturing, given geological data and fault mechanics. An in depth study of the fault rupture mechanics is required for a full understanding of the earthquake rupture process. This project proves to be a stepping stone for the future dynamic, three 
dimensional model. Implementation of this model will provide a more realistic description of dynamic earthquake rupture, which will enable us to narrow the bounds on the uncertainty in synthesized ground motions

The 1971 San Fernando earthquake is ranked as one of the major destructive shocks of the United States (Benfer, Coffman, Bernick, and Dees, 1971). It was a reverse fault earthquake that occurred beneath the San Fernando Valley region and along the frontal thrust fault system of the Santa Susanna Mountains (Hutchings and Jarpe, 1996). Its hypocenter was $10 \mathrm{~km}$ from the surface, and it ruptured up dip to the surface with primarily thrust fault motion (Hanks, 1974). We modeled this earthquake so that we could demonstrate how our methodology could be used to interpret fault rupture mechanics.

\section{Methodology}

A model of a 40 degree dipping fault and its surroundings was created using Maze. An elastic material type was defined for the ground and a "slide line" was defined to represent our fault. The dimensions of the model are $15 \mathrm{~km}$ in width and $25.2 \mathrm{~km}$ in depth. The length of the fault is $24 \mathrm{~km}$ (figure 1). There are a total of 


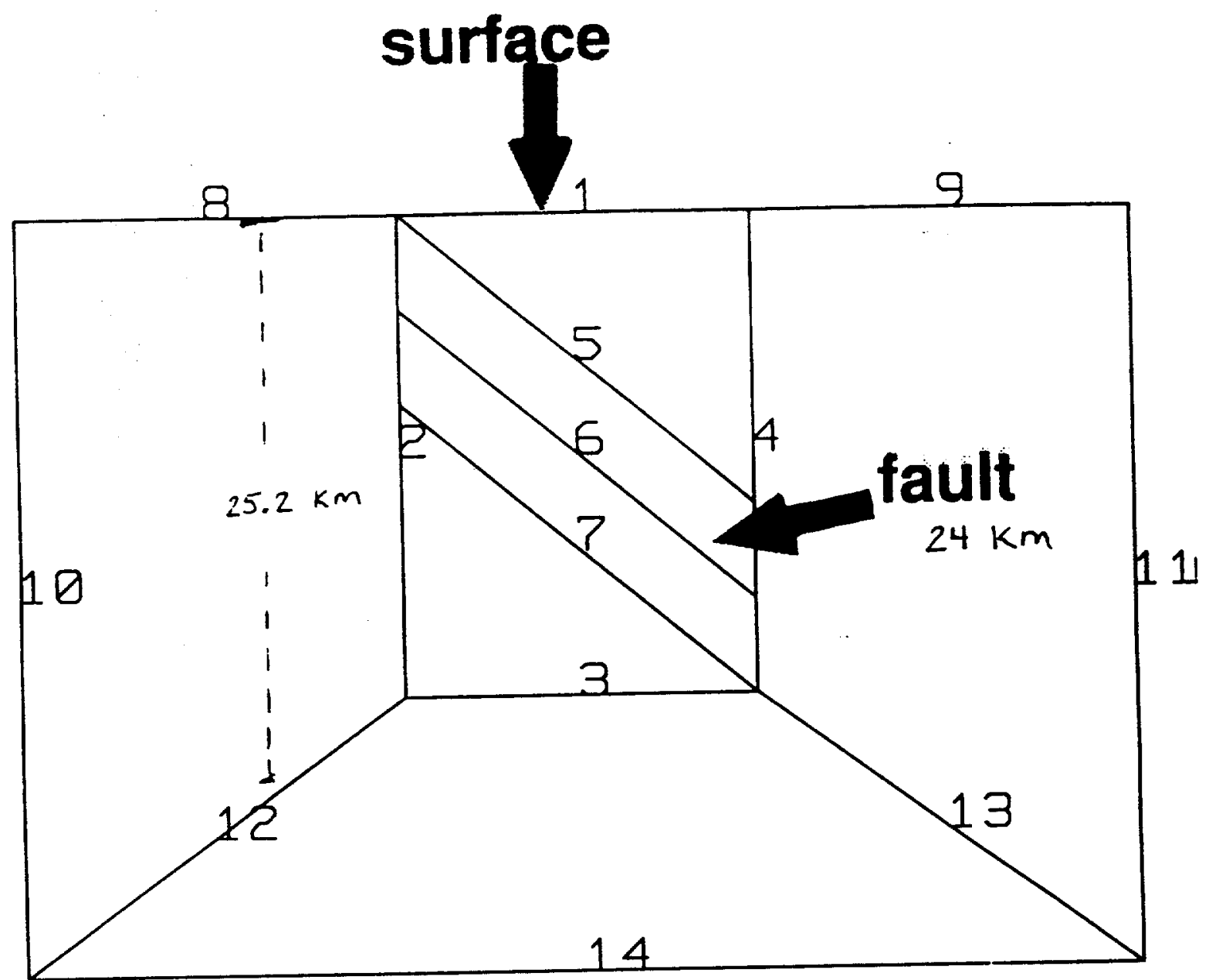

figure 1. The model of a fault and its surroundings, created in MAZE. Line 6 , represents our fault and line 1 represents the surface of the earth. The fault length is $24 \mathrm{~km}$ and the depth of the model is 25.2 $\mathrm{km}$. 
eighty nodes along each side of the fault and each node is $0.3 \mathrm{~km}$ apart. In order to create our dip slip motion, we assigned a velocity to nine nodes on the fault (giving us a $2.7 \mathrm{~km}$ rupture). Three rupture histories were assigned for the nodal displacements: bilateral, unilateral up dip, and unilateral down dip. We also used two types of load curves, gaussian and haskell, and three rupture velocities: $1.5 \mathrm{~km} / \mathrm{sec}, 2.5 \mathrm{~km} / \mathrm{sec}$, and $3.5 \mathrm{~km} / \mathrm{sec}$. This gave us a total of eighteen different rupture scenarios.

After this information is defined, Maze creates an input file for DYNA2D. The DYNA2D code is run and a file of all the nodal displacements is created. This file is used as input for a c-shell that creates the simulations and for a program that writes seismograms.

\section{Results}

The simulations show the propagation of waves through our model. Figures $2 a-2 c$ show a series of time steps for both haskell and gaussian, bilateral, $2.5 \mathrm{~km} / \mathrm{sec}$ velocity ruptures. There are a total of 121 time frames, ten frames per second. Within each frame there is representation of the horizontal and vertical particle velocity. The left side represents the horizontal component, and the right side represents the vertical component (figure 2a). The red 
40
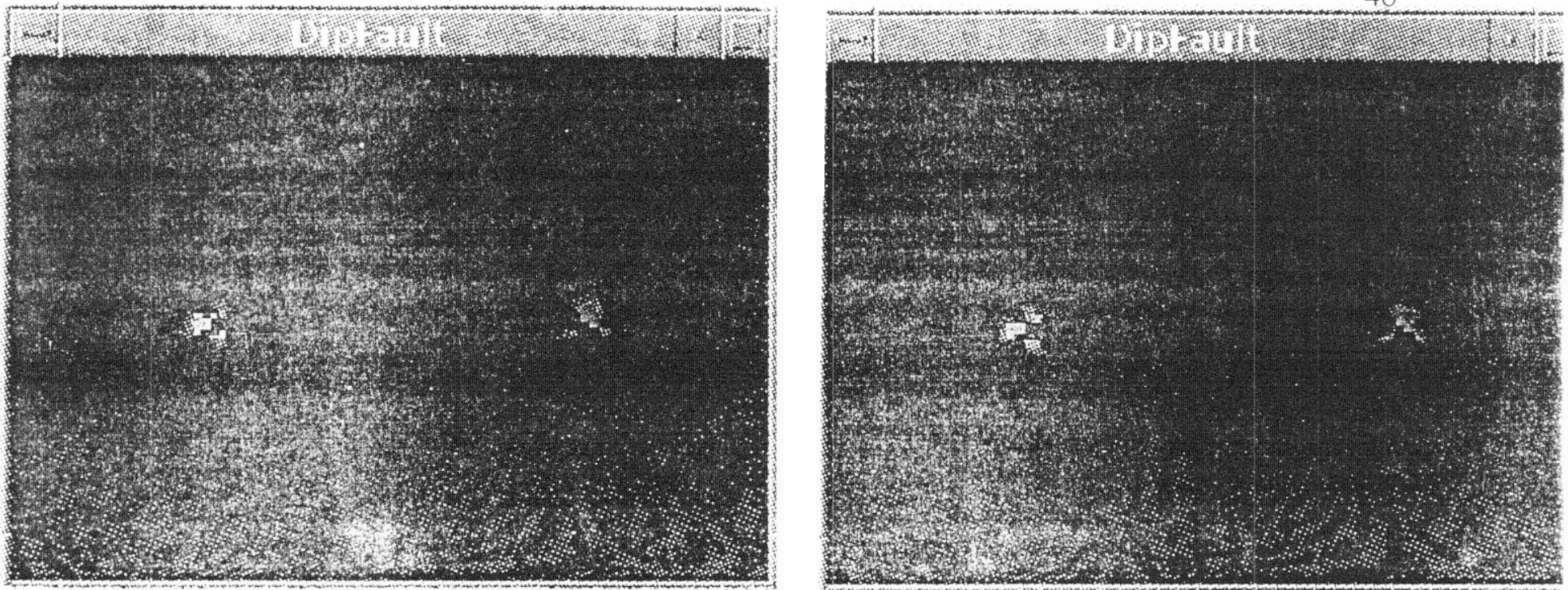

time $t=0.4 \mathrm{sec}$
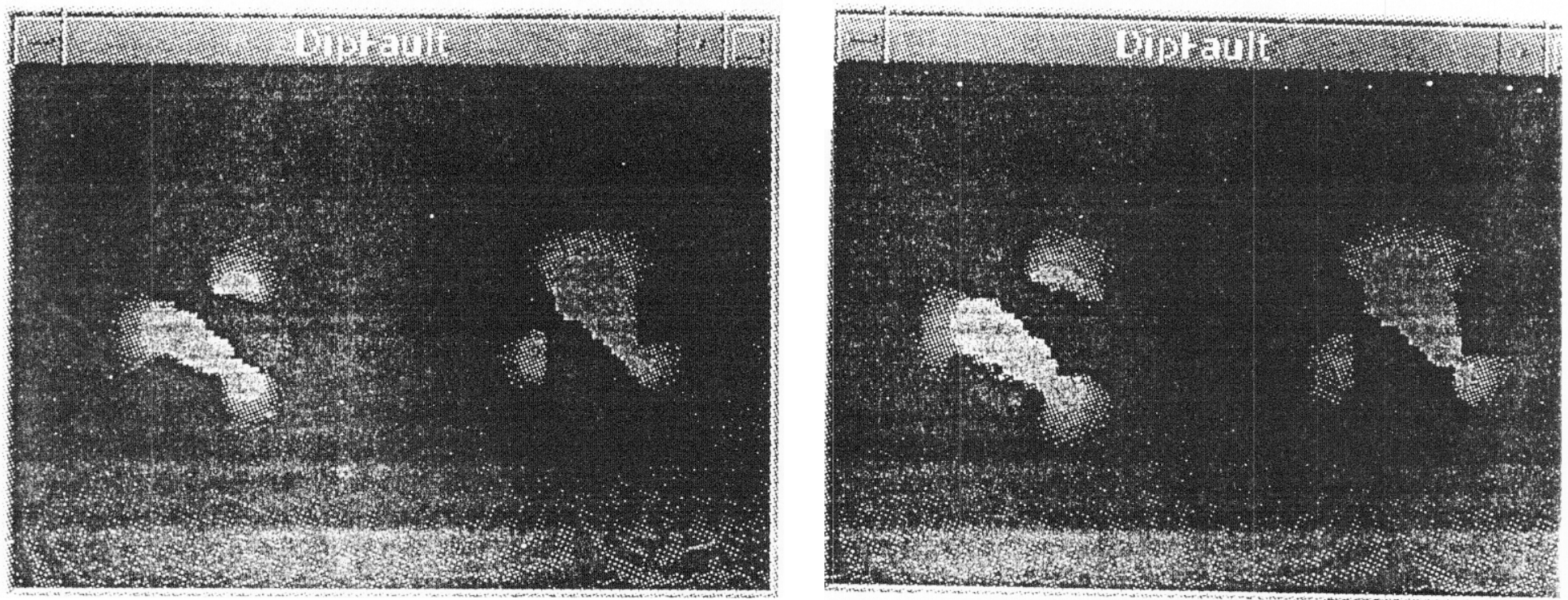

time $\mathrm{t}=1.1 \mathrm{sec}$

figure 2a. DYNA2D simulations of a bilateral, 2.5 velocity rupture. The left column represents gaussian simulations and the right column represents haskell. The left side of each frame represents the horizontal component and the right side represents the vertical component. The red color corresponds to the positive velocity and the blue corresponds to the negative velocity. 
colors indicate that the nodes are moving in the positive direction and the blue indicates the negative direction. The intensity of the colors represent the velocity of the nodes. The maximum and minimum velocities at which the colors saturate is $0.06 \mathrm{~m} / \mathrm{sec}$ and $0.06 \mathrm{~m} / \mathrm{s}$. The black color corresponds to a zero velocity.

The differences between the simulations of each load curve are small. At 2.0 seconds the simulations seem to show their bilateral orientation. The nodes along the fault have come to a rest and the rupture history takes shape (figure $2 \mathrm{~b}$ ). At 2.9 seconds the waves reach the top of the surface and they start to reflect at 4.5 seconds (figure $2 b, c$ ). Eventually the waves die off and the colors begin to fade (figure 2c).

Seismograms were created for three points on the surface. The first two points were chosen to demonstrate a comparison of the ground motion at a point closer to the fault to one further away. The first point is $1.2 \mathrm{~km}$ east of the fault and the second is $14.1 \mathrm{~km}$ east of the fault (figure 3). The gaussian load curves at point one seem to have a higher frequency than those at point two. The frequencies for the haskell load curves are about the same a both points. These 

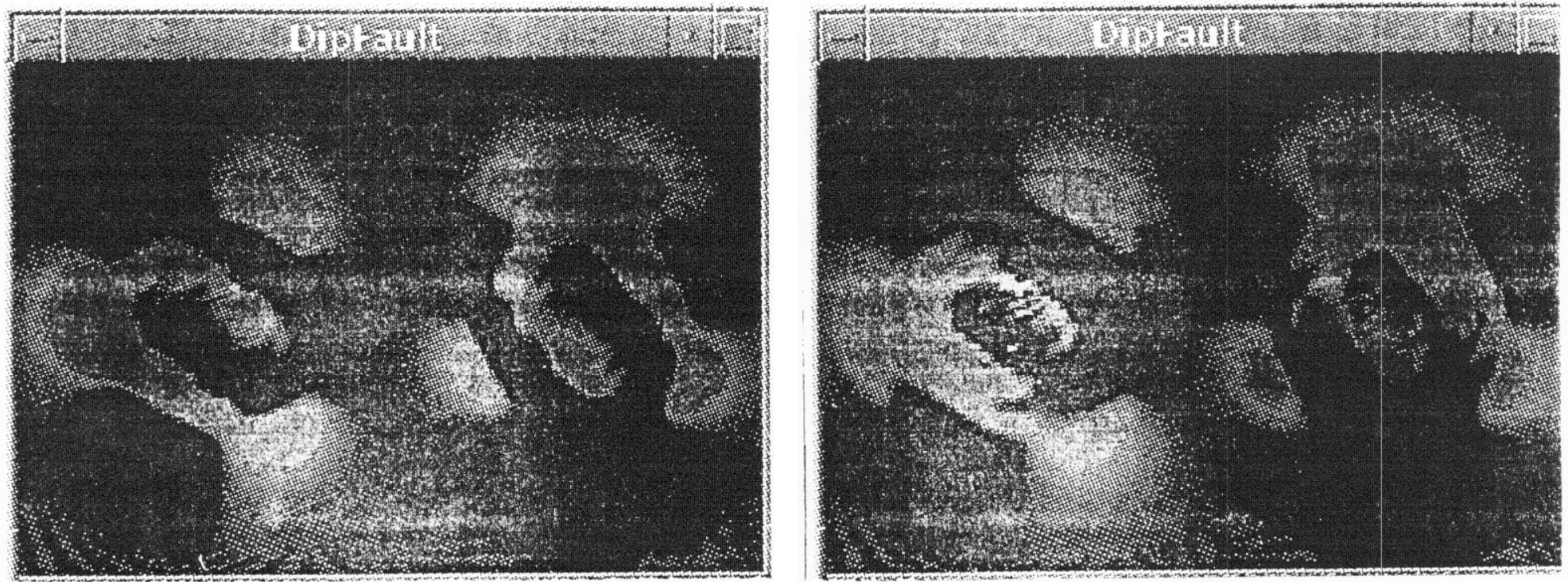

time $\mathrm{t}=2.0 \mathrm{sec}$
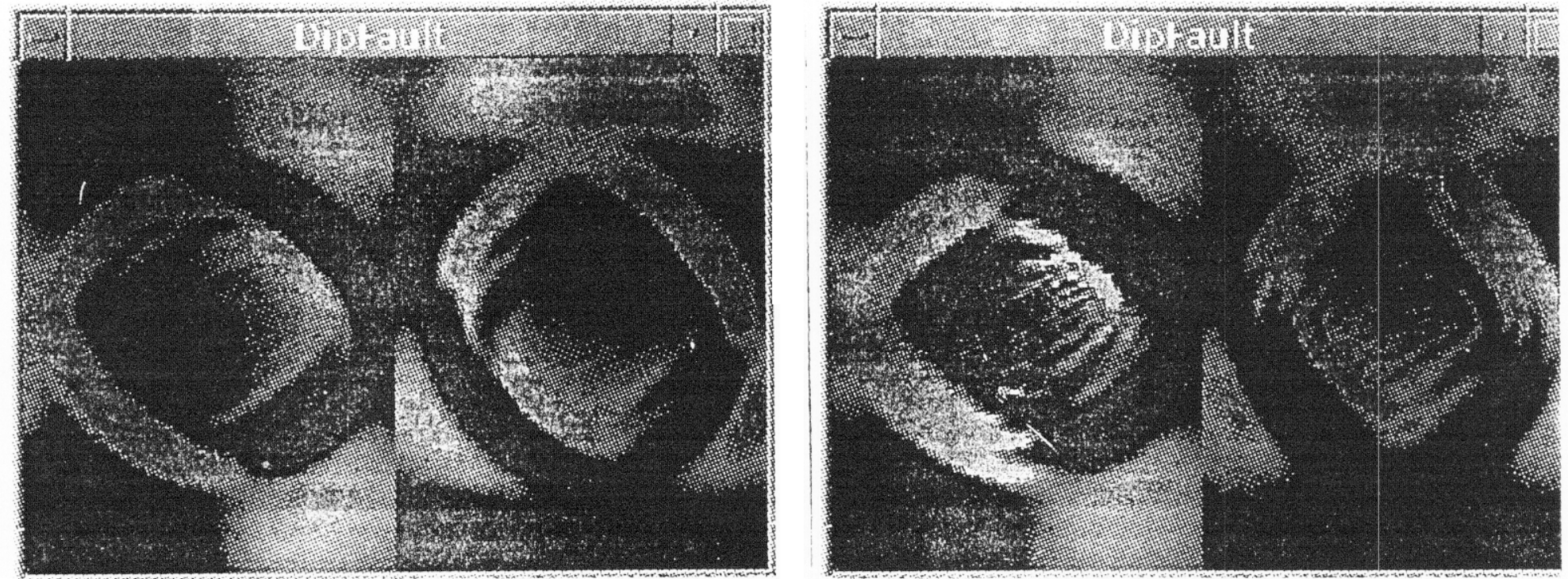

time $\mathrm{t}=2.9 \mathrm{sec}$

figure 2b. Continuation in time of figure $2 \mathrm{a}$. At 2.0 seconds the bilateral rupture history seems to take shape. At 2.9 seconds, the waves reach the surface of the earth. 

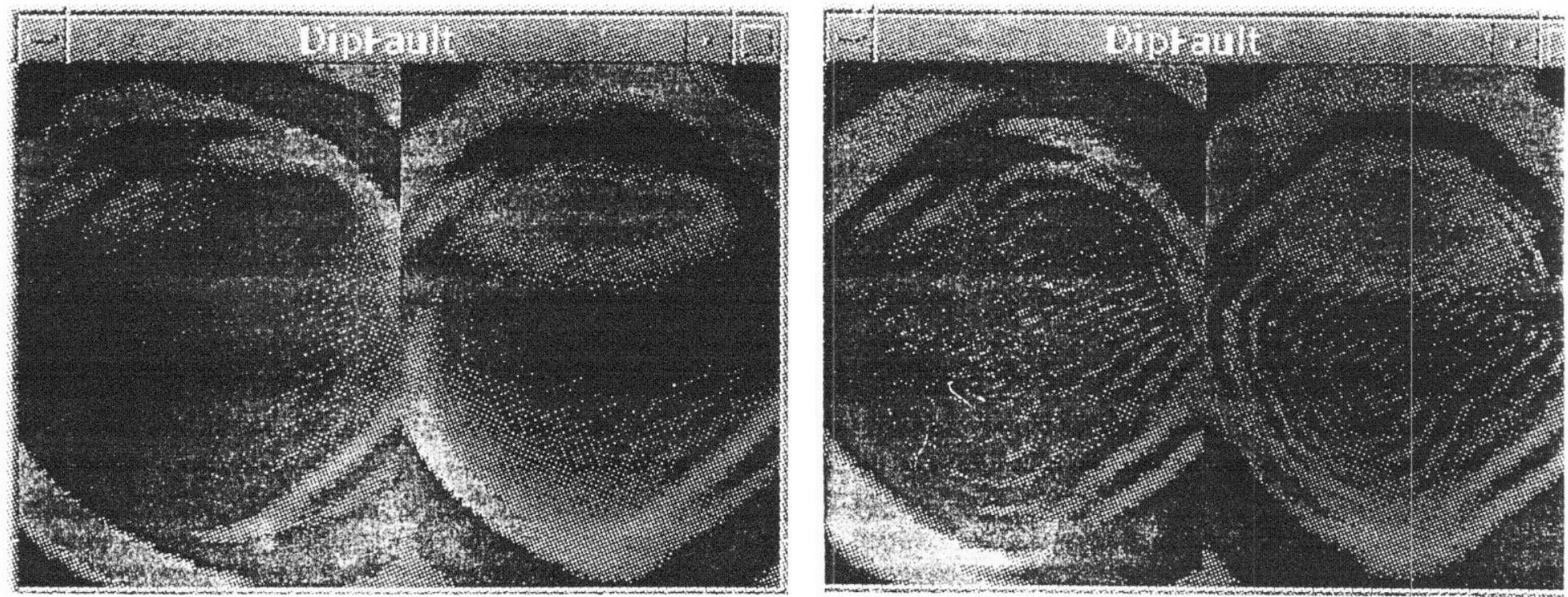

time $\mathrm{t}=4.5 \mathrm{sec}$
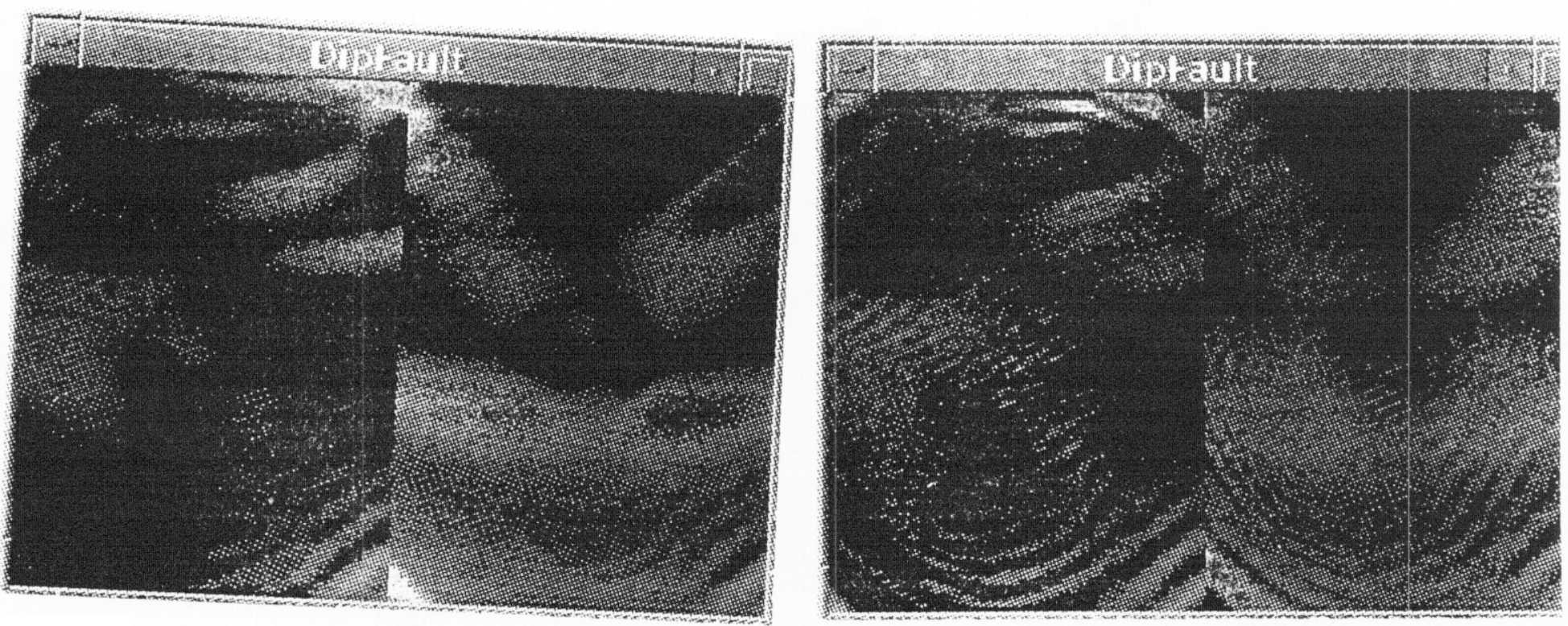

time $\mathrm{t}=0.1 \mathrm{sec}$

figure 2c. Continuation in time for figures $2 \mathrm{a}$ and $2 \mathrm{~b}$. At time $t=4.5$ seconds. the waves begin to reflect from the surface. At $t=6.1$ seconds, the waves begin to die off and the colors fade. The black color corresponds to a zero velocity. 


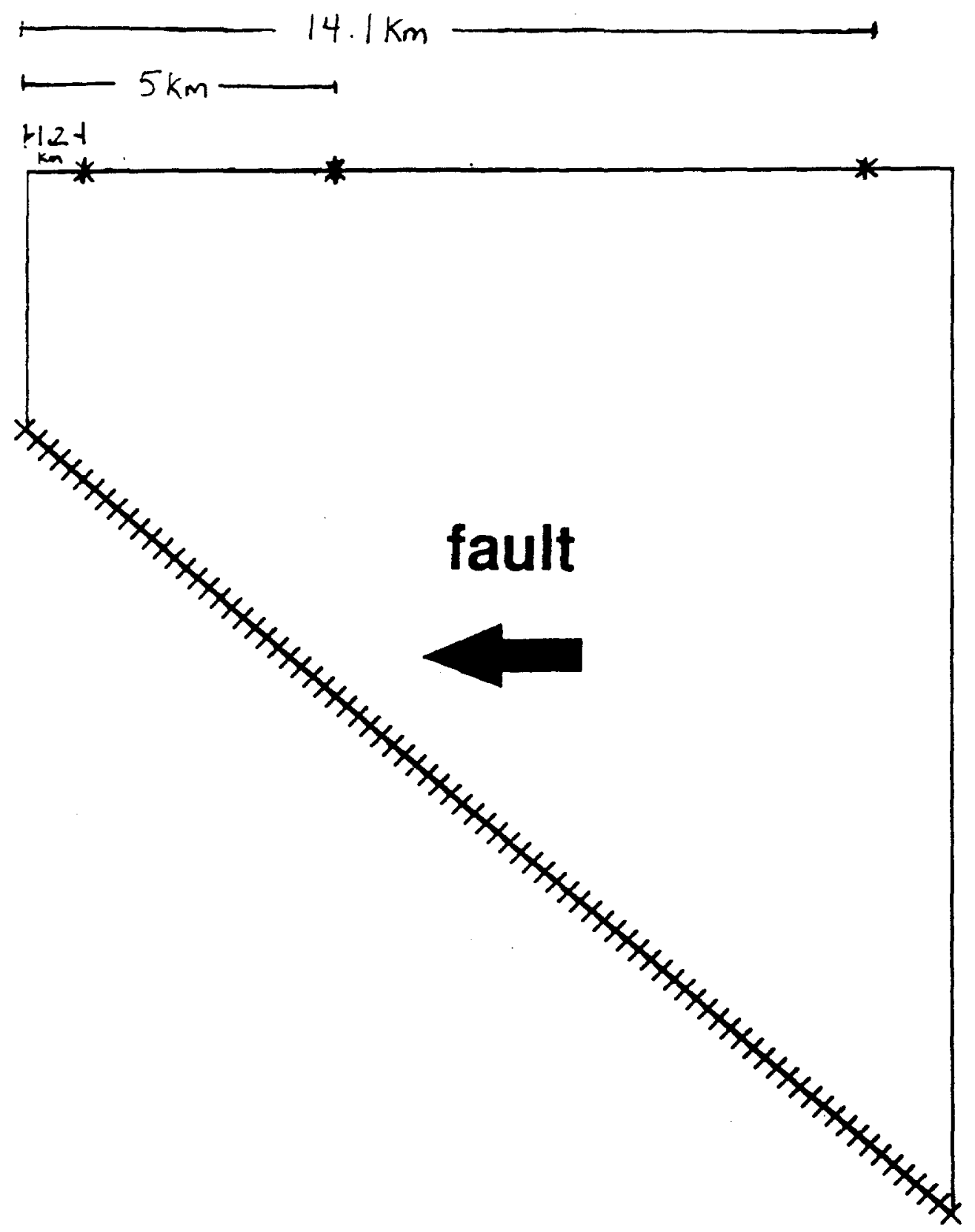

figure 3. The top piece of the fault showing the surface and the nodes which are moved. 
seismograms were created primarily to demonstrate the aptitude of our methodology (figure $4 a, b$ ).

In an attempt to model the 1971 San Fernando Earthquake, seismograms were created at point three, which is $5 \mathrm{~km}$ away from the fault (figure 3). This sight represents the Pacoima Dam. Although our earthquake did not rupture to the surface, and our hypocenter was $13.8 \mathrm{~km}$ from the surface, (unlike the San Fernando earthquake) an interpretation of the rupture process was made. In viewing the different seismograms, we have predicted that the 1971 San Fernando earthquake followed a haskell, down dip, 1.5 velocity rupture (figure 5).

\section{Conclusions}

In spite of the fact that past research has shown that the rupture history for this earthquake was up dip, our methodology proves to be proficient given a more realistic model. Our model could be improved by using the exact dimensions and fault properties of the 1971 San Fernando earthquake. This methodology has the capacity to simulate complicated fault geometries and more realistic rupture models. A dynamic, three dimensional approach is in the 
making, and it will be used to predict the ground motion at different geological sites. 
Coussion aro moskell up did vel 1.5 Point One (near the foull)
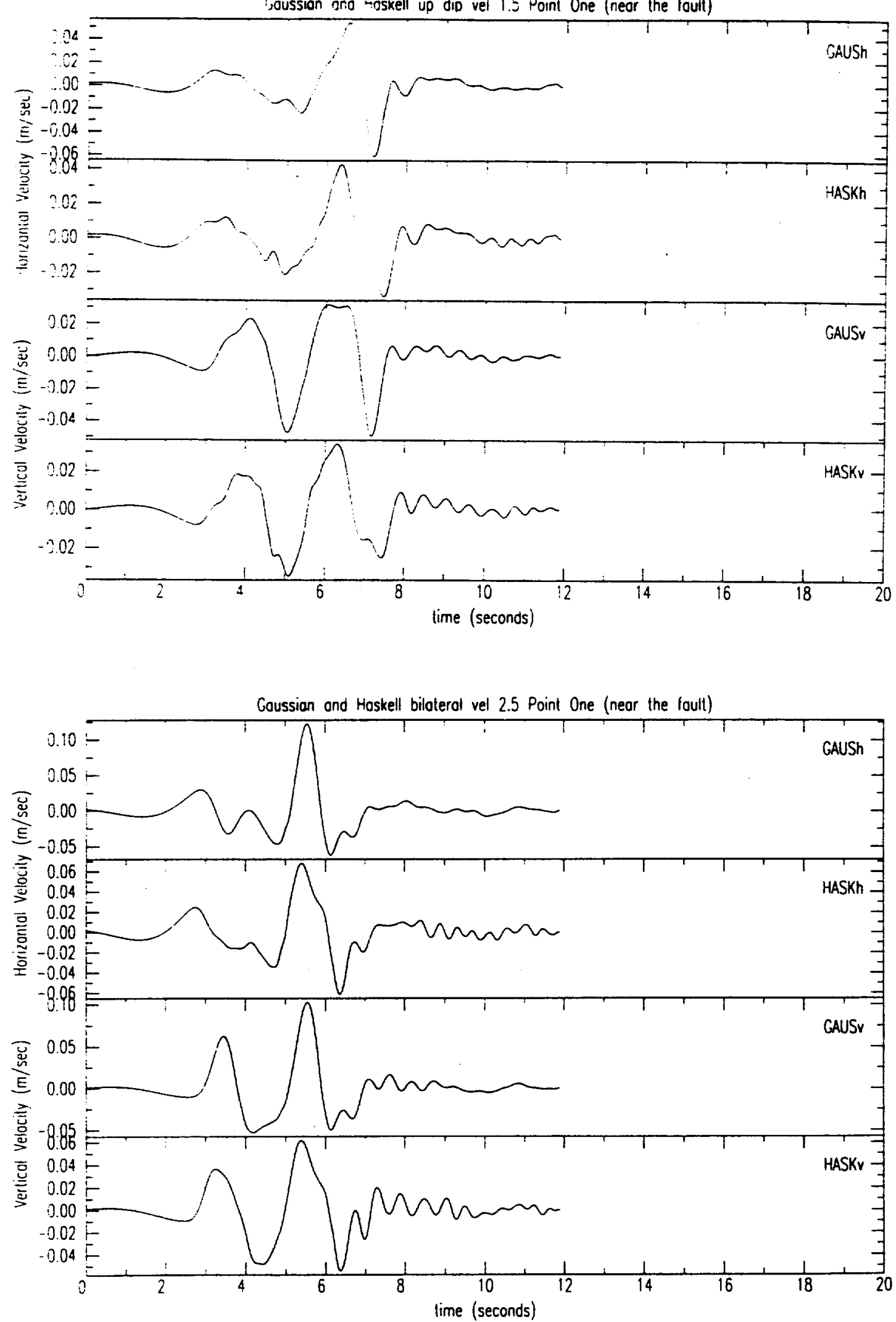

figure 4a. continued. Seismograms for gaussian and haskell load curves at point two. (14.1 km from the fault) 

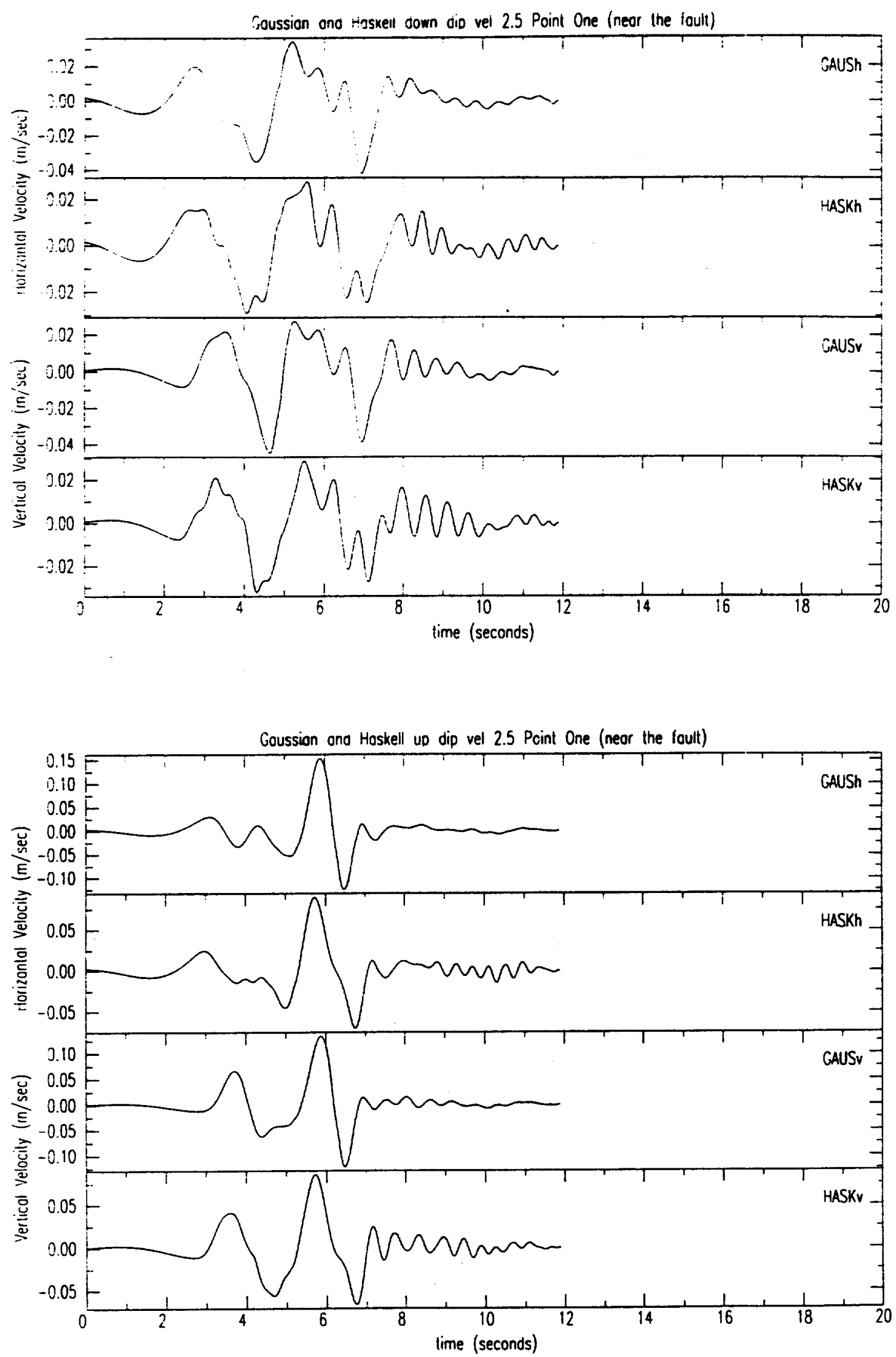

figure 4a. continued. Seismograms for gaussian and haskell load curves at point two. (14.1 km from the fault) 

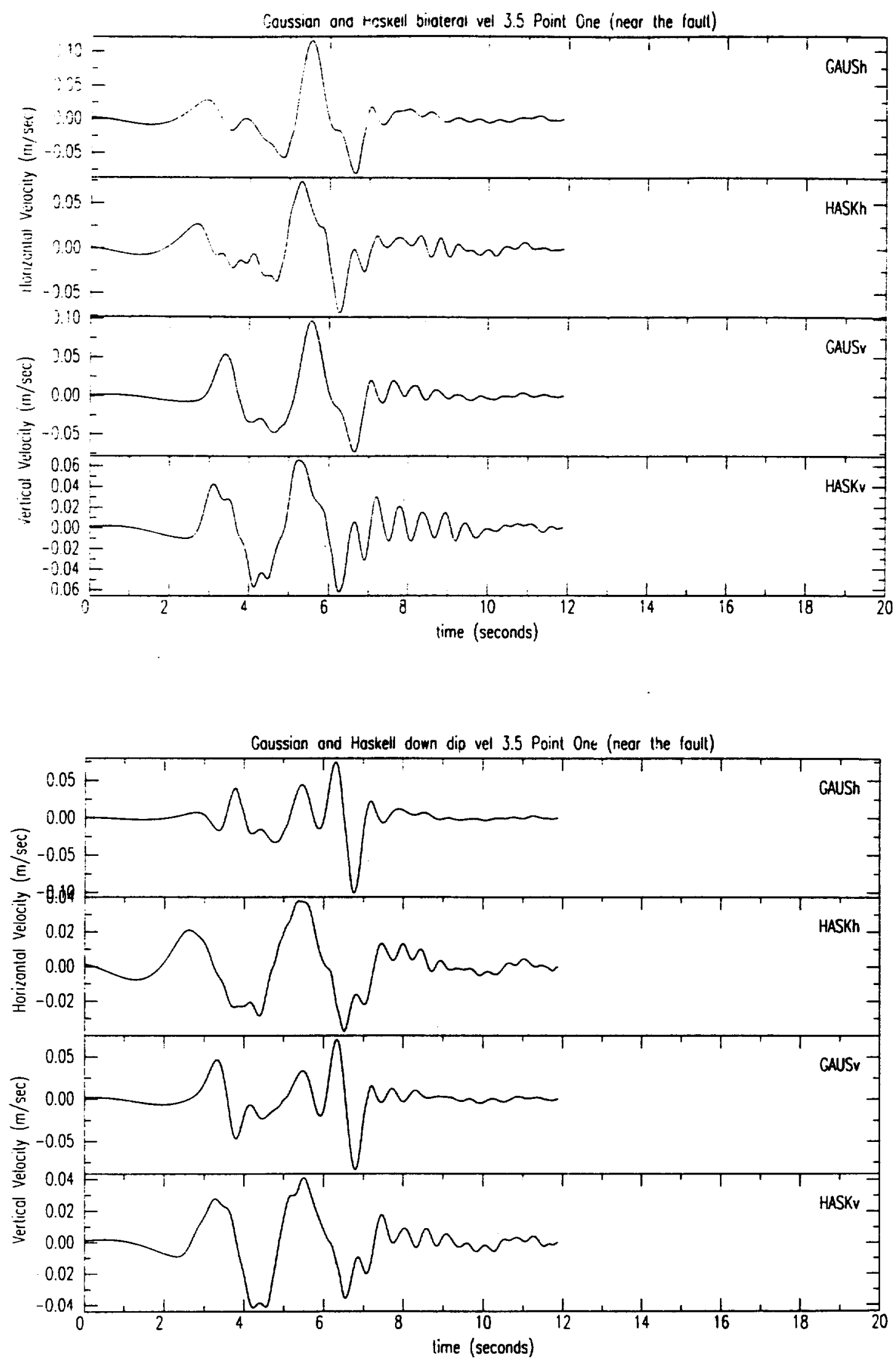

figure 4a. continued. Seismograms for gaussian and haskell load curves at point two. (14.1 km from the fault) 


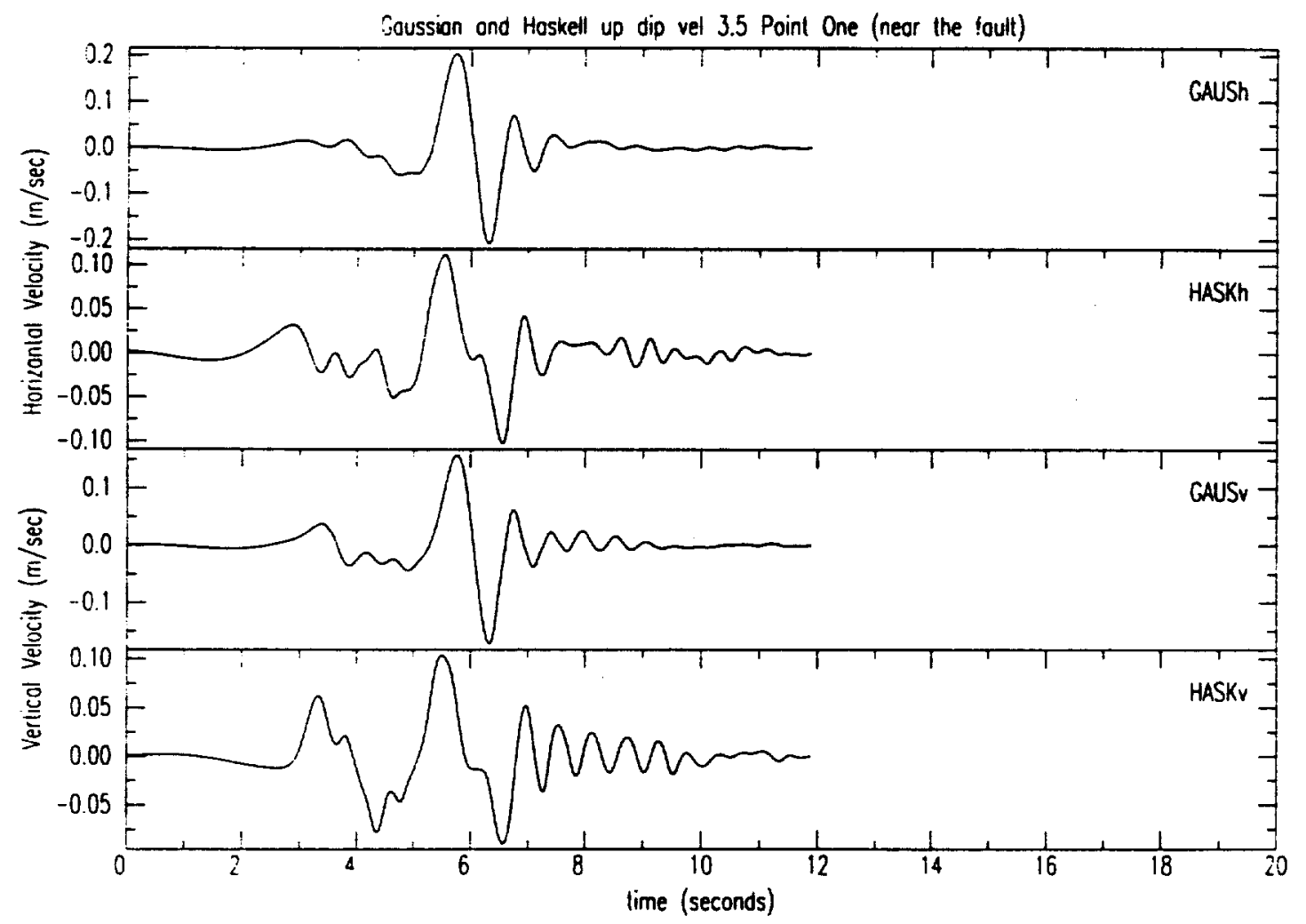

figure 4a. continued. Seismograms for gaussian and haskell load curves at point two. (14.1 km from the fault) 

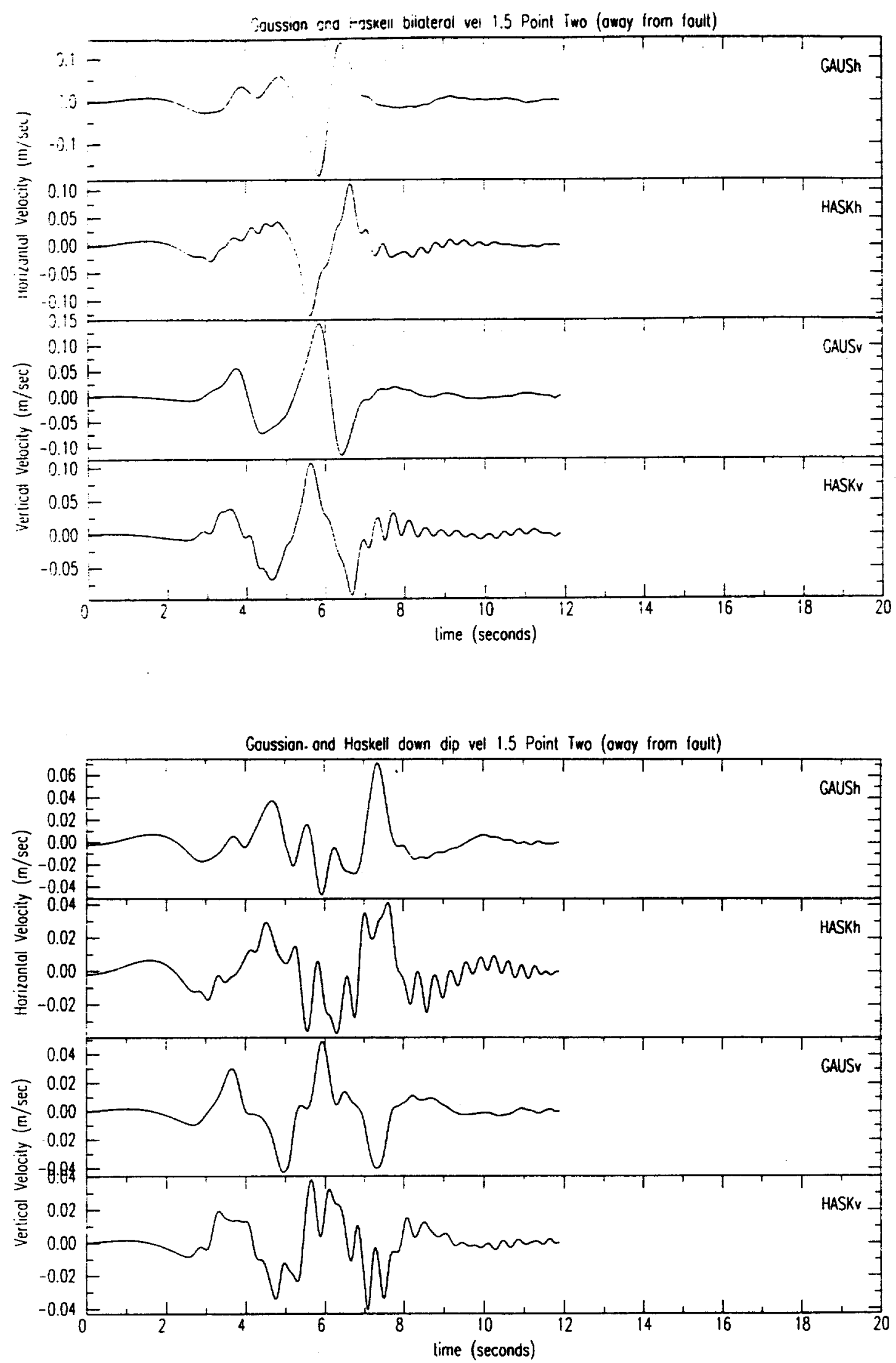

figure 4b. continued. Seismograms for gaussian and haskell load curves at point two. (14.1 km from the fault) 

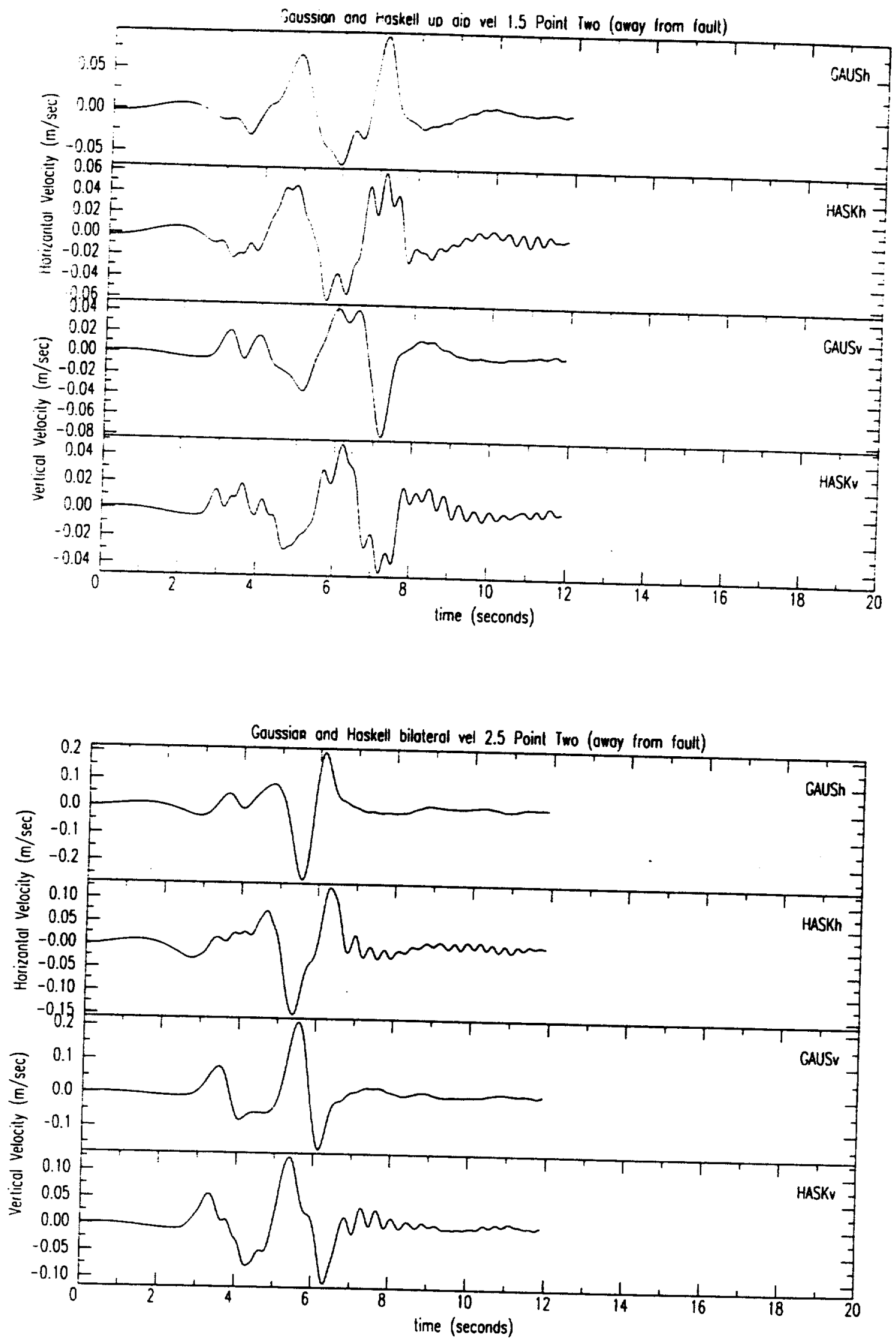

figure $4 \mathrm{~b}$. continued. Seismograms for gaussian and haskell load curves at point two. (14.1 km from the fault) 


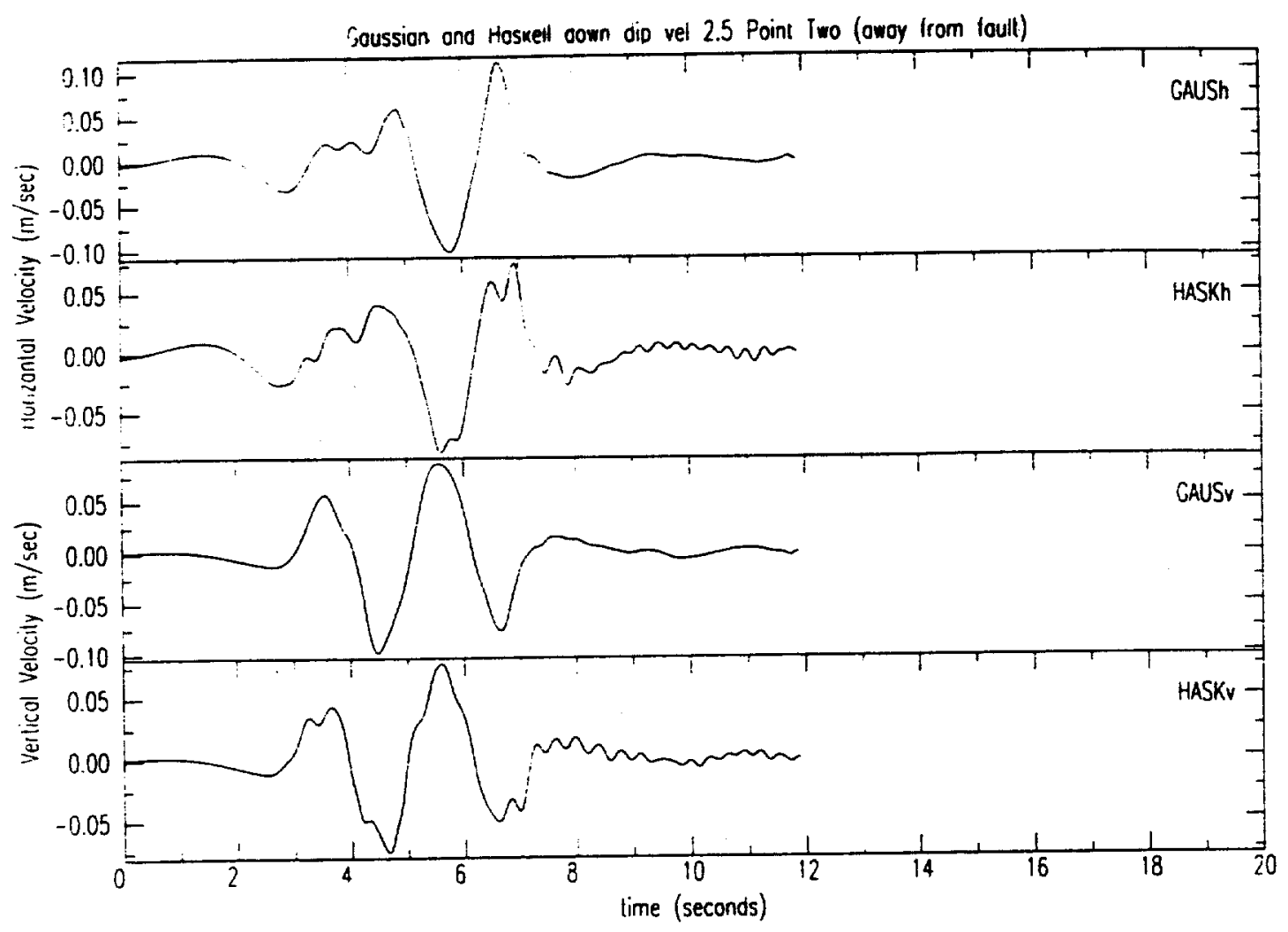

54

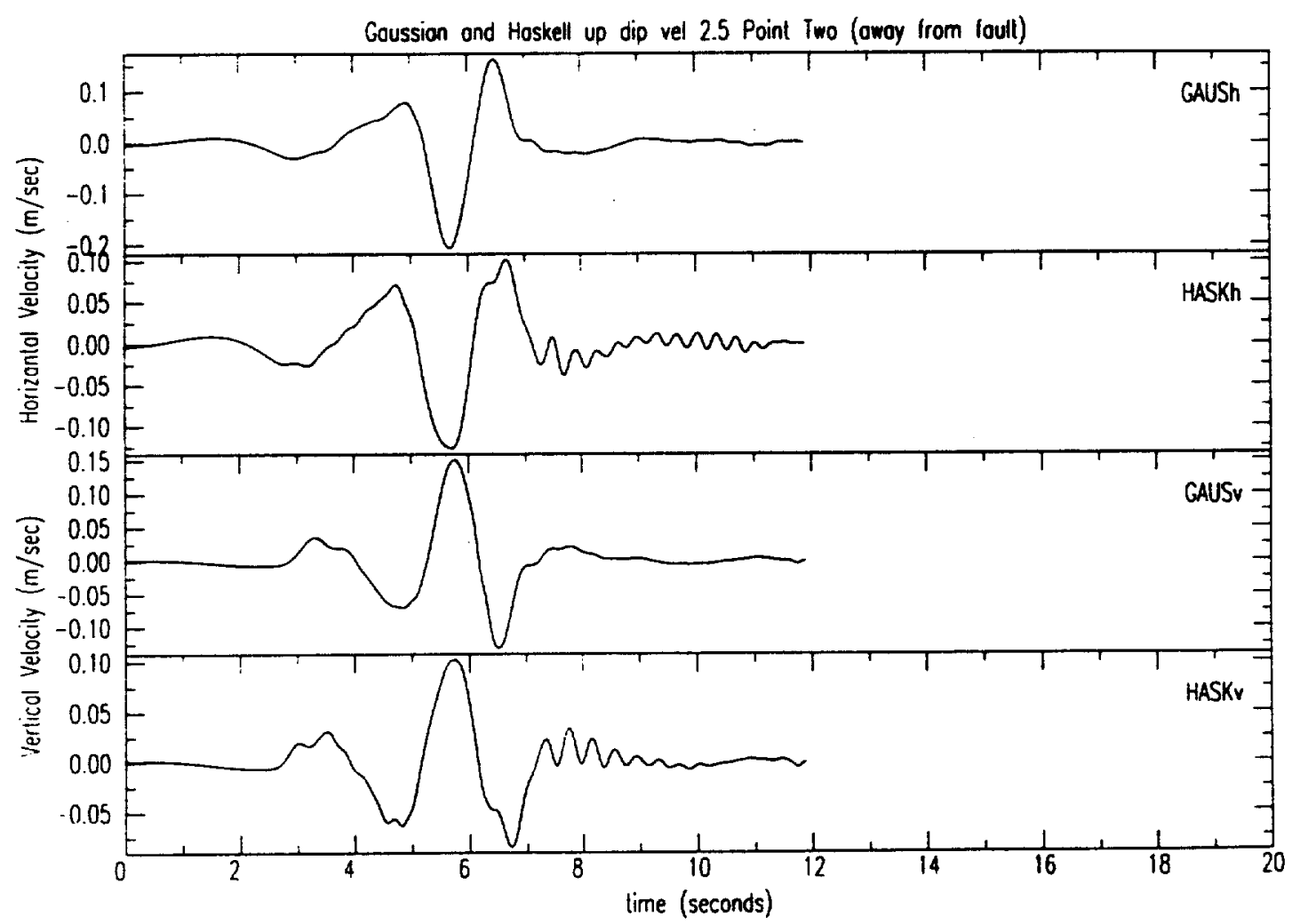

figure 4b. continued. Seismograms for gaussian and haskell load curves at point two. (14.1 km from the fault) 

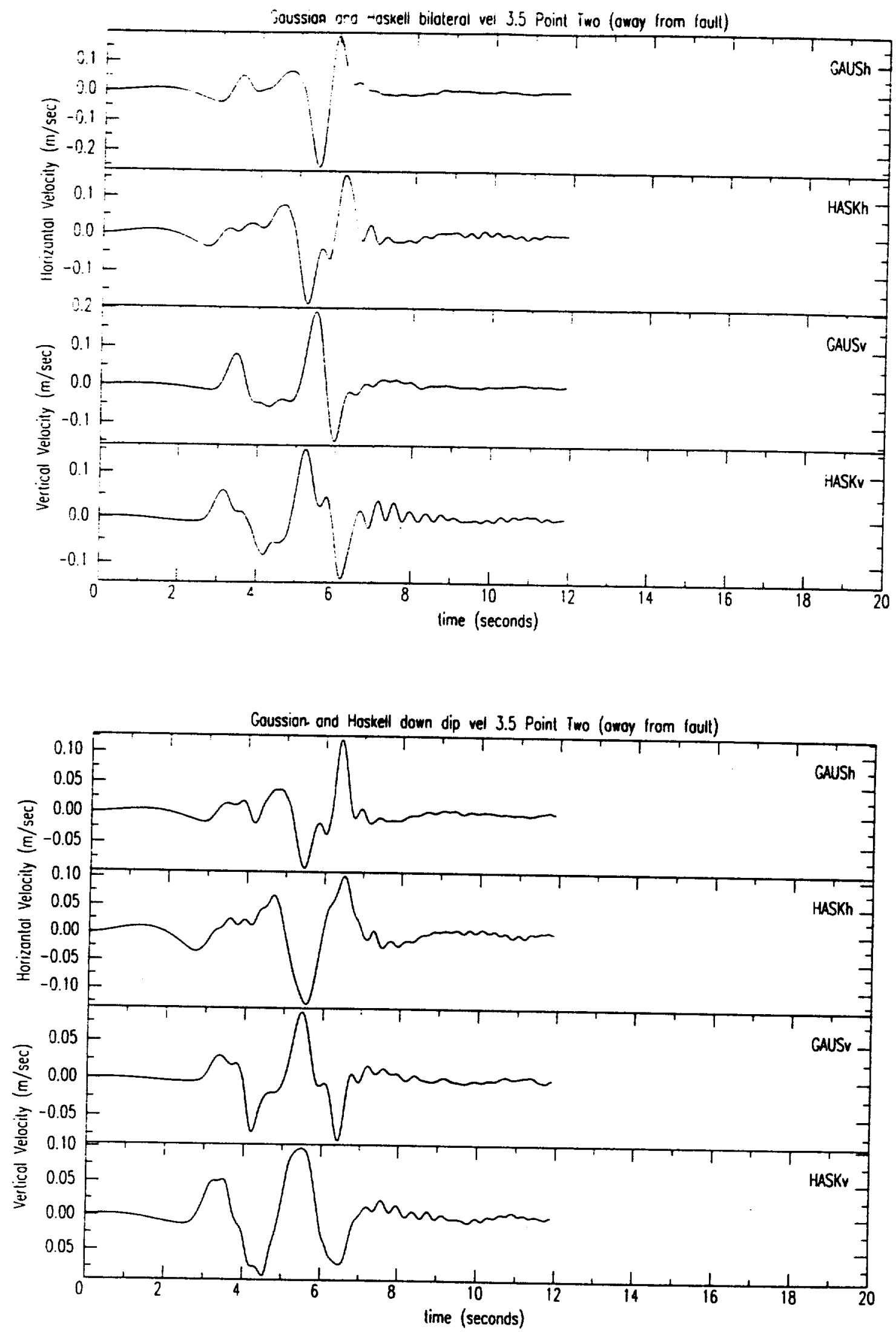

figure 4b. continued. Seismograms for gaussian and haskell load curves at point two. (14.1 km from the fault) 


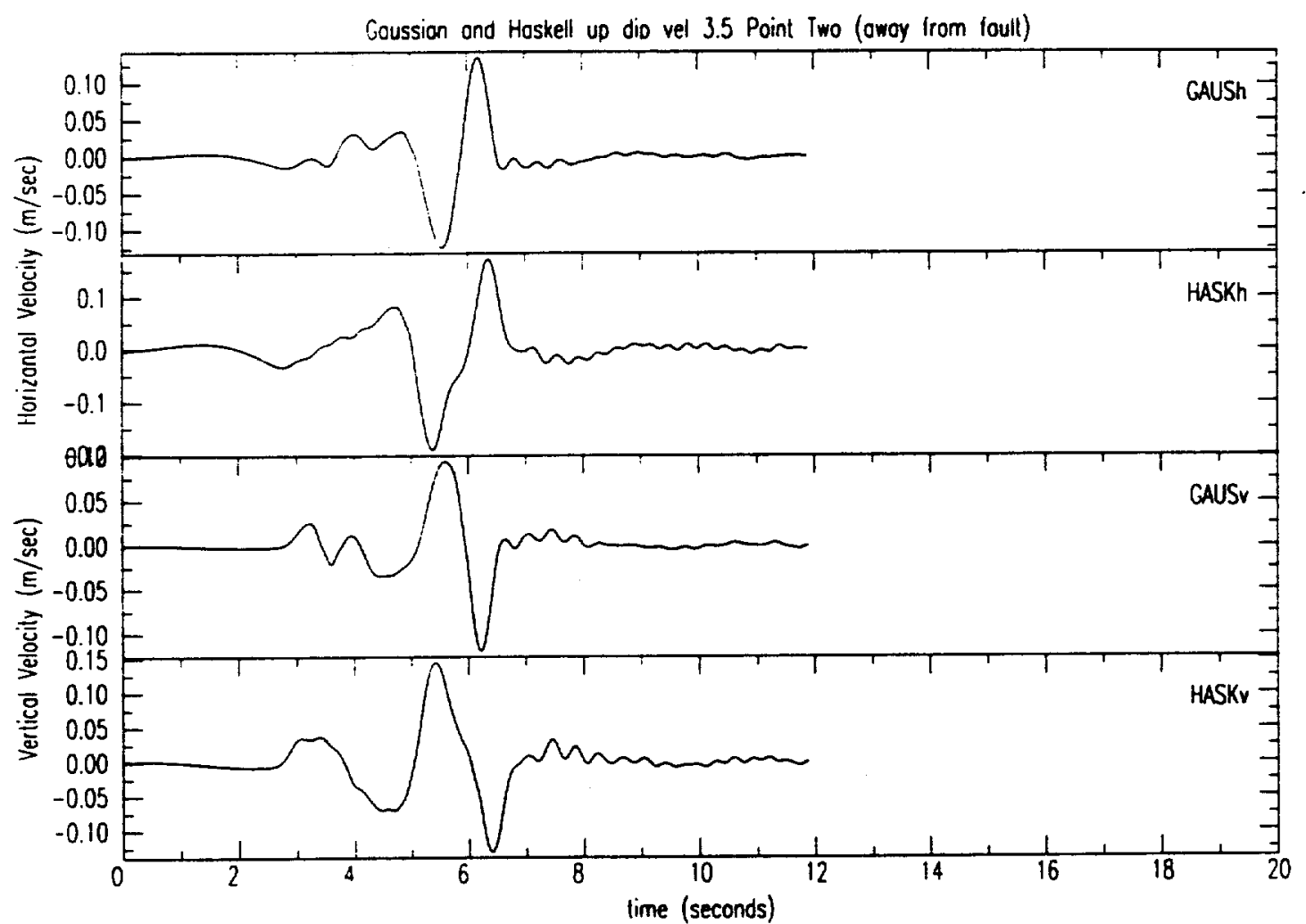

figure 4b. Seismogram for gaussian and haskell load curves at point two. (14.1 km from the fault) 


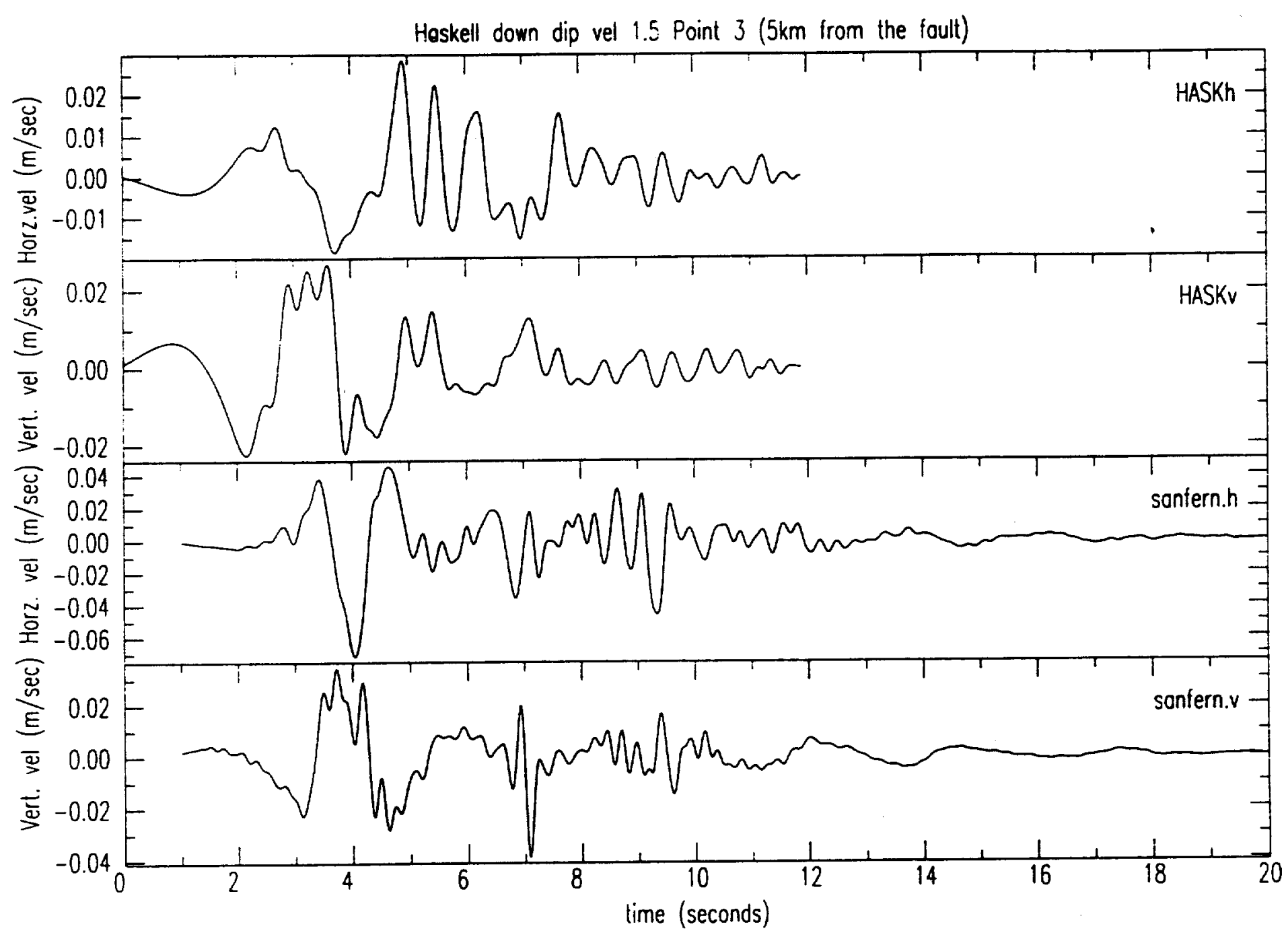

figure 5. Seismograms for the haskell load curve at point three. The first two are synthesized and the last two are observed. 


\section{References}

Benfer, N. A., J. Coffman, J. Bernick, and L. Dees (1971). San Fernando, California, Earthquake of February 9, 1971, Vol. III, Geological and Geophysical Studies.

Hanks, T. C. (1974). The faulting mechanism of the San Fernando earthquake, J. Geophys. Res. 79, 1215-1229.

Hutchings, L. (1994). Kinematic earthquake models and synthesized ground motion using empirical Green's functons, Bull. Seism. Soc. Am. 84, 1028-1050.

Hutchings, L. and S. P. Jarpe (1996). Ground-Motion Variability at the Highway 14 and I-5 Interchange in the Northern San Fernando Valley, Bull. Seism. Soc. Am. 84, S289-S299 


\title{
IMAGEne -- A Database of the Relationships Between Genes and Clones*
}

\author{
Michael Cariaso \\ University of Florida \\ Lawrence Livermore National Laboratory \\ Livermore, CA 94550
}

May 9, 1997

Prepared in partial fulfillment of the requirements of the Science and Engineering Research Semester under the direction of Greg Lennon, Research Mentor, in the Lawrence Livermore National Laboratory.

*This research was supported in part by an appointment to the U.S. Department of Energy Science and Engineering Research Semester (herinafter called SERS) program administered by LLNL under Contract W-7405-Eng-48 with Lawrence Livermore National Laboratory. Funding for the SERS Program provided by the Office of Defense Programs.

If this paper is to be published, a copyright disclaimer must also appear on the cover sheet as follows:

By acceptance of this article, the publisher or recipient acknowledges the U.S. Government's right to retain a non-exclusive, royalty-free license in and to any copyright governing this article. 


\section{Abstract}

This paper details the development of IMAGEne, a database which tracks the relationships between known genes and publicly available clones produced by the IMAGE Consortium. This software serves as a catalog of clones, reveals new properties of existing clones, and prototypes a planned more robust version. IMAGEne works by clustering ESTs with the known genes to which they are most similar. Detailed alignments demonstrate the cluster's coverage. This data is now ready for release on the world wide web. 


\section{Purpose}

Roughly $\mathbf{4 2 0 0}$ genes have been well studied and now have completely known sequences. Despite being well documented, often no physical samples are in the public domain. For most researchers further research on these genes is expensive or impossible.

My work intends to remedy this by identifying the public clones which represent these genes. To do this IMAGEne has been developed. Initially it will serve as a catalog of clones, permitting researchers to easily pick samples of a particular gene. Eventually it may automate some of the process of discovering new ones.

\section{Methodology}

IMAGEne has been developed as a fully functional prototype. It has aided the discovery of a methodology for identifying clones which represent genes. This methodology involves four distinct phases:

Data collection

Clustering

Alignment

Presentation

\section{Data Collection}

IMAGEne begins with data taken from GENBANK. As of this writing the current release is v99. We are interested in gbest, the EST database. Each entry in the DB is a collection of nearly all information known about the EST.

Beginning with the 700,000 ESTs in the genbank ones derived from nonhuman libraries, or produced by sources other than the IMAGE Consortium are discarded. Roughly 400,000 ESTs remain at this point. Sequences which are suspected to be reversed are removed. Regions of low quality sequence are also trimmed.

For my purposes a great deal of the information in a gbest record is unnecessary. The only data of concern is an EST's orientation, parent clone, and library source.

Since only a small amount of information is required the genbank format is excessive. Instead FASTA formatted records are used. This format has a single line of annotation followed by multiple lines of sequence. The annotation line is filled with the EST's identifier and the three relevant fields.

This collection of 400,000 ESTs in then accepted as the data for the next phase. 


\section{Clustering}

Clustering is the process of grouping similar ESTs. To do this a gene with a known sequence is compared to the ESTs. Ones which are sufficiently similar are identified.

To do this two publicly available programs are used. The first is BLAST by Steven Altschul. It is a sequence comparison package capable of analyzing 33,000 ESTs per second. Unfortunately it has a tendency to accept many false matches. FASTA is the second program. It was created by William Pearson to perform a more thorough analysis. The penalty for this improved reliability is speed. FASTA is only capable of 1,300 ESTs per second.

To get the best possible balance of performance to speed, IMAGEne uses both programs. Blast quickly identifies the ESTs which match well. These are then rigorously checked by FASTA.

\section{Alignment}

Alignment aids the interpretation of a cluster. To do this all ESTs in a cluster are compared to the known gene. Optimal placement of each EST (including gaps) is illustrated in a map. This map vividly illustrates the quality of each EST and its location. Maps from ESTs taken from the same clone are then combined to determine the size and placement of each clone.

\section{Presentation}

When the ESTs have been aligned they are ready for public release. To facilitate this release we chose a web based presentation method. This offers dynamic content and access to a large audience. Alignments may be searched in several ways, and related clusters may be cross-linked.

\section{Results}

IMAGEne is beginning its service as a catalog to the clones produced by the IMAGE Consortium. It has revealed interesting new statistical properties of the clones - current techniques are incapable of producing clones long enough to fully capture many genes. Most importantly many of the obstacles to the development of future versions have been identified.

\section{Conclusions}

IMAGEne's development has been very successful. It provides an elegant and functional tool for researchers, proves to be an educational prototype, and has had immediate rewards. Due to tremendous success, future development will continue. 


\title{
Developing a Prototype for the National Ignition Facility Optical Installation System*
}

Working scale model for National Ignition Facility laser optic installation

\section{Thomas Brett Hall}

\author{
North Carolina State University \\ Lawrence Livermore National Laboratory \\ Livermore, CA 94550
}

May 9, 1997

Prepared in partial fulfillment of the requirements of the Science and Engineering Research Semester under the direction of Erna Grasz and Tom Story, Research Mentors, in the Lawrence Livermore National Laboratory.

*This research was supported in part by an appointment to the U.S. Department of Energy Science and Engineering Research Semester (herinafter called SERS) program administered by LLNL under Contract W-7405-Eng-48 with Lawrence Livermore National Laboratory. Funding for the SERS Program provided by the Office of Defense Programs.

If this paper is to be published, a copyright disclaimer must also appear on the cover sheet as follows:

By acceptance of this article, the publisher or recipient acknowledges the U.S. Government's right to retain a non-exclusive, royalty-free license in and to any copyright governing this article. 


\title{
Developing a Prototype for the National Ignition Facility Optical Installation System
}

\author{
Thomas Brett Hall
}

\section{Abstract:}

This paper describes the design and assembly of a 1/3 scale model of an automated insertion system for laser optic modules for the National Ignition Facility. The model will serve as a proof of concept, an electronics test bed, and demonstration tool. This model was constructed by reducing and redesigning the full scale components.

It is anticipated that the fully developed scale model will be capable of performing the same functions as the full scale prototype. Results from the assembly and automation of the model will aid evaluation of key mechanical and electrical components. 


\title{
Developing a Prototype for the National Ignition Facility Optical Installation System
}

\author{
Thomas Brett Hall
}

\section{Background:}

The National Ignition Facility (NIF) is being built at Lawrence Livermore National Laboratory (LLNL) and upon completion will be the largest laser in the world, utilizing 192 laser beamlines focusing to a single point for scientific experimentation. This laser will have roughly a 30 year lifespan, and construction will be completed in 2002. During this lifespan the laser optics need to be continuously cleaned and correctly aligned, which necessitates periodical replacement. The Transport and Handling group of the NIF project is designing an automated system to deliver the optics to the laser, and install them with minimal manual intervention. This automated system will provide a clean, safe, and cost effective method of optic replacement for NIF.

\section{Introduction:}

The 1/3 scale model this paper describes will be a scaled down version of the periscope optic installation system for the Transport and Handling group (T\&H) of NIF. The periscope optic elevates the laser beam to different levels in the NIF structure. The full scale periscope canister system will lift and install periscope laser optics high into the laser beamline support structure which is raised 10 feet off of the floor. This lifting process requires multiple stages to lift the optic into the beamline at 25' high with a canister only 10' tall. The periscope optic installation is the most difficult task for T\&H because of this multiple stage lift; most of the NIF optics require only single stage lifts. This model will demonstrate the most complex system of tasks. Results from the scale model will aid evaluation of key mechanical and electrical components, and assist in the design, assembly, and operation of a fully capable periscope canister system.

The electronics and controls for automating the complex lift operation will also be built with the model. Automation and control of the system will be accomplished with a motion controller and computer interface, utilizing input from the motors and sensors. The electronics for the model will be the same as the full scale system, making the software and controls useful for both systems. This similarity will allow the control system to be built and tested independently of the full scale prototype, speeding up the iterative process. The model will also be a test bed for potentially useful electronics for the full scale prototype, including sensors and cameras. The controls for this model are being designed for human assisted automation, however 
the final goal for the canister is full automation. Full automation without human interaction is complex to do safely, and this model will be the first available hardware to begin this process.

The model started from scratch when I joined the group in January 1997. There have been several stages to getting this model underway, beginning with how it originated. The concept for the model started as an interesting and involved project for me to accomplish in a short period of time. As we put more thought into the concept it developed into a useful tool for electronics testing, proof of concept for the system, and a tool for visualization. The model would help analysis of the real canister, and help the group gain valuable experience with the real hardware. It became widely accepted as a good idea, and we began developing an approach to accomplish this aggressive task. I am the engineer on the project, responsible for coordinating the various tasks to build this model and designing the controls. The control system development and integration is being done alongside the mechanical design team, creating an aggressively parallel timeline. There have been many complex issues that have arisen, each of which provides guidance for the full scale prototype during model development.

This model is based on the design of the full scale canister which has undergone many revisions since the beginning of the project. These constant changes are expected in the iterative process of design, and the model is as similar as possible to the real canister.

\section{Mechanical Descriptions:}

The $1 / 3$ scale periscope canister model will incorporate 3 of the 4 main mechanisms internal to the full scale canister:

1. lift mechanism

2. spacer insertion mechanism

3. shelf mechanism

Space will be left to add the fourth mechanism at a later date. The cover removal mechanism was not fully designed when this project was started, and it is being prototyped full scale separately from the first canister.

1. * space to add cover removal mechanism

The lift mechanism is composed of 4 vertically mounted ball screws which are geared (slaved) to one motor and connected with shafting. These 4 ball screws are synchronized and attached to a plate that holds the periscope LRU on 3 kinematic 
mounts. This plate will lift the periscope LRU and the spacers from inside the canister vertically into the laser beamline structure.

The shelf mechanism is composed of 3 pneumatic rotary actuators with paddles attached to the shafts. These actuators are mounted at the top of the canister, and will suspend the LRU above the canister after the initial lift. This allows the lift mechanism to then lower and retrieve a spacer, which is then lifted again creating a stack underneath the LRU. With this technique, the LRU can be lifted even further into the beamline structure.

The spacer insertion mechanism is composed of 1 linear rail and one horizontally mounted ball screw. This mechanism will carry each spacer from the storage positions inside the canister onto the lift platform. The lift platform will then lift the spacers off of the spacer insertion mechanism, and the mechanism will retract leaving the spacer on the lift platform. There are 2 spacers required to reach a full 25 ' high on the real system.

\section{Control and Sensor Strategles:}

One of the goals for the electronic system is not to become exceedingly complex. Motors, sensors and wiring take up valuable space adding complexity to the system, and needs to be minimized. Our goal was to design a simple but thorough system of sensors and controls which effectively controls the system. This design is composed primarily of a laptop computer and motion controller. The laptop will run the software which will control the system and respond to sensor information from the motion controller. This motion controller will run two motors and ball screw systems, and interpret sensor information back to the laptop. A pneumatic valve will also be controlled, engaging and disengaging the rotary actuators.

The lifting mechanism is composed of 4 ball screws which are mechanically slaved to the same motor. This mechanical link between the four ball screws and one motor does not allow the controls to correct for binds or tilt in the mechanism, only giving it one degree of freedom. This increases the control system simplicity, and makes early error detection vital in failure situations.

Sensors are needed to check and verify positions, and verify that interactions are taking place correctly. The sensor strategy needs to be complete enough such that the insertion process can be shut down before major damage results from a failure, and robust enough to know when operations in the canister have finished and the next can begin. Two sensors have been picked for trial in the model canister:

Load cells are mounted on the three point kinematic connections between the LRU and each spacer to the lift platform. These load cells will read how 
much weight each point on the lift platform is carrying, and will be very useful for understanding what the lift mechanism is doing. They will enable us to watch LRU and spacer acquisition and "drop off" when the shelf mechanism is holding them. The load cells will ensure that the LRU and spacers are correctly oriented before they are acquired, and enable acquisition and drop off verification. The load cells will also be able to shut down the operation if the LRU binds or crashes.

Optical Proximity Sensors located internally in the canister will watch the horizontal spacer position during an insertion. These sensors will tell us if the spacers are inserted correctly, and if the spacer stack is beginning to tilt during insertion. The usable range of these diffuse optical sensors is roughly 6 " to $2.5^{\prime}$, which makes them potentially useful for other operations inside the canister.

\section{Summary:}

This scale model of an optic installation system for NIF will be an instrumental part in the design and assembly of it's full scale counterpart. The model will enable evaluation of key mechanical and electrical components of one of the most difficult task of the T\&H group. The model canister will also begin to uncover sub system integration issues which can be addressed before the full scale prototype is built. Electronically, the controls for the model will be very similar; allowing the control system to be duplicated for use on the full scale canister. This similarity will allow the control system to be built and tested independently of the full scale prototype, speeding up the iterative process. The model will also be a test bed for potentially useful electronics for the full scale prototype. Results from this first integrated prototype will be extensively useful in the design and assembly of the full scale system. 

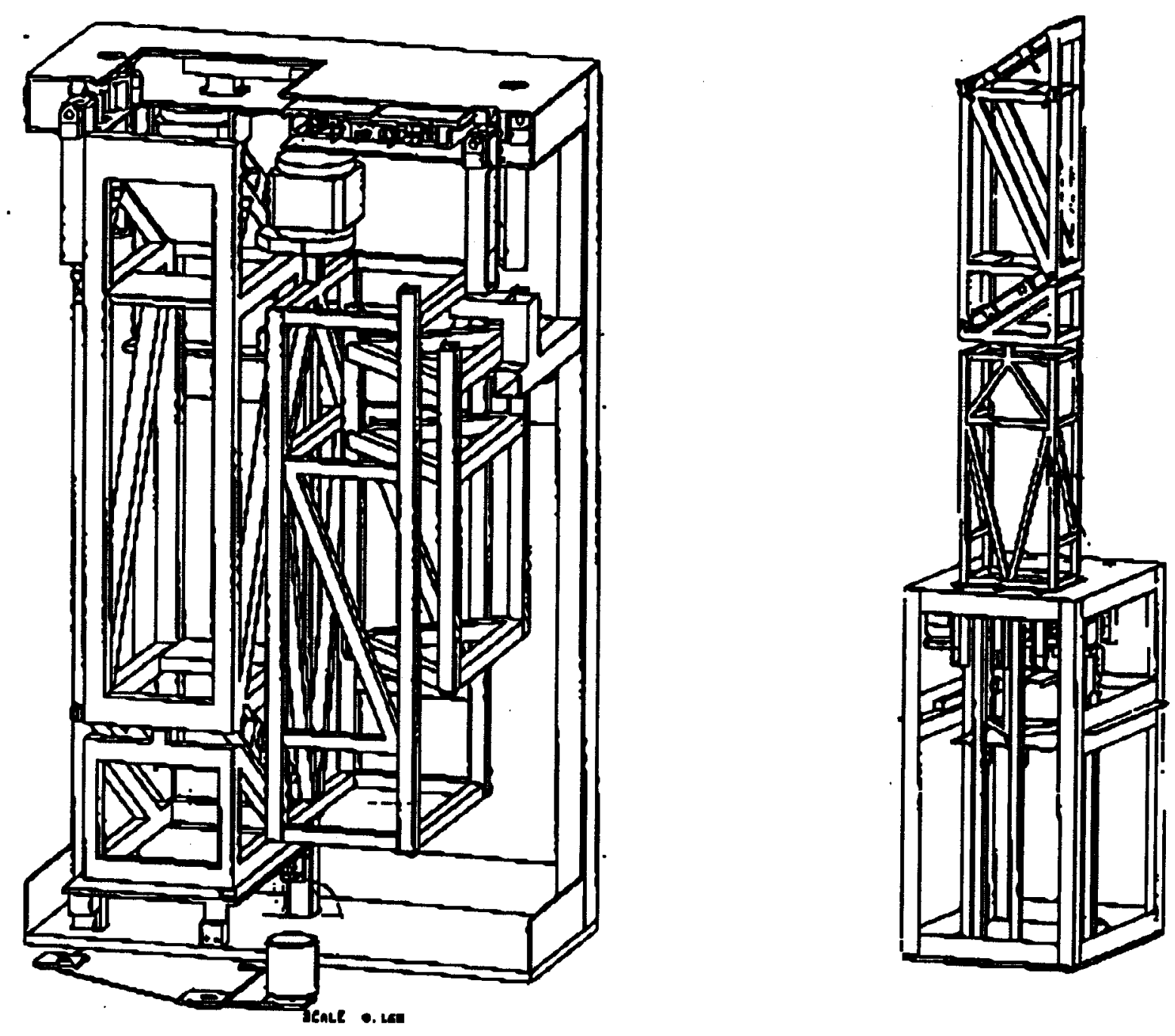
Optical Insertion Model Froject Schedule

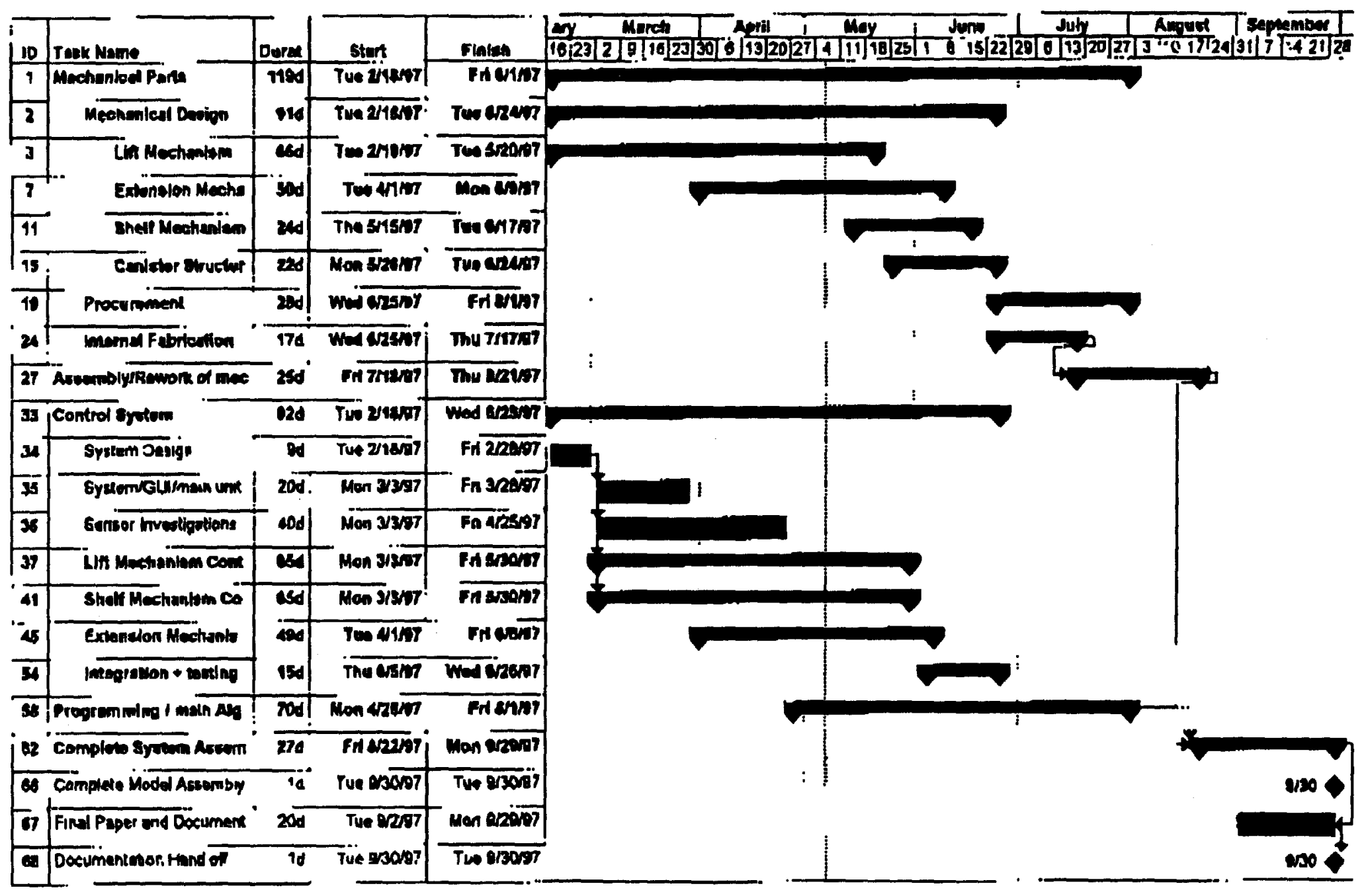




\title{
ANALYSIS OF ACID-VOLATILE SULFIDE (AVS) \\ AND SIMULTANEOUSLY EXTRACTED METALS (SEM) \\ FOR THE CHARACTERIZATION OF TOXIC SEDIMENTS \\ IN THE SAN FRANCISCO BAY *
}

\author{
Charity Hayden \\ Norwich University \\ Lawrence Livermore National Laboratory \\ Livermore, California 94550
}

8 May 1997

Prepared in partial fulfillment of the requirements of the Science and

Engineering Research Semester under the direction of Dr. John Knezovich, Research Mentor, in the Lawrence Livermore National Laboratory.

* This research was supported in part by an appointment to the U.S. Department of Energy Science and Engineering Research Semester (hereinafter called SERS) program administered by LLNL under Contract W7405-Eng-48 with Lawrence Livermore National Laboratory. Funding for the SERS Program provided by the Office of Defense Programs.

If this paper is to be published, a copyright disclaimer must also appear on the cover sheet as follows:

By acceptance of this article, the publisher or recipient acknowledges the U.S. Government's right to retain a non-exclusive, royalty-free license in and to any copyright covering this article. 


\section{BACKGROUND}

A section of the Alameda Naval Air Station is being evaluated for use as a public recreation site. Figure 1 shows the Air Station with respect to the San Francisco Bay and the Oakland Bay Bridge. Figure 2 shows Seaplane Lagoon, the site being evaluated. The sediment in the affected area is potentially hazardous to aquatic life due to prior practices of dumping oil, gasoline, metals, and solvents. In order to evaluate the hazard posed by these contaminants and to choose the most effective clean up alternative, it is necessary to characterize the chemicals that are causing the toxicity. The focus of this work is to evaluate the potential hazard posed by heavy metals (e.g., copper, nickel, lead) at this site.

Acid-volatile sulfide (AVS) and simultaneously extracted metals (SEM) are methods which are used to analyze the relationship between sulfide and metals in aquatic sediments. The ratio of SEM to AVS will be used to evaluate the potential toxicity metals present in sediments. Sulfides, which are natural components of sediments, react with metals and render them unavailable to organisms. Therefore, only when the concentration of metals exceed the concentration of sulfides are there metals available to harm aquatic organisms.

Sulfide is extracted from the sediment by cold acid, forming hydrogen sulfide. The hydrogen sulfide is then distilled and trapped. When the sulfide is liberated the metals are left behind. The amount of sulfide is determined spectrophotometrically. The amount of absorption is directly related to the concentration by a standard curve. The concentrations of soluble metals are determined by atomic absorption spectrophotometry. The ratio of SEM to AVS is subsequently determined and will be used to assess if metals are responsible for toxicity observed at the site.

\section{OBJECTIVES}

The objectives of this project were to: set up the AVS and SEM apparatus; create a calibration curve for sulfide; create a calibration curve for soluble metals; and use the ratio of SEM to AVS to determine if metals are responsible for toxicity observed at Seaplane Lagoon. 


\section{Figure 1 - Alameda Naval Air Station}

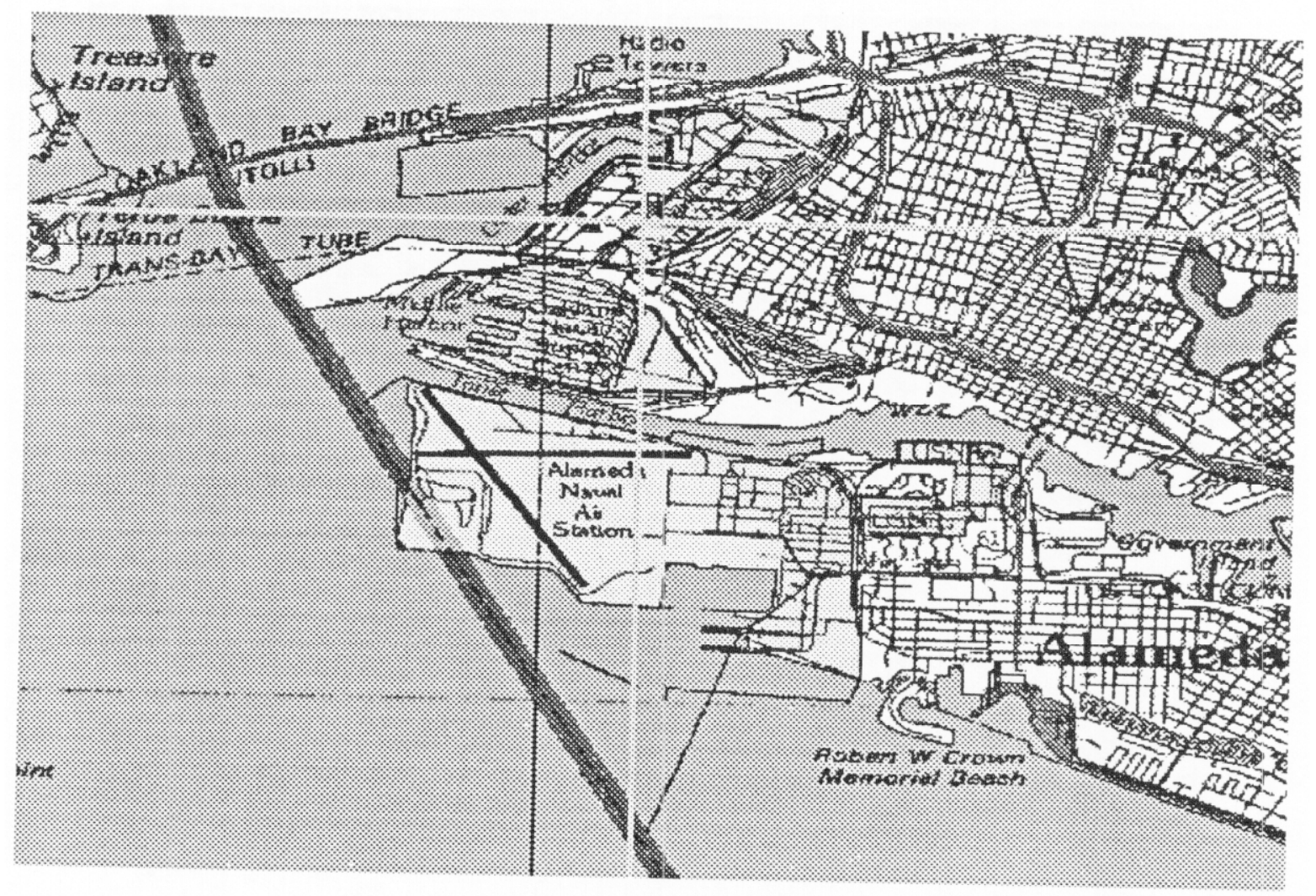


Figure 2 - Seaplane Lagoon - outlined in red

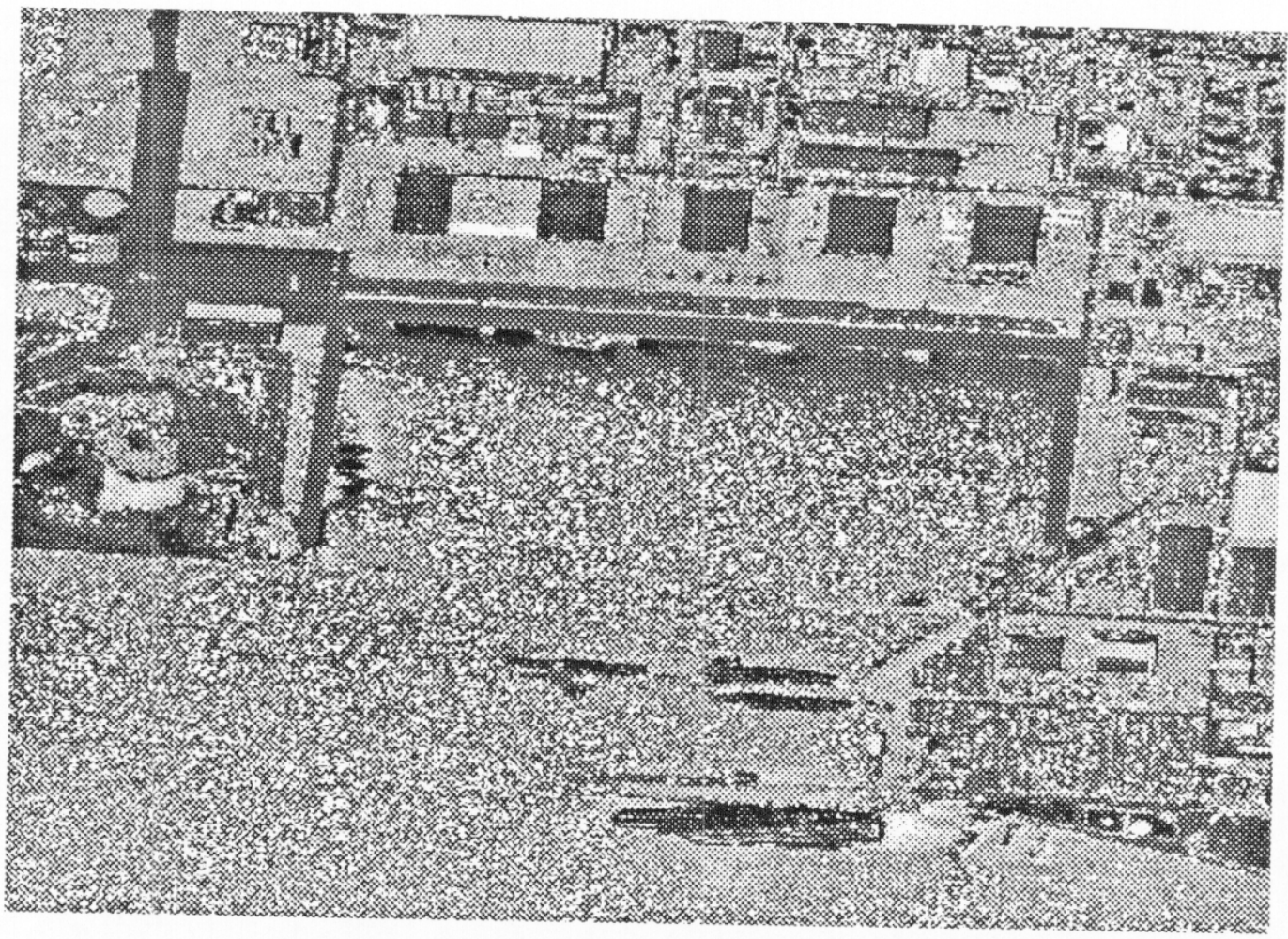




\section{INTRODUCTION}

A part of the Alameda Naval Air Base is being evaluated for clean up possibilities in order to turn it into a public recreational area. Table 1 shows the prior practices of dumping oil, gasoline, solvents and metals at Seaplane Lagoon. Some of the sources of these contaminants include: aircraft maintenance, paint shops, and storage facilities for pesticides and herbicides. The plating bath dumps contained many heavy metals. Copper was present in paint wastes.

An evaluation of the toxicity of the sediment must be done before clean up options are considered. In order to choose the most realistic and cost wise option, we must characterize what toxic components are present.

One source of contamination is the tin paint which was used on the hulls of the air craft carriers. Tin paint was used because it lasted longer.

Not all metals have the same toxicity. For example, cadmium as an ion $\left(\mathrm{Cd}^{++}\right)$ is about 1000 times more toxic than iron $\left(\mathrm{Fe}^{++}\right)$. Cadmium, along with the other four metals we are concerned with, are listed in Table 2. Sulfide and Cadmium form a very insoluble precipitate. This is a more stable bond than iron sulfide (FeS) therefore, the reaction shown below would shift to the right.

$$
\mathrm{Cd}++(\mathrm{aq})+\mathrm{FeS}(\mathrm{s}) \rightarrow \mathrm{CdS}(\mathrm{s})+\mathrm{F} \theta++(\mathrm{aq})
$$

The metal bioavailability is regulated by acid volatile sulfides. The first graph shows that SEM to AVS ratios above one, have steep increases in mortality. The relationship between the mortality of organisms and total metal concentrations in San Francisco Bay sediments is shown in the following graph. The ratio of metals to sulfides is more important than just the concentration of the metals because toxicity does not necessarily increase as metals increase. When there are high concentrations of sulfide present the metals are not a problem.

Sediment core samples were taken from the lagoon in order to identify the depths of contaminants. These depths, shown in Table 2, represent a timeline of the contamination which is very useful. The contamination located $85-95 \mathrm{~cm}$ down represents the 1940's when there were less environmental regulations on discharging. As regulations were implemented and new sediment settled, the contamination decreased. Dredging the lagoon may not be the best solution for clean-up because the biggest contamination is underneath the surface. 
Table I - A Voriely of Contaminants Were Discharged To Seaplane Lagoon

PD 680(petroleum hydrocarbon solvent)

Hydraulic Oil

Paint Wastes

Dry Cleaner

Lindane

Malathion

Telvar

2.4-D

Princep

Plating Bath Dumps

Paint Strippers

Herbicides

Cleaning Solvents
Trichlorofluoroethane

Trichloroethane

Used Hydraulic Oils

Chlordane

DDT

Diazinon

Chiorvar

Roundup

Krovar 1

Paints

Pesticides

Oils and Grease

PCB Contaminated Oils

Table 2 - Sediment Core Samples from Seaplane Lagoon

Total Metals $(\mathrm{mg} / \mathrm{kg}$ )

Cadmium

Copper

Lead

Nickel

Zinc

\author{
Metals Data \\ Sampling Depth $(\mathrm{cm})$ \\ $0-10$ \\ $10-40$ \\ 40-70
}

85-95

29

230

110

1,400

150

350

210

620

440

2,800

1,100

4,000

170

130

110

870

700

1,400 


\section{EQUIPMENT NEEDED}

500-ml round bottom, 2 neck flask 2

magnetic stirrer and magnet 1

250-ml separatory funnel with stop cock 2

oxygen scrubber/trap 1

$500-\mathrm{ml}$ oxygen gas washing bottle 1

$125-\mathrm{ml}$ gas washing bottles 4

flow controller 1

ring stands 5

" nitrogen tank access

The equipment listed above is acid washed so that it is analytically clean.

0.5-M sodium hydroxide $(\mathrm{NaOH}), 6-\mathrm{M}$ hydrochloric acid $(\mathrm{HCl})$ and the mixed diamine reagent (MDR) are prepared as stock solutions. The MDR is prepared by mixing two components. Component $A$ is prepared by adding $340 \mathrm{ml}$ deionized water to $660 \mathrm{ml}$ of concentrated sulfuric acid. After the diluted acid cools, $2.25 \mathrm{~g} \mathrm{~N}, N$ - dimethyl-p -phenylenediamine oxalate is dissolved in it. Component $\mathrm{B}$ is prepared by dissolving $5.4 \mathrm{~g}$ ferric chloride hexahydrate $\left(\mathrm{FeCl}_{3} \cdot 6 \mathrm{H}_{2} \mathrm{O}\right)$ in $100 \mathrm{ml}$ concentrated hydrochloric acid and diluting to $200 \mathrm{ml}$ with deionized water. (11) Some of the deionized water for each component should be used to rinse the reagents into the containers.

The MDR is combined with the trapped sulfide to obtain a measurable characteristic. The amount of sulfide present can then be determined by the absorption readings on the spectrophotometer. Sodium sulfide is used for preparing a standard curve. The curve is used to find an unknown sulfide concentration of a sediment sample using the absorption readings.

\section{METHODS}

The apparatus used to generate AVS and liberate SEM is shown In Figure 3. It is important to remove all of the oxygen from the system so the sulfide does not react with it. Nitrogen does not react easily so it is used to push the hydrogen sulfide through the system.

Sulfide and metal background concentrations are first checked by running the apparatus without a sediment sample. This is called a blank, a standard method used to determine the pre-existing concentrations in order to get true sample readings. The apparatus must also be checked with known sulfide concentrations, matrix spikes (adding a known amount of sulfide to a standard), and dilution readings before a sediment sample can be tested.

The reaction vessel is set up with deionized water and magnetic stirrer. $100 \mathrm{ml}$ of sodium hydroxide is placed in each trapping vessel. The apparatus is deaerated by bubbling nitrogen @ $100 \mathrm{~cm} 3 / \mathrm{min}$ for $10 \mathrm{~min}$. 
Approximately $10 \mathrm{~g}$ of wet sediment from Seaplane Lagoon is weighed on a piece of parafilm. The parafilm and sample are placed in the round-bottom flask so that none of the sample is lost in the transfer. The parafilm has been found to be free of sulfide. To avoid oxidation, rinsing the samples into the flask is not recommended.

The volume of water added with sediment sample is computed using the sediment dry-weight-to-wet-weight ratio below:

$$
W_{\text {water }}=W_{S+W} \cdot\left(W_{\text {dry }} W_{\text {wet }}\right) W_{S+W}
$$

$W_{S+W}=$ wet weight of sample taken for AVS testing (g)

Wwater $=$ weight of water in the sediment taken for AVS testing $\left(W_{\text {wet }}-W_{\text {dry }}\right) g$ $W_{\text {wet }}=$ wet weight of sediment sample (g)

$W_{\text {dry }}=$ weight of sediment sample after drying $48 \mathrm{hrs} @ 60^{\circ} \mathrm{F}(\mathrm{g})\left(W_{\mathrm{dry}}<\right.$ Wwet)

The sample is purged with nitrogen $940 \mathrm{~cm} 3 / \mathrm{min}$ for $10 \mathrm{~min}$, then the nitrogen is stopped to add the acid to the flask. (Before adding the $20 \mathrm{ml}$ of $6-\mathrm{M} \mathrm{HCl}$ to the reaction vessel it is bubbled with nitrogen for $20 \mathrm{~min} @ 20 \mathrm{~cm} 3 / \mathrm{min}$ ). The $\mathrm{HCl}$ is added to the reaction vessel through the separatory funnel. The procedure is completed when nitrogen has been bubbled through the system for an hour@ $20 \mathrm{~cm} 3 / \mathrm{min}$.

\section{RESULTS}

Standard calibration curves have been started for sulfide but need to be refined. The progress of these curves is shown on the next page. The decrease in absorption over time shows that sulfide has a short shelf life. Therefore, samples should be analyzed the same day the apparatus is run. Refrigeration may extend the shelf life.

\section{PREDICTED VALUES / DISCUSSION}

The sulfide necessary to offset metal concentrations at Seaplane Lagoon were calculated using total metals data. SEM makes up $80 \%$ of total metals therefore predictions are conservative. Calculated metal concentrations in Seaplane Lagoon were 14-65 $\mu \mathrm{mol} / \mathrm{g}$. This identifies how much sulfide needs to be present to bond all of the metals. If there is not enough sulfide, the metals are available and toxic to aquatic life. The maximum concentration for AVS observed at other sites in San Francisco Bay is $\sim 45 \mu \mathrm{mol} / \mathrm{g}$. Therefore, metals are expected to cause toxicity in some Seaplane Lagoon sediments. 


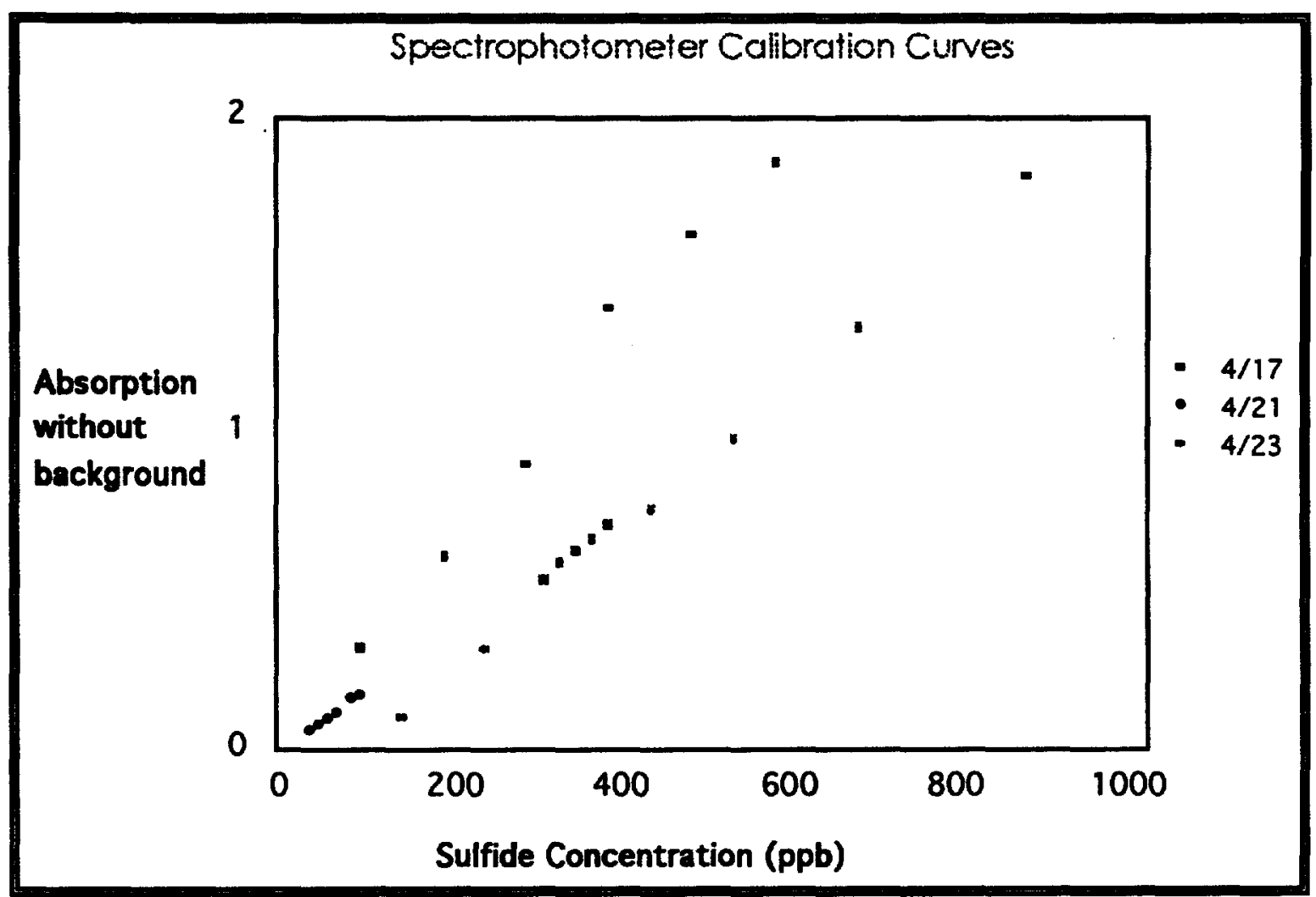




\section{NEXT TASKS}

\section{TASK 1:}

Before sediment samples from Seaplane Lagoon are run through the system, known sulfide concentrations, matrix spikes (adding a known amount of sulfide to a standard), and dilution checks must be done. Known sulfide concentrations are run through the system to determine the amount of sulfide that is being recovered. If $10 \mathrm{~g}$ of sulfide is in the reaction vessel, then we hope to get $10 \mathrm{~g}$ of sulfide in the trapping vessels. If we only get $7 \mathrm{~g}$ then we only have $70 \%$ recovery. Half of the concentration is expected when the trapped sulfide is diluted 1 to 1 .

\section{TASK 2:}

Obtain Samples from Seaplane Lagoon
A. Sediment samples contained in 1-gal $(3.79 \mathrm{~L})$ wide-mouth glass jars, shipped in ice chests.
B. Samples transferred to a refrigerator and stored at $4^{\circ} \mathrm{C}$ until used

\section{TASK 3:}

Analysis of Field Samples
A. The amount of sulfide is determined spectrophotometrically.
B. Soluble metals are determined by atomic absorption spectrophotometry.
C. Use the ratio of SEM to AVS to determine if metals are responsible for toxicity observed at Seaplane Lagoon.




\section{WORKS CITED}

1. "Predicting the Toxicity of Metal-Contaminated Field Sediments Using Interstitial Concentration of Metals and Acid-Volatile Sulfide Normalizations"

2. "Sediment Quality And Aquatic Life Assessment"

3. "Sediment Toxicity Evaluations"

4. "Toxicity of Cadmium in Sediments: The Role of Acid Volatile Sulfide"

5. "The Utility of Pore-Water Toxicity Testing for Developing of Site-Specific Marine Sediment Quality Objectives for Metals"

6. "Predicting the Toxicity of Metal Spiked Laboratory Sediments Using AcidVolatile Sulfide and Interstitial Water Normalizations"

7. "Effects of Acid-Volatile Sulfide on Zinc Bioavailability and Toxicity to Benthic Macroinvertebrates. A Spiked-Sediment Field Experiment"

8. "Predicting the Toxicity of Metal-Contaminated Field Sediments Using Interstitial Concentration of Metals and Acid-Volatile Sulfide Normalizations"

9. "Evaluation of Metal : Acid-Volatile Sulfide Relationships in the Prediction of Metal Bioaccumulation by Benthic Macroinvertebrates"

10. "Particle Oxidation Model of Synthetic FeS and Sediment Acid-Volatile Sulfide"

11. "Analysis of Acid-Volatile Sulfide (AVS) and Simultaneously Extracted Metals (SEM) for the Estimation of Potential Toxicity in Aquatic Sediments"

12. "Analysis and Distribution of Iron Sulfide Minerals in Recent Anoxic Marine Sediments"

13. "Sulfide Tolerance of Four Marine Species Used to Evaluate Sediment and Pore-Water Toxicity"

14. "Intrinsic Sediment Processes Study Sites 2 and 17 Naval Air Station Alameda"

15. "Instrumental Methods of Analysis - Chapter 12 - Flame Emission and Atomic Absorption Spectrometry" 


\title{
Changes in pore water chemistry as a function of microbial growth in Yucca Mountain tuff *
}

\author{
Anabel Miranda \\ Universidad del Turabo
}

May 8, 1997

Prepared in partial fulfillment of the requirements of the Science and Engineering Research Semester under the direction o $\mathrm{fDr}$. Joanne Horn and Annemarie Meike, Research Mentors, in the Lawrence Livermore National Laboratory.

* This research was supported in part by an appointment to the U.S. Department of Energy Science and Engineering Research Semester (hereinafter called SERS) program administered by LLNL under Contract W7405-Eng-48 with Lawrence Livermore National Laboratory. Funding for the SERS Program provided by the Office of Defense Programs.

If this paper is to be published, a copyright disclaimer must also appear on the cover sheet as follows:

By acceptance of this article, the publisher or recipient acknowledges the U.S. Government's right to retain a non-exclusive, royalty-free license in and to any copyright covering this article. 


\section{Abstract}

The U.S. DOE has been charged with the design and construction of a nuclear waste repository. This repository must safely contain these wastes over a period of at least 10,000 years. The location of the repository has been proposed to be at Yucca Mountain, Nevada, below the ground surface in welded volcanic ash tuff. The purpose of this study is to determine effects of microbial growth on Yucca Mountain tuff pore water chemistry and cement stability to determine the chemical impact of microbial activity in a tuff and tuff +concrete environment as a function of macronutrient supply. To distinguish between abiotic vs. biotic chemistry, it will be necessary to sterilize the YM tuff used in these experiments. The goal of the work described here is aimed at sterilize tuff obtained from Exploratory Studies Facility (ESF Yucca Mountain, Nevada) without substantially altering tuff chemistry. The tuff was sterilized using treatments such as antibiotics, Sodium Azide, sonication, heat, and a combination of antibiotics and azide. The treated samples are incubated to determine effectiveness of sterilization. The treatments that continue to show no growth after incubation are candidate sterilization methods for the sterile controls in this experiment. 


\section{Introduction}

The Lawrence Livermore National Laboratory (LLNL) is involved with the design of a repository to be used for the permanent disposal of high level nuclear waste. The repository, is being designed specifically to facilitate safe disposal for a period of at least 10,000 years at Yucca Mountain, Nevada (YM). The proposed YM repository is situated well above the deep ground water level. Thus, the nuclear waste would be emplaced in an unsaturated environment. Bacteria, may affect the containment of the radioactive waste in the repository by degrading repository materials, including cement and metal either directly or indirectly through the alteration of pore water chemistry. While other studies emphasize Microbially Induced Corrosion (MIC) of metals [2], [1] this study will aid in the design and selection of appropriate repository construction and waste package materials. This study is aimed at describing and assessing the effect of bacterial activity under a range of nutrients on water chemistry and the stability of Ordinary Portland Cement (OPC) based concrete. To prepare this study we will use $\mathrm{YM}$ volcanic welded tuff aseptically crushed to a specified size $(2.36 \mathrm{~mm}-1.68 \mathrm{~mm})$. To determine the effects of microbes on pore water and cement, microcosm will be constructed (Figure 1) and alterations in microcosm efflux chemistry as a result of bacteria growth will be determined. Conditions in the repository are expected to include- increased temperature, and varying nutrient availability. The impact of temperature, nutrient conditions on microbial growth and the consequent modification of aqueous chemistry that may affect the integrity of the repository will be assessed. A series of 40 separate conditions will be tested, each for a period of six months. Conditions will include a basic growth medium, and macronutrient concentrations, which will be varied. Each experimental condition will include a sterile control whereby the ground tuff alone or with cement is exposed to identical conditions absent bacteria to account for abiotic chemical alterations. Prior to constructing microcosms, preliminary experiments to determine effectiveness tuff sterilization, procedures that results in minimal (or traceable) alterations in chemistry have been determined. Therefore, the purpose of this work is to determine the best method and establish the protocol for the subsequent experiments. 


\section{Methods}

In order to find out the better way to sterilize tuff we used the following treatments: sodium azide, antibiotics, heat, sonication and the combination of azide + antibiotics were used (See [3] for detailed discussion of methods). The treatments were divided in three different sterilization methods and a positive and a negative control:

- Sterility Test A/ Chemical Sterilization (Figure 2)

The use of sodium azide, antibiotics (Rifampicin, Streptomycin), and the combination of sodium azide + antibiotics.

- Sterility Test B / Heat and Pressure Sterilization (Figure 3)

The use of high temperature $\left(125^{\circ} \mathrm{C}\right)$ and pressure (15psi) for $45 \mathrm{~min}$.

- Sterility Test C /Ultrasonication (Figure 4)

The use of an ultrasonic tip, to break down th cellular structure of the bacteria.

- Negative Control/Double Distilled(dd) water

To assure no contamination from water supply.

- Positive Control/Water + tuff

To assure haw bacteria grow when no treatm applied.

From each treatment, including the negative and the positive control, we took water samples for absorbency readings and chemical analysis (Inductively couperd plasma mass spectrometry (ICPMS), ion chromatography (IC), total organic carbon (TOC)) in order to determine the presence of bacteria, if any, after each treatment and changes in rock chemistry. 
The tuff from each treatment was washed with dd water and again, samples for absorbency readings and chemical analysis, in order to determine the effectiveness of sterilization were taken. After washing, the tuff was combined with $10 \mathrm{ml}$ of growth media (M9). Three days later, samples from each treatment were inoculated onto M9 plates. After 3 days, the plated samples were reinoculated to another set of $M 9$ plates to differentiate between light lawn ${ }^{1}$ and very fine rock powder produced by crushing.

1. Light Lawn - is defined as an extremely low density of microbial growth on the surface of a plate. 


\section{Results}

The microbial studies show that all methods of sterilization will achieve the desired results. Whereas the negative control indicated no contamination from the wash water, and the positive control indicated the presence of many bacteria, all sterilization methods indicated no growth. This indicated by re-inoculation (Table 2) for the cases in which a"light lawn" was observed for the initial inoculation (Table 1).

Chemical analyses at the time of this report are not complete. However, inorganic analyses of Sterility Test A samples (Figures 7-9) compared to the positive and negative controls (Figures 5-6) suggest that the chemical signature of these sterilization methods will overlap the chemical species of interest. 


\section{Conclusion and continuing work}

Our findings show (tables $1 \& 2$ ) that all sterilization protocols tested are effective in preventing microbial growth under conditions tested. The addition of antibiotics and $\mathrm{Na}$-azide are unacceptable methods because the chemical signature overlaps the area of interest. The heat treatment results are not complete. However, it is expected that the heat will alter some mineral constituents of the rock to make them more soluble. This would also be unacceptable. Continuing work rests on the use of a chemical signature distinct from the chemistry of interest, and thus not affect the baseline information for our experiment. 


\section{Summary}

The U.S. Department of Energy is currently conducting feasibility studies to asses the long term performance of a potential geological repository at Yucca Mountain, Nevada. Microbial growth of both native and introduced bacteria in the potential repository site, may jeopardize the integrity geologic nuclear waster disposal facilities by directly promoting degradation of repository components and waste package materials. Therefore, it is important to assess the impact of temperature, and nutrient conditions on microbial growth and the consequent modification of aqueous chemistry that may affect the integrity of the repository. This study constitutes the initial steps toward investigating the influence of microbes on chemistry. Ultimately, microcosms will be constructed to determine the alterations in microcosm efflux chemistry as a result of bacteria growth using YM volcanic welded tuff, crushed to a specified size. Our purpose in the present work has been determine to appropriate sterilization methods. $\mathrm{YM}$ tuff has been treated with different methods for been used as a sterile control with the different microcosm conditions. The sterilization technique should destroy microbial cells while, at the same time, not significantly altering the chemical and physical characteristics of the crushed rock and water system. Moreover, sterilization requires destruction of microbial cells which may germinate days or weeks after sterilization process, if conditions are appropriate and sterilization process was not initially complete. There are numerous difficulties associated with sterilization, especially if it is necessary to sterilize large volumes or masses of soils. Using $10 \mathrm{~g}$ of tuff for each trial, the results show that all sterilization treatments are effective in preventing microbial growth under conditions tested. However, we have not yet discovered a technique that fits our chemical criteria. Finally, it will be necessary to incubate the tuff for 2-10 days to ensure that slow growing or injured microbial cells are given the opportunity to form colonies if present. 


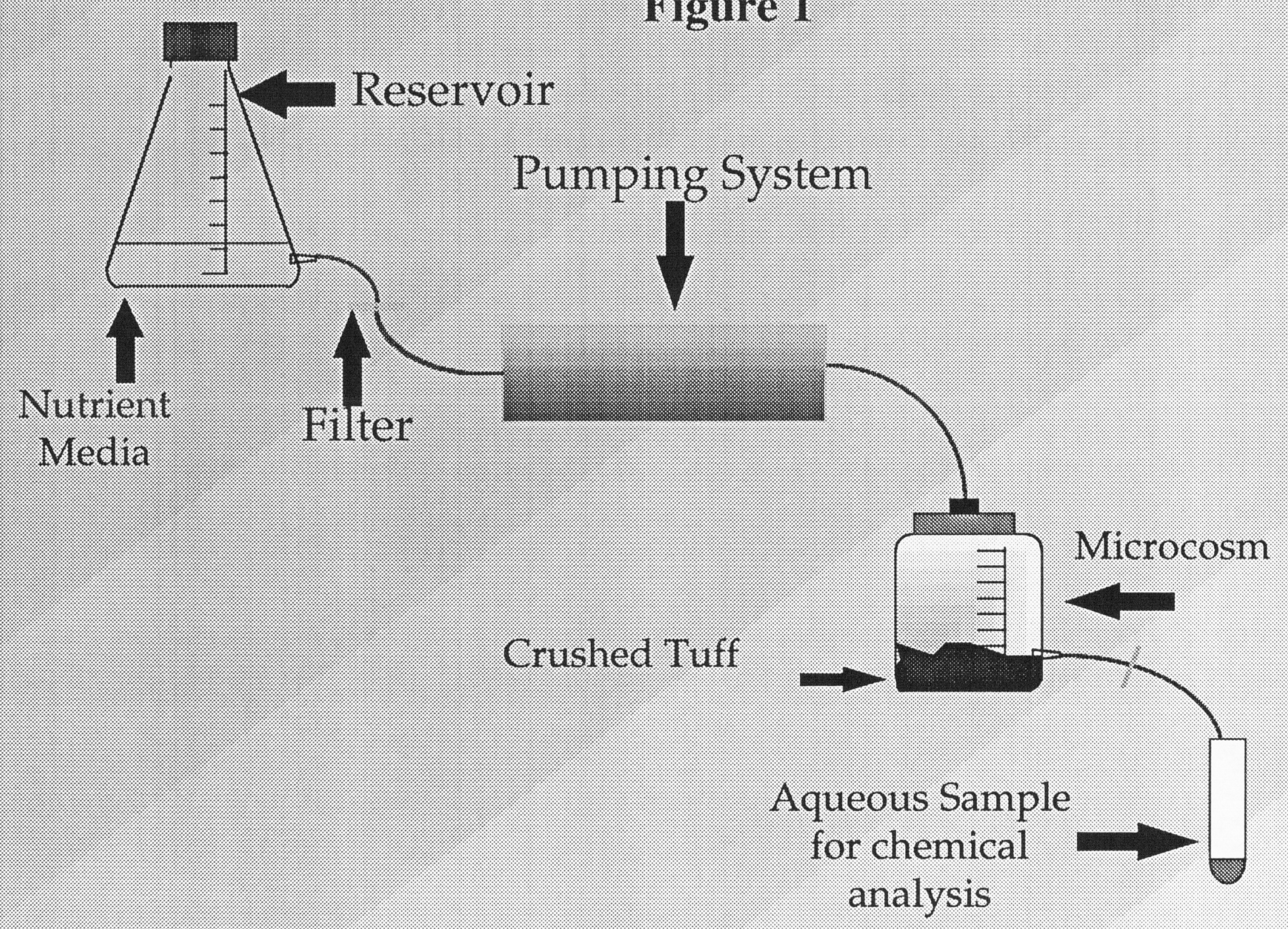

\section{Figure 1}




\section{Sterility Test A}

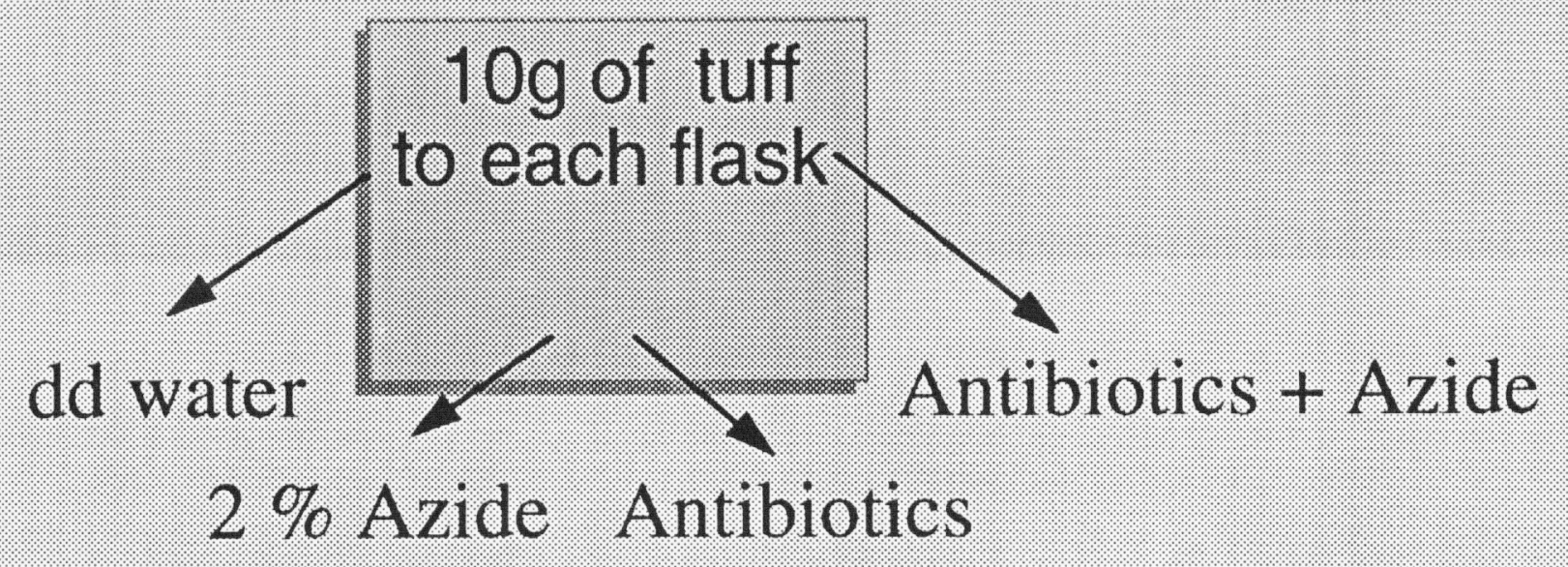

- Each flask was incubated for 1 hour

- A negative control was used for sterility test A, B and C, following the same steps.

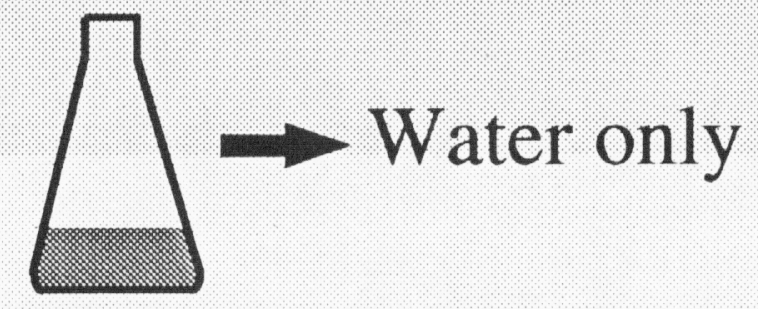




\section{Heat}

Figure 3

\section{Sterility Test B}

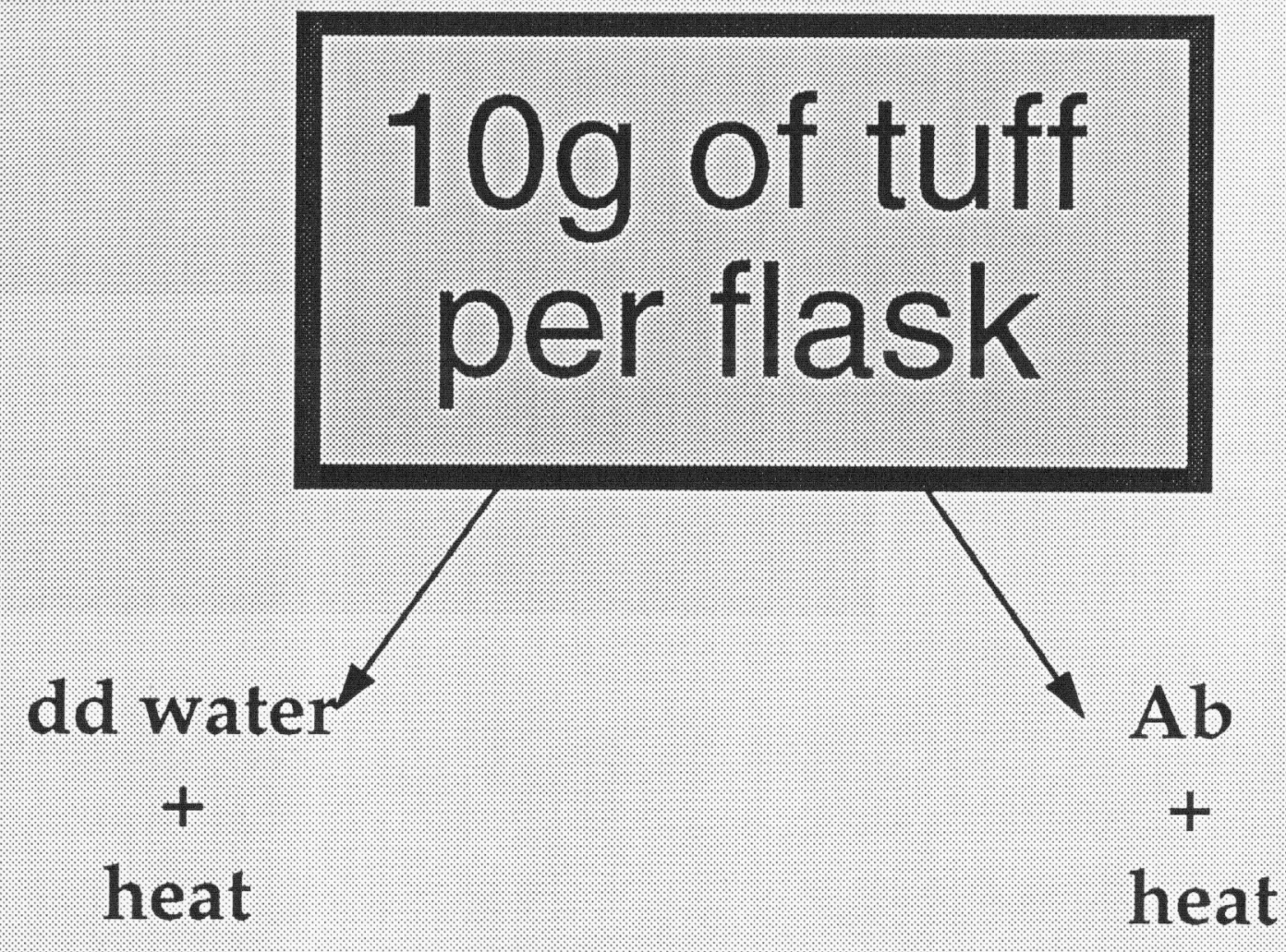

- The ab flask flask was autoclaved once for $45 \mathrm{~min}$.

- The dd water was autoclaved 4 times every 24 hours 


\section{Sonication}

Figure 4

\section{Sterility Test C}

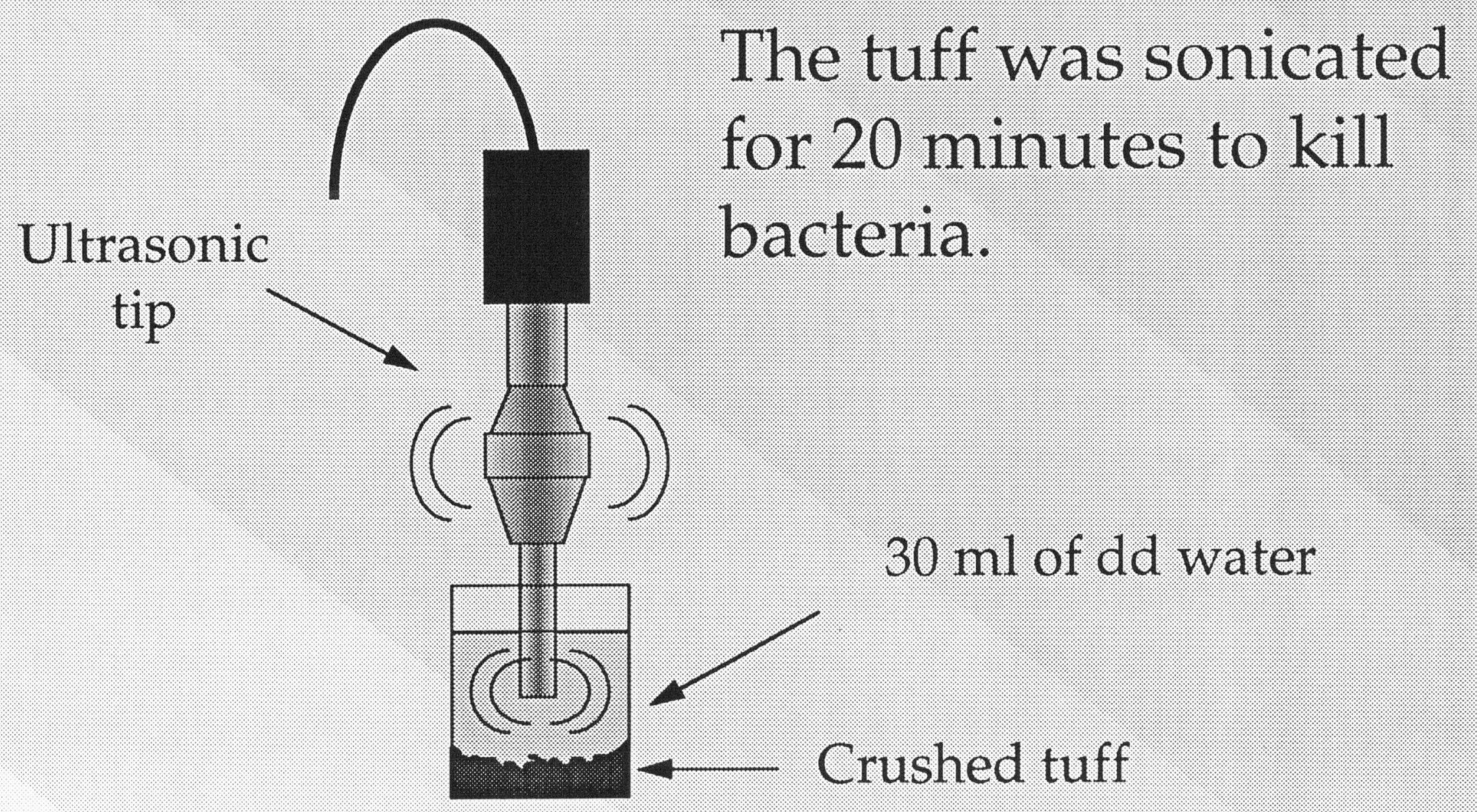




\section{Figure 5}

\section{H2O no tuff}

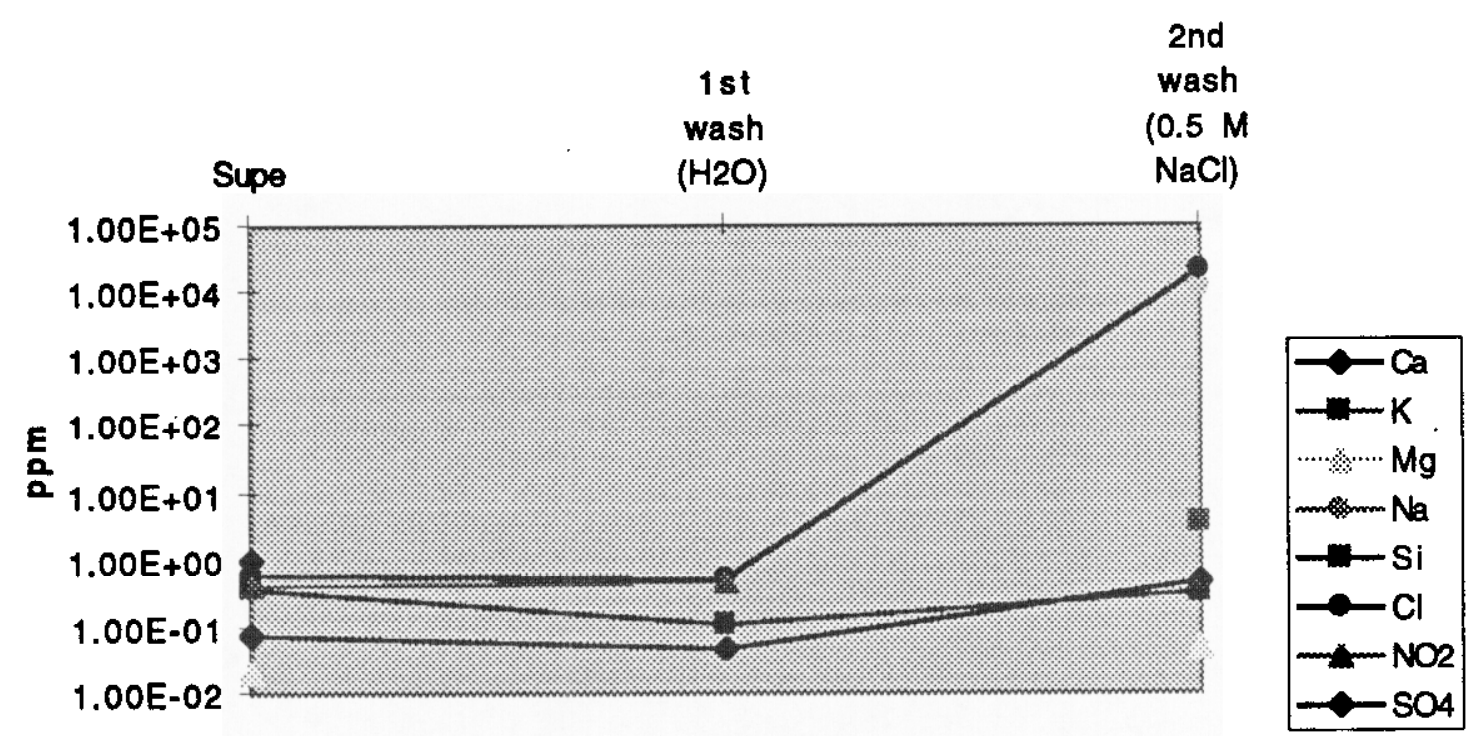


Figure 6

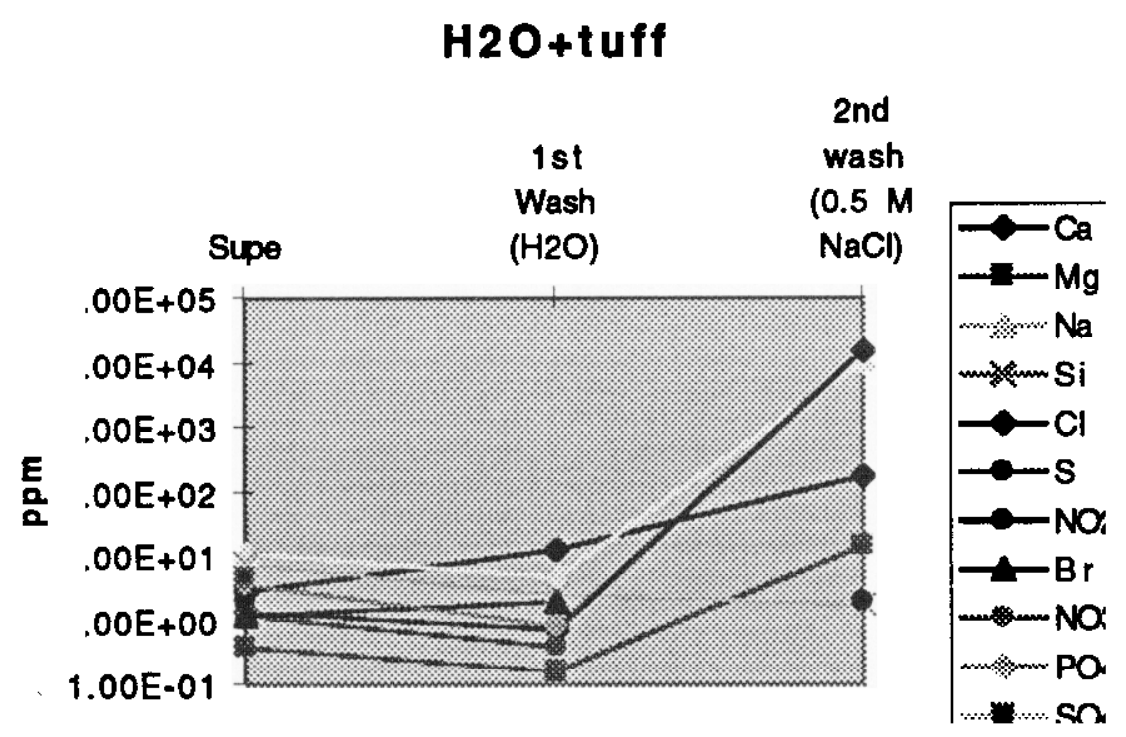




\section{Figure 7}

\section{Sodium Azide + Tuff}

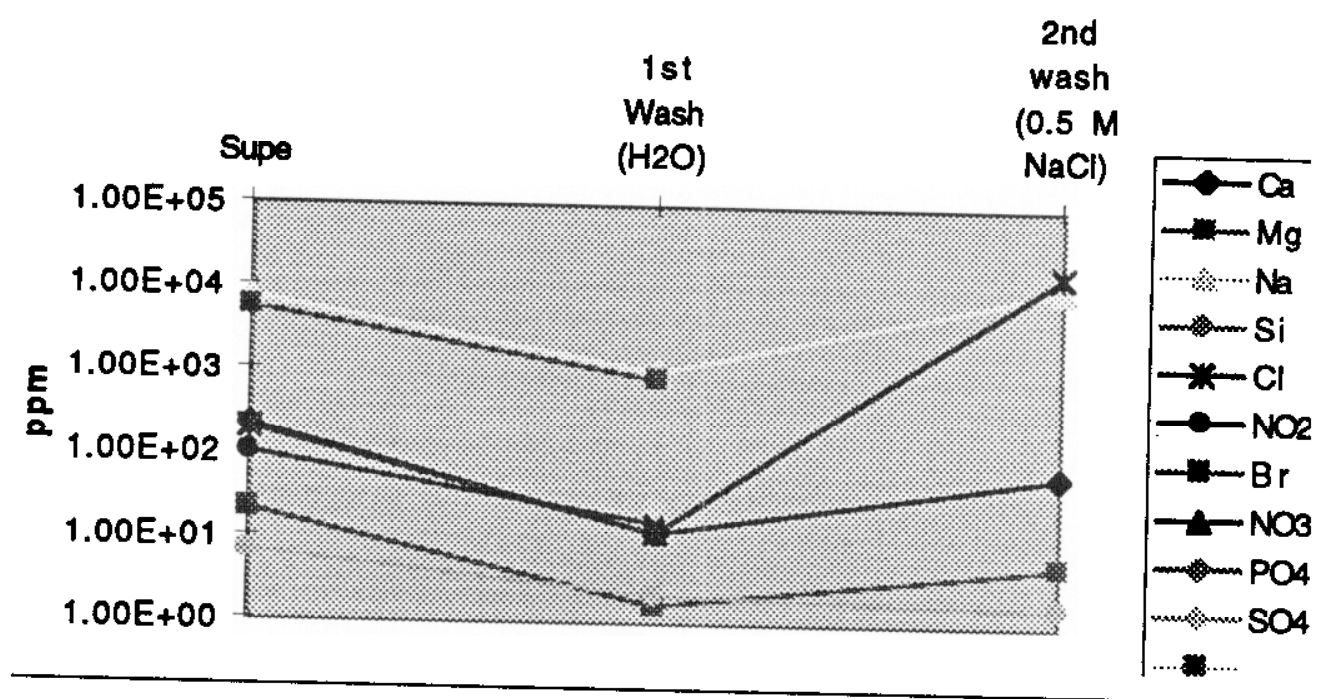


Figure 8

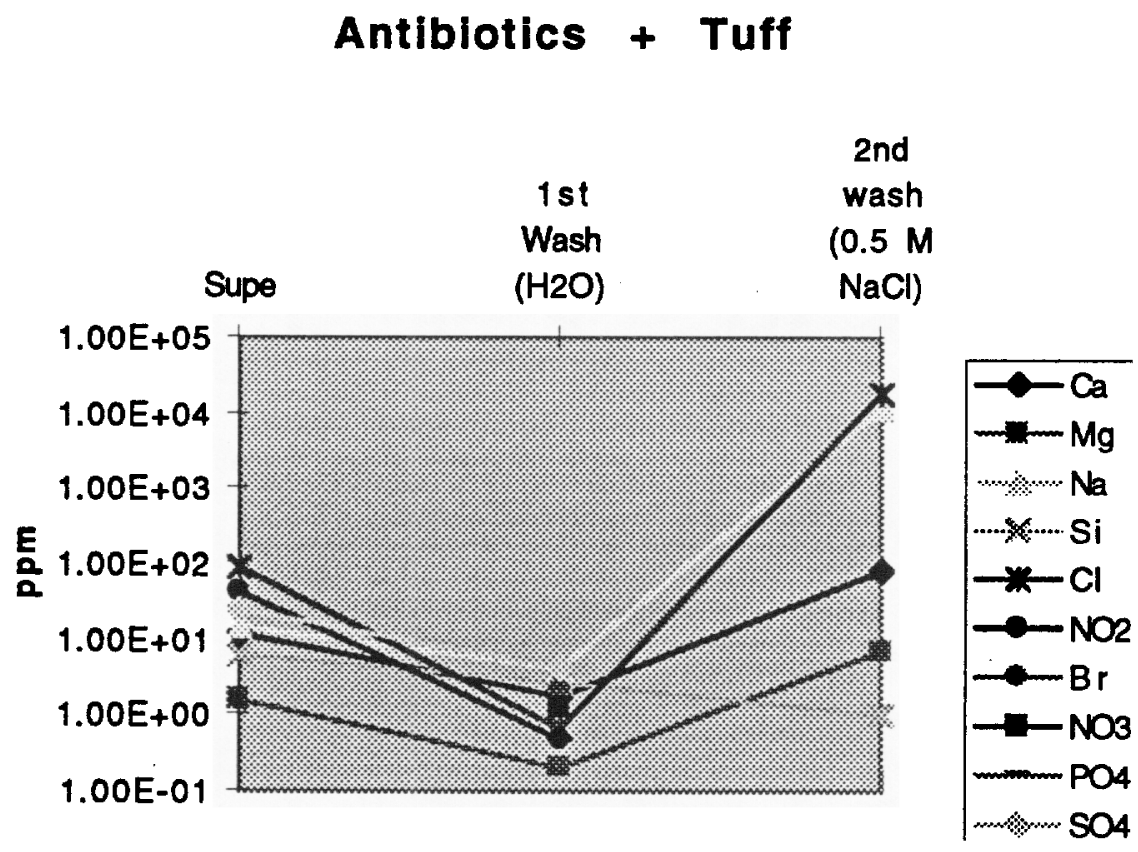




\section{Figure 9}

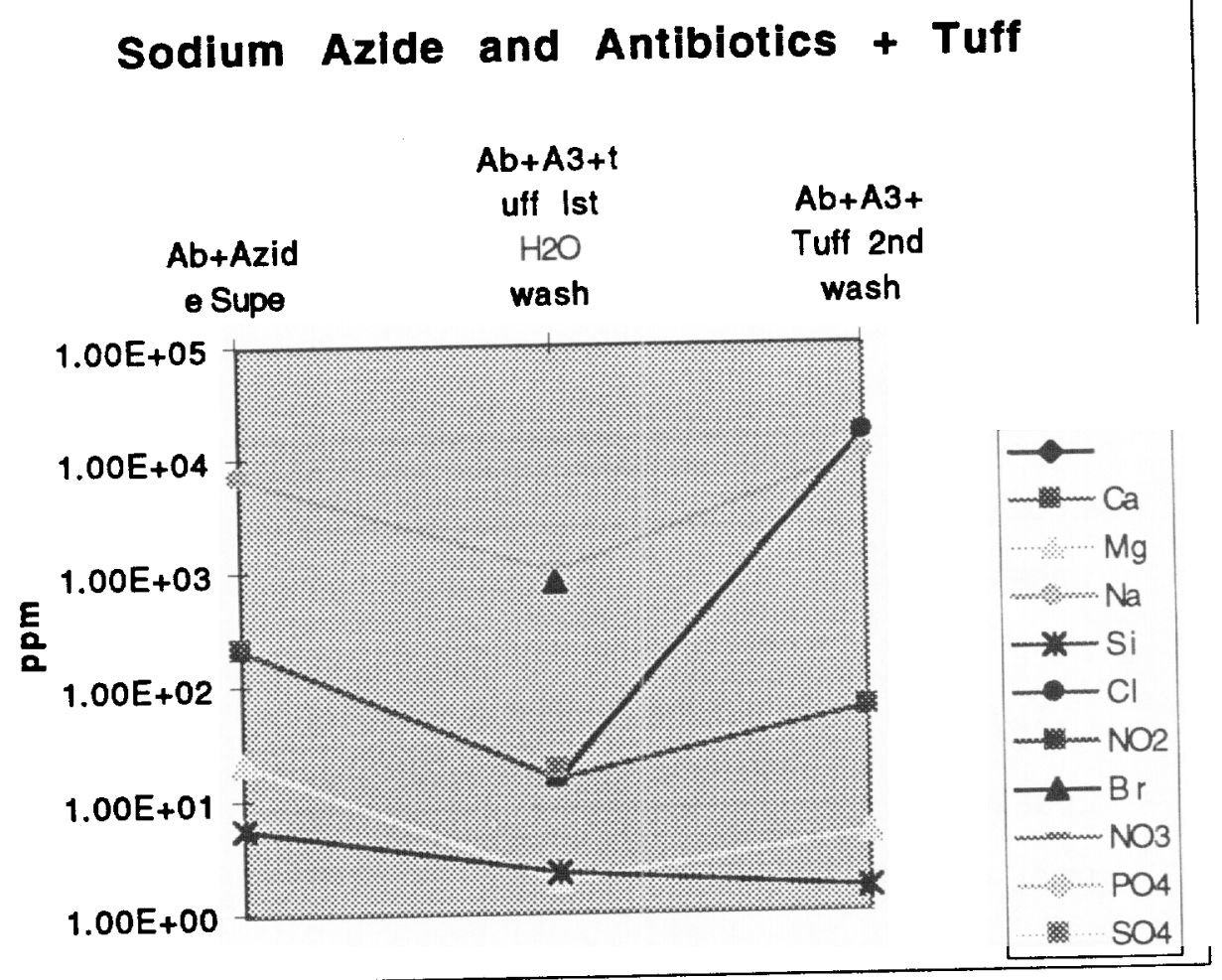




\section{Table 1}

\section{Results from inoculation}

Treatments

Water only (control)

Water + tuff (control)

$2 \%$ Azide

Antibiotics

Antibiotics + Azide

$A b+$ heat

Water + heat

Sonication
Before wash

No growth

TMTC

No growth

No growth

Light Lawn

Light Lawn

Light Lawn

Light Lawn
Wash

No growth

TMTC

No growth

No growth

Light Lawn

Light Lawn

Light Lawn

Light Lawn 


\section{Table 2}

\section{Results from re-inoculation}

Treatments

Water only

Water + tuff

$2 \%$ Azide

Antibiotics

Antibiotics + Azide

$\mathrm{Ab}+$ heat

Water + heat

Sonication
Before wash

No growth

TMTC

No growth

No growth

No growth

No growth

No growth

No growth

\section{Wash}

No growth

TMTC

No growth

No growth

No growth

No growth

No growth

No growth 


\section{References}

1. Joanne Horn, Annemarie Meike (1995) Microbial Activity at Yucca Mountain. Yucca Mountain Site Characterization Project. Report UCRL-ID122256.

2. Angel Rivera, (1996) Testing Candidate Alloys for Resistance to Microbial Induced Corrosion. Lawrence Livermore National Laboratory Paper, Science and Engineering Semester Program.

3. Journal of Microbiological Methods 20 (1996) Sterilization and Inhibition of Microbial Activity in Soil. Laboratory of Microbial Technology, Department of Environmental Biology. University of Guelph, Ontario, Canada. 


\title{
NO SIGNIFICANT EVIDENCE FOUND FOR A DNA FINGERPRINT FROM DENSELY IONIZING RADIATION BASED ON F RATIOS CALCULATED FROM STABLE CHROMOSOME ABERRATIONS *
}

\author{
S. W. Oram, F. S. Hill, A. M. Chen, and J. N. Lucas \\ University of California \\ Lawrence Livermore National Laboratory \\ P. O. Box 808, Livermore, CA 94550
}

$$
\text { May 9, } 1997
$$

Prepared in partial fulfillment of the requirements of the Science and Engineering Research Semester under the direction of Dr. Joe Lucas, Research Mentor, in the Lawrence Livermore National Laboratory.

* This research was supported in part by an appointment to the U.S. Department of Energy Science and Engineering Research Semester (hereinafter called SERS) program administered by LLNL under Contract W-7405-Eng-48 with Lawrence Livermore National Laboratory. Funding for the SERS Program provided by the Office of Defense Programs.

If this paper is to be published, a copyright disclaimer must also appear on the cover sheet as follows:

By acceptance of this article, the publisher or recipient acknowledges the U.S. Government's right to retain a non-exclusive, royalty-free license in and to any copyright covering this article. 


\section{ABSTRACT}

The purpose of this study is to measure the ratio of translocations to pericentric inversions for low-LET radiation and high-LET radiation using fluorescence in situ hybridization (FISH). A composite chromosome 1p telomeric region specific probe, a chromosome 1 heterochromatin probe and a pan-centromere probe were developed to identify pericentric inversions. A chromosome 1 paint probe was employed to measure translocations on chromosome 1 as described by Lucas et al. $(1989,1992)$. Translocation frequencies and pericentric inversion frequencies were calculated as described by Lucas et al. (1989, 1996).

Translocations are interchromosomal aberrations (breaks in different chromosomes), while pericentric inversions are intrachromosomal aberrations (breaks in the same chromosome). High-LET radiation produces energy depositions that are much closer together (dense) than those produced by low-LET radiation (sparse). Hence, it may be more likely for high-LET radiation to cause multiple breaks in the same chromosome than it is for low-LET radiation. If this is true, then it is expected that the ratio of translocations to pericentric inversions(F-Ratio) for high-LET radiation will be less than the F-Ratio for low-LET radiation. Therefore facilitating a "fingerprint" for high-LET radiation (Brenner, 1996).

Contrary to prediction, there does not appear to be a "fingerprint" for high-LET radiaiton. The F-Ratios found for highand low-LET radiation were similar, with the high-LET radiaiton being slightly lower. 


\section{INTRODUCTION}

The purpose of this study is to measure the ratio of translocation to pericentric inversions for high-LET radiation and low-LET radiation using fluorescence in situ hybridization (FISH). Dicentrics and translocations are interchromosomal aberrations, caused by breaks in different chromosomes (Figure 1); while centric rings and pericentric inversions are intrachromosomal aberrations, caused by multiple breaks in the same chromosome (Figure 2). HighLET radiation produces energy depositions that are much closer together (dense) than those produced by low-LET radiation (sparse). Hence, it may be more likely for high-LET radiation to cause multiple breaks in the same chromosome than it is for low-LET radiation. Therefore, it is expected that the ratio of translocations to pericentric inversions or dicentric to centric rings for high-LET radiation will be lower than the ratio for low-LET radiation. However, dicentrics and centric rings are unstable with time, so we chose to measure translocations and pericentric inversions. Measurement of pericentric inversions using FISH have not been reported previously.

Here, a rapid and accurate method for measuring pericentric inversions using FISH is described. The method to measure pericentric inversions employs fluorescent probes generated by degenerate oligonucleotide-primed-polymerase chain reaction (DOPPCR). Probes consisting of a composite chromosome 1p telomeric region specific probe (labeled green), a chromosome 1 heterochromatin region probe (labeled green) and a pan-centromere probe (labeled red) were developed to identify pericentric 
inversions. A chromosome 1 paint probe was employed to measure translocations on chromosome 1 as described by Lucas et al. (1989, 1992). A pericentric inversion is made distinct by the position change of the fluorescent signals relative to the chromosome centromere. When the two probes (green) were used in combination with a pan-centromere probe (red), pericentric inversions were easily scored based on an inverted color pattern change among the probes.

Being able to distinguish high-LET radiation will allow distinction between high-LET radiation and low-LET radiation by facilitating a "fingerprint" for high-LET radiation (Brenner 1996).

\section{METHODS AND MATERIALS}

FISH ANALYSIS: We used DNA probes specific for the heterochromatin (pUC 1.77) and $p$ arm telomere region (1p36.3) on chromosome number 1 in combination with a pan-centromere probe. The pan-centromere probe was amplified and directly labeled with Tetramethylrhodamine-6-dUTP (Boehringer Mannheim) by DOP-PCR. The pUC 1.77 DNA for the heterochromatin and the $p$ arm telomere DNA were also amplified by DOP-PCR. The telomere and pUC 1.77 probes were then labeled with FluoroGreen (Amersham) in a second round of amplification. Details of the hybridization procedures are as described in Pinkel et al. (1986). Briefly, the target metaphase spreads were denatured in $70 \%$ formamide/2XSSC at $70^{\circ} \mathrm{C}$, dehydrated and air-dried. The directly labeled probes in hybridization buffer ( $50 \%$ formamide/2XSSC, $10 \%$ dextran sulfate) 
were thermally denatured at $70^{\circ} \mathrm{C}$ and added to the slides. The cover slips were sealed, and the slides were incubated overnight at room temperature. After washing, the slides were counterstained with 2,6-diamidino-2-phenylindole (DAPI).

CELL CULTURE: Procedures are as described in Lucas et al. (1989). Heparinized whole blood from a healthy male donor was irradiated at ambient room temperature with different levels of high- and lowLET radiation. Absorbed doses to the blood in Gy were obtained from procedure described in Lucas et al. (1989). Lymphocytes were separated from whole blood of a healthy male donor by centrifugation through a continuous density gradient formed by mixing whole blood with a commercially available separation medium (Sepracell-MN, Sepratech Co., Oklahoma City, OK). The lymphocytes were stimulated to proliferate with phytohaemagglutinin $(0.15 \mathrm{mg} / \mathrm{ml})$. The cells were maintained in suspension cultures in upright T-75 flasks in $50 \mathrm{ml}$ RPMI 1640 medium containing $20 \%$ fetal bovine serum. After 48 hours, colcemid was added to the cultures for 4 hours, and metaphase spreads were prepared by the method of Evans et al. (1971).

SCORING: For pericentric inversion identification a metaphase spread was scored as normal if green fluorescent domains positioned on opposite sides of a red fluorescent centromere were present on each of the two no. 1 chromosomes. Two kinds of chromosome rearrangements involving chromosome 1p were scored: (1) Pericentric inversions with one breakpoint in $1 \mathrm{p}$ and the other in 1q; 
these produced a derivative chromosome with a visible change in the color pattern (Figure 3). (2) Centric rings with one breakpoint in 1p and the other in 1q; these produced centric rings with the ring carrying the paracentromeric locus of chromosome 1 and an accentric fragment containing the telomeric locus. All metaphase spreads containing structural aberrations involving $1 \mathrm{p}$ were photographed and the scoring was reviewed in conference.

Identification and scoring of translocations using FISH employed the methods of Lucas et al. (1992). Only reciprocal translocations were used in determining the translocation frequency.

\section{GENOMIC TRANSLOCATION AND PERICENTRIC INVERSION}

CALCULATIONS: Identification and scoring of chromosome exchange aberrations using FISH employed the methods of Lucas et al. (1992). The scoring criteria are equivalent to those described by Simpson and Savage (1995) as apparently simple exchange-type painting pattern. Only apparently simple translocations (AST's) were used to calculate $F$ ratios (Lucas et al. 1996). The translocation frequency measured by FISH was scaled to full genome equivalents using the Lucas et al. formula (Lucas et al. 1992). In brief, the formula relates the translocation frequency measured by FISH, $F_{p}$, to the genomic translocation frequencies, $F G$, through the fraction of the genome covered by the probes, $f_{p}$, as follows:

$$
F_{G}=F_{p} /\left(2.05 f_{p}\left(1-f_{p}\right)\right)
$$

where the genomic conversion factor for chromosome 1 is 0.156 .

The FISH measured pericentric inversions, $\mathrm{p}_{i}$, involving the ith chromosome is proportional to the product of the long $\left(\mathrm{L}_{\mathbf{i}}\right)$ and short 
$\left(\mathrm{S}_{\mathrm{i}}\right)$ arms of the ith chromosome. The total genomic number of pericentric inversion, $P$, is obtained similarly (Hlatky et al. 1992) from the ratio of the product of the long and short arms of the ith chromosome to the sum of products of the long and short arms for the total genome to the product of the long and short arms of the ith chromosome, times the FISH measured pericentric inversions, $\mathrm{pi}$, involving the ith chromosome: where $\mathrm{L}_{\mathbf{i}}$ and $\mathrm{S}_{\mathbf{i}}$ are the long and short arms of the ith chromosome.

$$
P=p_{i} \sum_{j=1}^{46}\left(L_{j} S_{j}\right) / L_{i} S_{i}
$$

\section{RESULTS}

Table 1 lists the translocation frequencies, pericentric inversion frequencies and $F$ ratios for both high- and low-LET radiation. For the 2.89 Gy Co-60 gamma irradiation (low-LET radiation), 1966 metaphase lymphocytes were scored. There were 24 pericentric inversions and 140 reciprocal translocations. Resulting in a translocation frequency of 0.53 and a pericentric inversion frequency of 0.083 . Indicating a $F$ ratio (translocation frequency/ pericentric inversion frequency) of 5.7 .

The high-LET radiation Iron (Fe-56) study consisted of two different doses ( $0.25 \mathrm{~Gy}$ and $1.25 \mathrm{~Gy})$. Data for the $0.25 \mathrm{~Gy}$ dose consisted of 8682 metaphase lymphocytes, with 15 pericentric inversions and 35 translocations. Resulting in a translocation 
frequency of 0.065 and a pericentric inversion frequency of 0.015 . Thus giving a $F$ ratio of 4.45 . The other group consisting of a dose of $1.25 \mathrm{~Gy}$ had 4922 metaphase lymphocytes with 21 pericentric inversions and 32 translocations. Resulting in a translocation frequency of 0.160 and a pericentric inversion frequency of 0.036 . Indicating a $\mathrm{F}$ ratio of 4.10 .

The high-LET radiation Carbon (C-14) study contained 1070 metaphase lymphocytes, resulting in 16 pericentric inversions and 31 translocations. Thus giving a translocation frequency of 0.820 and a pericentric inversion frequency of 0.123 . Resulting in a $F$ ratio of 6.5 .

\section{DISCUSSION}

In summary, we have presented a rather simple method for measuring pericentric inversions using FISH. This method requires three DNA probes: a chromosome 1p telomere (green), a chromosome 1 heterochromatin (green), and a pan centromere (red). The three probes represent a color pattern that allows for rapid identification of pericentric inversions.

The $F$ ratio (reciprocal translocations to pericentric inversions) measured in low-LET (2.89 Gy Co-60 gamma) irradiated lymphocytes was 5.7. This compared to a $F$ ratio of $\sim 4.5$ for high-LET $(0.25$ and $1.25 \mathrm{~Gy} \mathrm{Fe}-56$ particles) irradiated lymphocytes demonstrates a slight decrease in the F-ratio for high-LET radiation. However, the $F$ ratio for high-LET (3.0 Gy C-14 particles) irradiated human 
lymphocytes was 6.6. Which demonstrates a slight increase in $F$ ratio for high-LET Carbon. Although neither of these findings appear to be significantly different than the $F$ ratio for low-LET radiation. Indicating that there is no significant evidence to indicate a DNA "fingerprint" from densely ionizing radiation based on $F$ ratios calculated from stable chromosome aberrations (translocations and pericentric inversions).

However during our research we noted a rather large increase of non-reciprocal translocations (otherwise known as a can't see blue piece (CSBP) translocations) for the high-LET radiation. At this time it is not known what these CSBP translocations represent. Some believe that they are reciprocal translocations, but you can not see the translocated piece because it is too small. We believe that they are non-reciprocal translocations caused by a random relocalization of broken chromosome pieces. We are now working on developing an all human telomere probe which will allow us to determine what a CSBP translocation really is. If we are correct about the CSBP translocations than we believe we can facilitate a "fingerprint" for high-LET radiation by comparing the ratio of CSBP translocations for high- and low-LET radiation. 


\section{ACKNOWLEDGEMENTS}

I would like to thank Mike Cassel, Francesca Hill, and Joe Lucas for their guidance and support with this project. Work was performed under the auspices of the U.S. DOE by LLNL under contract no. W7405-ENG-48. 
TABLE 1: Translocation frequencies, pericentric inversion frequencies and F-ratios for high- and low-LET radiation.

Cells Dose Trans. Freq Inv. Freq F-ratio

High-LET Radiation

Iron (Fe-56)

Lymphocytes

$1.25^{0.25}$

$0.160^{0.065} \quad 0^{0.036^{0.015}} 4.10^{4.45}$

Carbon (C-14)

Lymphocytes

3.00

0.820

0.123

6.6

Low-LET Radiation

Gamma Rays

Lymphocytes

2.89

0.530

0.083

5.7 


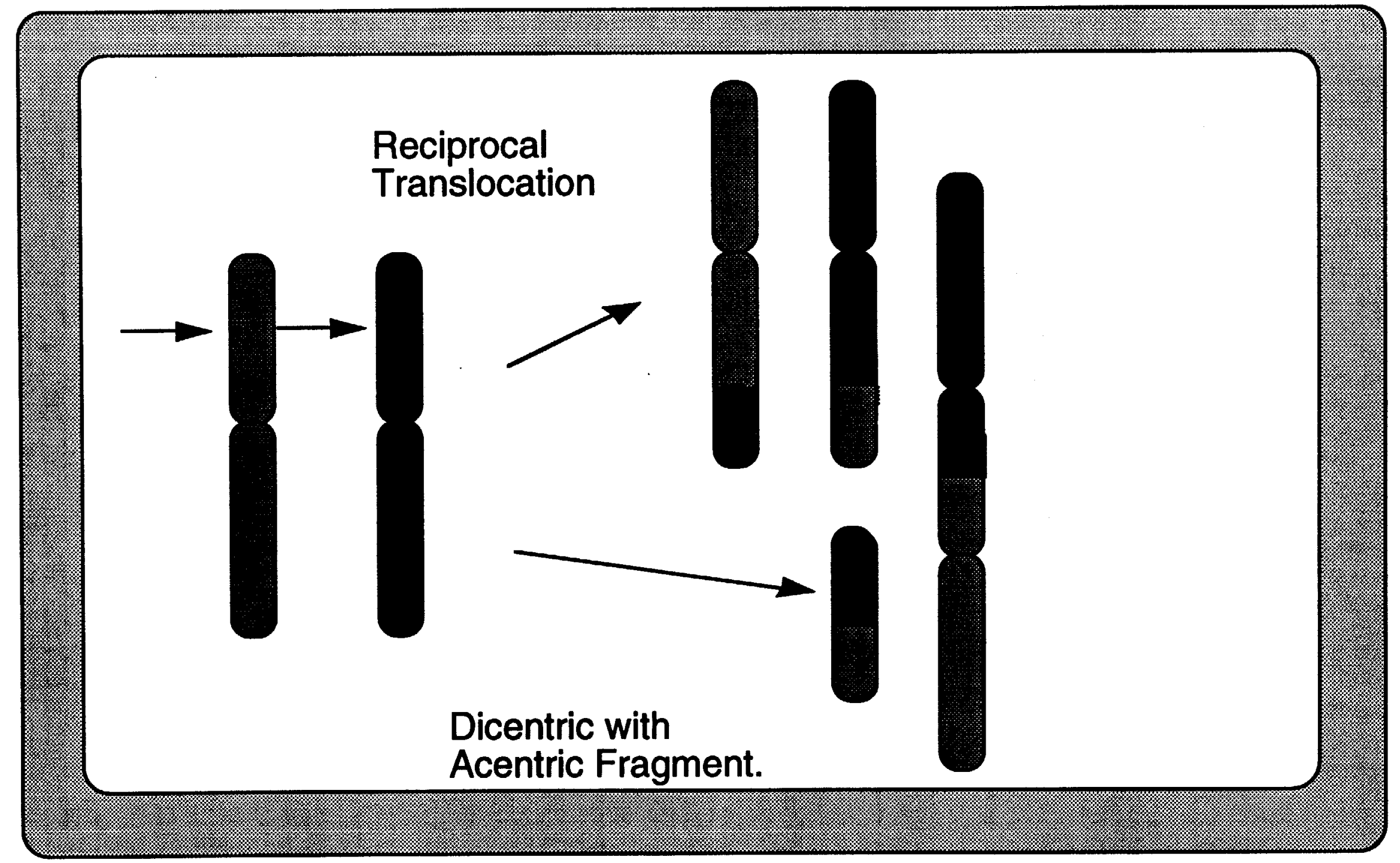

Figure 1: Example of an interchromosomal aberration, resulting in elther a translocation or a dicentric. 


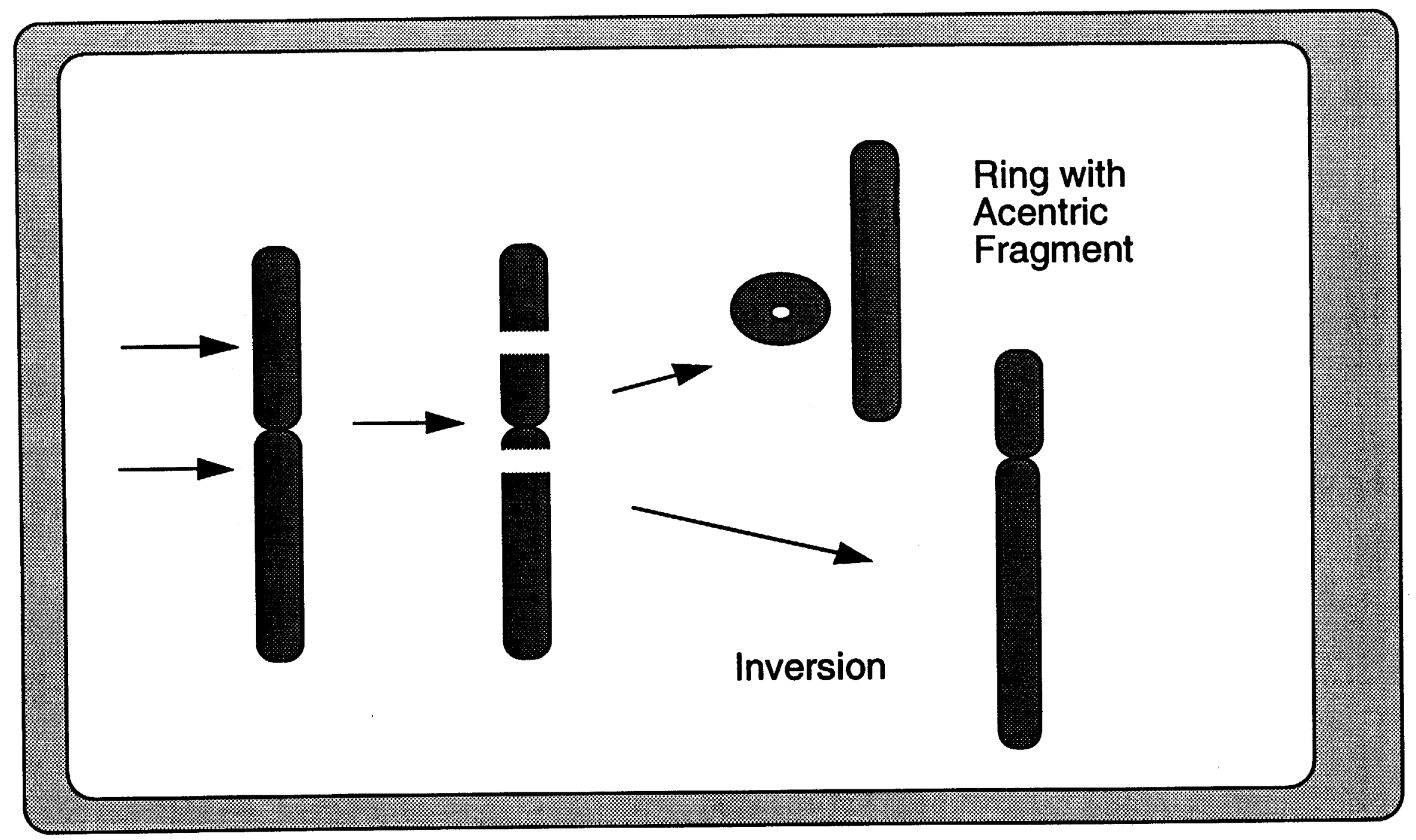

Figure 2: Example of an Intrachromosomal aberration, resulting In elther a pericentric inversion or a centric ring. 


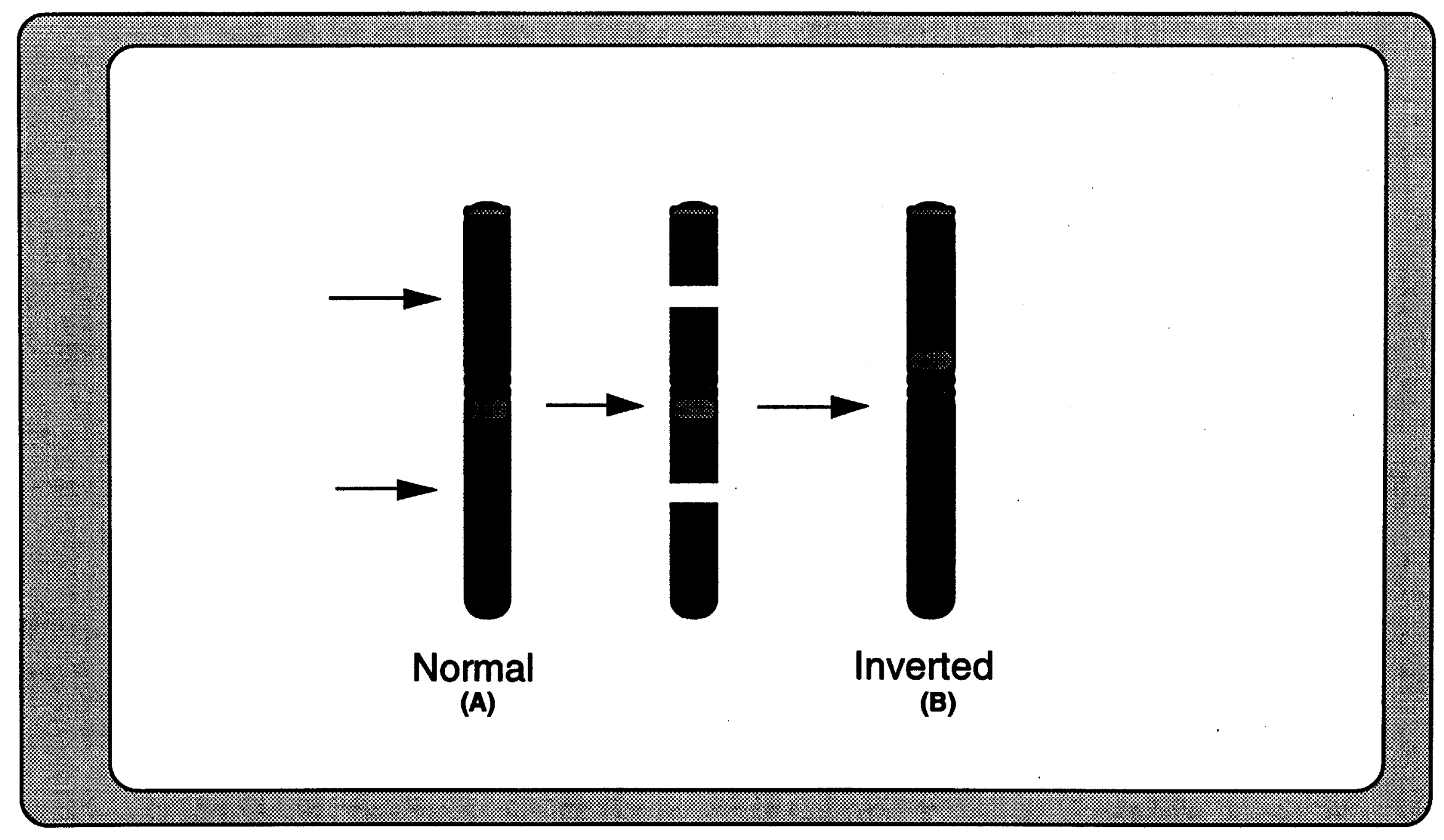

Figure 3: Schematic representation of the design of speciflc chromosomal probes to detect pericentric inversions. (A) Normal chromosome with a telomere probe and a heterochromatin probe on opposite arms labeled green, and a centromere labeled red. (B) Schematic of a pericentric inversion showing the green probes in (A) on the same arm. 
BRENNER, D. J., 1996, Direct biological evidence for a significant neutron dose to survivors of the Hiroshima atomic bomb. Radiation Research, 145, 501-507.

Chen, A. M., LuCAS, J. N., Hill, F. S., BREnNER, D. J. and SACHS, R. K., 1996, Proximity effects for chromosome aberrations measured by FISH. International Journal of Radiation Biolog $\$, 69,411-420$.

Griffin, C. S., Marsden, S. J., Stevens, D. L., Simpson, P., Savage, J. R., 1995, Frequencies of complex chromosome exchange aberrations induced by $238 \mathrm{Pu}$ alpha-particles and detected by fluorescence in situ hybridization using single chromosome-specific probes. International Journal of Radiation Biology, 67, 431-439.

GuAN, X .Y., ZhaNG, H., BittneR, M., Jiang, Y., MeltzeR, P. and TRENT, J., 1996, Chromosome arm painting probes. Nature Genetics, 12, 10-11.

HLATKY, L. R., SACHS, R. K. and HAHNFELDT, P., 1992, The ratio of dicentrics to centric rings produced in human lymphocytes by acute low-LET radiation. Radiation Research, 129, $304-308$.

KovaCS, M. S., EvanS, J. W., JohnSTONE, I. M. and BROWN, J. M., 1994, Radiation-induced damage, repair and exchange formation in different chromosomes of human fibroblast determined by fluorescence in situ hybridization. Radiation Research, 137, 34-43.

lucas, J. N., Awa, A., Straume, T., Poggensee, M., Kodama, Y., Nakano, M., Ohtaki, K., Weier, H.-U., PINKel, D., GRAY, J. and LiTtlefield, G., 1992, Rapid translocation frequency analysis in humans decades after exposure to ionizing radiation. International Journal of Radiation Biology, 62, 53-63.

LUCAS, J. N., CHEN, A. M. and SACHS, R. K., 1996, Theoretical predictions on the equality of radiation-produced dicentrics and translocations detected by chromosome painting. International Journal of Radiation Biology, 69, 145-153. 
lucas, J. N., Tenjin, T., Straume, T., Pinkel, D., MoOre II, D. M., LitT, M. and Gray,

J. W., 1989, Rapid determination of human chromosome translocation frequency using a pair of chromosome-specific DNA probes. International Journal of Radiation Biology, 56, 35-44.

MORTON, N. E., 1991, Parameters of human genome. Proceedings of the National Academy of Sciences (USA), 88, 7474-7476.

MUHLMANN-DIAZ, M. C. and BEDFORD, J. S., 1995, Comparison of gamma-ray-induced chromosome ring and inversion frequencies. Radiation Research, 143, 175-180.

SaChS, R. K., AWA, A., Kodama, Y., NaKano, M., OHTAKI, K. and LuCaS, J. N., 1993, Ratios of radiation-produced chromosome aberrations as indicators of large-scale DNA geometry during interphase. Radiation Research, 133, 345-350.

SAVAGE, J. R. K. and PAPWORTH, D. G., 1982, Frequency and distribution studies of asymmetrical versus symmetrical chromosome aberrations. Mutation Research, 95, 7-18.

SIMPSON, P. J. and SAVAGE, J. R. K., 1995, Estimating the true frequency of X-ray-induced complex chromosome exchanges using fluorescence in situ hybridization. International Journal of Radiation Biology, 67, 37-45.

SIMPSON, P. J. and SAVAGE, J. R. K., 1996, Personal communications. 


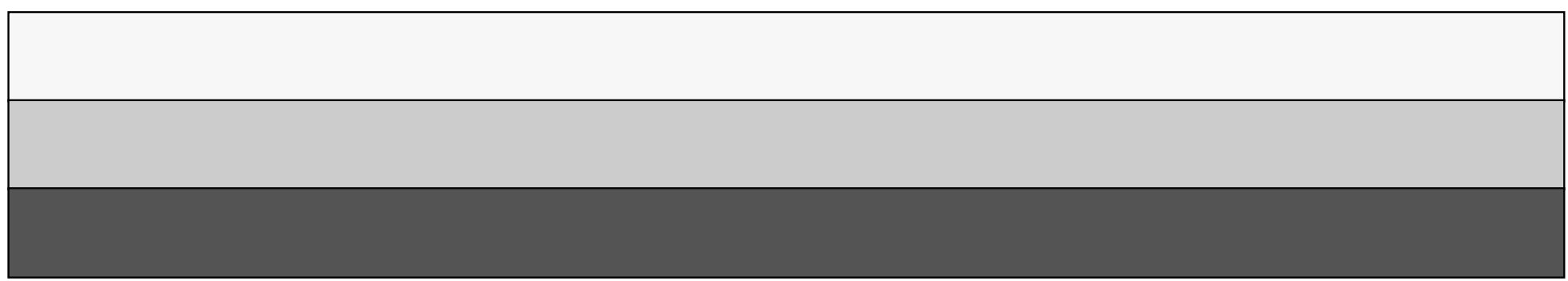

